\title{
Biology OF Disease
}

\section{Neutrophils: Molecules, Functions and Pathophysiological Aspects}

\author{
Véronique Witko-Sarsat, Philippe Rieu, Béatrice Descamps-Latscha, \\ Philippe Lesavre, and Lise Halbwachs-Mecarelli
}

INSERM U507, Necker Hospital, Paris, France

\section{INTRODUCTION}

I. NEUTROPHIL MOLECULES AND FUNCTIONS I.A. ADHESION AND MIGRATION

I.A.1. Traffic and margination

I.A.2. Adhesion to the Endothelial Wall

Rolling and Tethering

Neutrophil Priming During Rolling

Firm Adhesion and Spreading

I.A.3 Extravasation and Diapedesis Toward Inflammatory Stimuli

Transendothelial Migration

Migration Within Interstitial Tissues

Signaling by Chemoattractants

Transepithelial Migration

I.B. PHAGOCYTOSIS, DEGRANULATION AND BACTERIA KILLING

I.B.1. Phagocytosis

I.B.2. Degranulation

Granule Biogenesis

Mechanisms of Degranulation

I.B.3. Microbicidal Molecules

NADPH-Derived Oxidants

The $\mathrm{H}_{2} \mathrm{O}_{2}$-Myeloperoxidase System

Nitric Oxide-Synthase-Derived Reactive Nitrogen Intermediates

Granule Proteins

Antimicrobial Proteins

Proteases

I.C. CYTOKINE SYNTHESIS

I.C.1. TNF- $\alpha$ as a Proinflammatory Cytokine

I.C.2. IL-1 and IL-1 Receptor Antagonist (IL-1-Ra)

I.C.3. IL-8 as a Prototype of Chemokines

I.C.4. Modulation of Cytokine Expression by Neutrophils

IFN- $\gamma$
Received February 8, 2000.

Address reprint requests to: Dr. V. Witko-Sarsat, INSERM U507, Necker Hospital, 161, rue de Sèvres, 75015 Paris, France. Fax: 01456651 33; E-mail:witko-sarsat@necker.fr
IL-10

IL-4 and IL-13

I.C.5. Molecular Regulation of Cytokine Production

I.D. APOPTOSIS AND RESOLUTION OF ACUTE INFLAMMATION

I.D.1. Progressive Decrease of Neutrophil Recruitment

I.D.2. Apoptosis in Resolution of Inflammation

II. NEUTROPHILS IN PATHOLOGY

II.A. Bacterial Infection

II.B. Tissue Injury-Induced Inflammation: IschemiaReperfusion Injury

II.C. Crystal-Induced Inflammation

II.D. Complement-Induced Inflammation and Oxidative Stress: Hemodialysis

II.E. Immune Complex-Induced Inflammation: Antibody-Mediated Glomerunephritis

II.F. Cytokine-Induced Inflammation: Rheumatoid Arthritis

II.G. Antineutrophil Cytoplasmic Antibodies and Vasculitis: Autoimmunity Against Neutrophil Components

II.H. Genetic Disorders of Neutrophil Regulations: Hereditary Periodic Fever Syndromes

II.I. Cystic Fibrosis: The Paradox of an Exacerbation of Neutrophil-Mediated Tissue Damage and a Concomitant Persistence of Infection

CONCLUSION

7 he notion that inflammation is the net resultant of 1 pro and contra inflammatory pathways (Fauve, 1980 ) is well illustrated by the dual role of neutrophils which combine an anti-infectious and a proinflammatory role (Klebanoff, 1992; Ward, 1999; Weiss, 1989). The aim of this report is to review the main physiological and pathogenic activities of neutrophils-ie, adherence and migration, degranulation and release of inflammatory mediators, phagocytosis and apoptosis-in the light of the most recent molecular data on 
extracellular effectors and regulators, membrane receptors, and intracellular signaling pathways involved in these functions.

Leukocyte adhesion processes have been studied extensively during the last decade and most membrane molecules responsible for leukocyte interactions with other cells or with the extracellular matrix have been identified. New data are constantly reported on sophisticated intracellular pathways that allow neutrophils to integrate signals transmitted by adhesion partners with those of chemoattractants and cytokines. What remains puzzling is that leukocytes mostly use the same adhesion molecules to adhere to inflamed endothelium, as do lymphocytes to constantly recirculate from the blood to lymphoid tissues. Still, naive lymphocytes are the only leukocytes to cross endothelia of lymphoid high endothelial venules, while neutrophils are the first leukocytes, hours before monocytes or lymphocytes, to migrate specifically across the endothelium adjacent to the inflammation site. The selectivity and specific timing of such a highly redundant system is just becoming comprehensible, in particular with the description of the chemokine and serpentine families.

Another aspect reviewed here is the wide variety of effector molecules required to achieve the usual microbicidal role of neutrophils, including radical oxygen species (ROS), proteinases, bactericidal proteins and cytokines, which either alone or in concert may interact in up- or down-regulating the major inflammatory processes. We emphasize new directions of investigation regarding these neutrophil-derived effector molecules, as exemplified by myeloperoxidasederived oxidants whose implications go far beyond inflammatory diseases. The potential clinical use of neutrophil-derived antibiotic proteins is illustrated by the Bactericidal Permeability Increasing protein (BPI), now undergoing clinical trials, and the design of novel antimicrobial peptides based on studies on defensins and cathelicidins.

Finally, we illustrate the various aspects of neutrophil biology by classifying, according to their predominant neutrophil-activating mechanism, diseases in which neutrophils play a pivotal role. Comprehension of the activation pathways will allow us to analyze, and possibly prevent, chronic inflammation processes where dysregulated neutrophil recruitment and activation results in severe damage of adjacent normal tissues.

\section{Neutrophil Molecules and Functions}

\section{I.A. Adhesion and Migration}

\section{I.A.1. Traffic and Margination}

Neutrophils are partitioned in the blood between a circulating pool, present in large blood vessels and in the axial stream of small vessels, and a marginating pool. In the absence of inflammation, the marginating pool, better called "physiological regional granulocyte pool" (Peters, 1998), comprises granulocytes transiently arrested in narrow, mainly pulmonary, capillaries. This physiological retention of neutrophils in capillaries appears to be a mechanical process due to the stiffness of neutrophils-as compared with the high deformability of erythrocytes (Downey et al, 1990)and does not involve cell adhesion (Doyle et al, 1997; Mizgerd et al, 1996; Yamaguchi et al, 1997; Yoder et al, 1990).

Conversely, in inflamed organs, neutrophil traffic involves a selectin- and integrin-dependent sequestration in capillaries and post-capillary venules (Adams and Shaw, 1994; Springer, 1994). Intravascular injection of inflammatory mediators first results in rapid sequestration that involves a decrease in neutrophil deformability, followed by prolonged accumulation of neutrophils in the lung and liver parenchyma, by a process involving CD11b/CD18 integrins and L-selectin (Doerschuk, 1992; Doyle et al, 1997; Erzurum et al, 1992; Hogg and Doerschuk, 1995; Jaeschke and Smith, 1997; Tedder et al, 1995). Mechanisms involving adhesion also occur when neutrophil emigration follows instillation of stimuli in airways, peritoneum, or skin. Defective neutrophil recruitment to inflamed sites in leukocyte adhesion deficient (LAD) patients and in adhesion molecules-knock-out mice shows that these emigration processes require selectins (Borges et al, 1997; Bullard et al, 1996; Doyle et al, 1997; McEver and Cummings, 1997; Tedder et al, 1995) and the interactions of leucocyte CD18 integrins with endothelial ICAM-1 (Mizgerd et al, 1997; Sligh et al, 1993). However, animal models using intratracheal instillation of Streptococcus pneumonia suggest that neutrophil pulmonary traffic, at least in mice and rabbits, may differ from what happens in the systemic circulation and in some cases may involve selectinand integrin-independent emigration from systemic venules (Mizgerd et al, 1996).

\section{I.A.2. Adhesion to the Endothelial Wall}

The dual neutrophil functions of immune surveillance and in situ elimination of microorganisms or cellular debris require a rapid transition between a circulating non-adherent state to an adherent state, allowing them to migrate into tissues where necessary. The initial event is the appearance, on the endothelium adjacent to the inflamed site, of new adhesion molecules, induced by inflammation mediators released by damaged tissues, which result in local extravasation of leukocytes. In postcapillary venules or in pulmonary capillaries, the slow flow rate, further reduced by vessel dilatation at sites of inflammation, allows a loose and somewhat transient adhesion, referred to as "tethering," and resulting in the rolling of leukocytes along the endothelium. During this tethering step, neutrophils respond to ligands-mainly chemokinesdispatched on the endothelium surface by a signaling event that activates integrin-mediated sustained, stationary adhesion and spreading (Springer, 1994). 


\section{Rolling and Tethering}

The rolling step is mediated by neutrophil L-selectin and by $\mathrm{E}$ - and P-selectins newly expressed on inflamed endothelial cells. Rare deficits in neutrophil selectin ligand expression, due to a metabolic defect in a synthetic pathway common to all selectin ligands, lead to faulty neutrophil trafficking in humans suffering from the LAD type 2 syndrome (Phillips et al, 1995). $\mathrm{P}$-selectin, readily mobilized in a few minutes to the endothelial cell surface following stimulation by thrombin, histamine, or oxygen radicals, interacts primarily with a mucin-like ligand PSGL-1 (P-selectin glycoprotein ligand-1), located at the tip of leucocyte microvilli ( McEver and Cummings, 1997; Moore et al, 1995).

Rolling subsequently involves E-selectin, which appears on endothelial cells one to two hours after cell stimulation by IL-1, TNF $\alpha$, or LPS (Lawrence and Springer, 1993; Patel et al, 1995). E-selectin counterreceptors include PSGL-1 and ESL1 (E-selectin-ligand 1), a molecule highly homologous to the cystein-rich FGF receptor (CFR) and located on neutrophil microvilli (Steegmaier et al, 1997).

The kinetic of neutrophil recruitment in selectindeficient mice suggests that $\mathrm{P}$ - and L-selectin contribute sequentially to leucocyte rolling and shows that L-selectin is involved in the prolonged neutrophil sequestration in inflamed microvasculature (Doyle et al, 1997; Ley et al, 1995; Steeber et al, 1998). Unlike Pand E- selectins, L-selectin is constitutively present on leukocytes. Its binding capacity is however rapidly and transiently increased after leukocyte activation, possibly via receptor oligomerization (Li et al, 1998). So far, only one inducible L-selectin counter-receptor, specifically expressed on inflamed endothelium, has been described, which is bearing the cutaneous lymphocyte antigen (CLA) (Tu et al, 1999). In addition to its binding to endothelial ligands, leucocyte PSGL-1 is a counterreceptor for leukocyte L-selectin and there is evidence that neutrophils roll, via L-selectin, on previously adherent neutrophils (Alon et al, 1996; Bargatze et al, 1994). This secondary tethering would synergistically enhance leukocyte accumulation on inflamed endothelium.

\section{Neutrophil Priming During Rolling}

The endothelium of inflamed microvessels produces chemoattractants such as platelet-activating factor (PAF), leukotriene B4, and various chemokines, immobilized via a "presentation molecule" (proteoglycan) on the luminal surface of endothelial cells. Among these chemokines, interleukin 8 (IL-8) specifically attracts neutrophils, while having no effect on monocytes (Premack and Schall, 1996; Rollins, 1997) and being unable to promote lymphocyte transmigration through endothelium (Roth et al, 1995). IL-8 is a major neutrophil chemoattractant, as shown by the complete inhibition of neutrophil recruitment in inflammation sites by anti-IL8 monoclonal antibodies in animal models (Folkesson et al, 1995; Matsumoto et al, 1997; Sekido et al, 1993). There is evidence that microvascular endothelial cells not only synthesize IL-8 in response to IL-1 or LPS, but also store IL-8 in Weibel-Palade bodies and release it upon stimulation by histamine or thrombin (Utgaard et al, 1998; Wolff et al, 1998). Moreover, tissue-derived IL-8 is internalized by endothelial cells of postcapillary venules and small veins, transcytosed in the abluminal-to-luminal direction via plasmalemmal vesicles (caveolae), and presented at the tips of microvilli of the endothelial cell luminal surface (Middleton et al, 1997).

Neutrophils bear several receptors for chemoattractants, which belong to the super-family of seventransmembrane receptors associated with intracellular GTP-binding heteroproteins. As described below, the engagement of these $\mathrm{G}$ protein-coupled receptors triggers a variety of signal transduction cascades that lead to firm leukocyte adhesion and activation of direction-specific movement, but also to a wide range of functions such as degranulation or respiratory burst. These latter effects do not normally occur during the initial adhesion to endothelial cells, but are delayed until leukocytes have reached the inflammatory focus. Ceramide, resulting from TNF-activated sphingomyelinase, has been proposed as one of the regulating mediators responsible for this delay (Fuortes et al, 1996).

\section{Firm Adhesion and Spreading}

Firm neutrophil adhesion to endothelial cells appears to involve exclusively the interaction of leucocyte integrins of the $\beta 2$ subfamily (CD11a, CD11b, CD11c/ CD18) with ICAM-1, as shown by the defects observed in CD18-deficient LAD patients and in ICAM-1 knock-out mice (Anderson et al, 1984; Fischer et al, 1983; Sligh et al, 1993). This differs from monocytes and lymphocytes, which also react via $\alpha 4 \beta 1$ integrin with endothelial VCAM-1.

$\beta 2$ integrins are unable to interact with their physiological ligands in unstimulated neutrophils, a safety mechanism that controls acute and chronic inflammatory responses. The ligand binding capacity is acquired upon activation signals ("inside-out signaling") that lead to integrins clustering and to a transition of a $\beta 2$-integrin subpopulation to a high affinity state (Rieu and Arnaout, 1996; Stewart and Hogg, 1996). Various agonists trigger CD11b/CD18 activation in neutrophils, including chemoattractants (PAF, IL8, fMLP, C5a), cytokines and growth factors (TNF $\alpha$ or GMCSF), and bacterial products (formylated peptides and LPS). During the initial rolling on endothelial cells, integrin "activation" signals are given by chemoattractants displayed on the endothelial membrane and presumably also by the engagement of selectins and their counter-receptors. Indeed, ligation of L-selectin by antibodies or carbohydrates that mimic natural L-selectin ligands (Simon et al, 1995)_or PSGL-1 interaction with P-selectin (Yago et al, 1999)—signal neutrophil adhesive functions via CD11b/CD18 integrins (Brenner et al, 1996; Steeber et al, 1997). Insideout signaling pathways that lead to integrin switch to an active conformation differ with the stimulating 
agonist and are still incompletely characterized (Blouin et al, 1999; Capodici et al, 1998; Jones et al, 1998).

The regulation of $\beta 2$-integrin avidity (clustering) involves interactions of both $\alpha$ and $\beta$ chain cytoplasmic tails with the cytoskeleton (Van Kooyk et al, 1999) and the membrane association of cytohesin-1, a guanine nucleotide exchange protein that binds to the cytoplasmic portion of CD18 and up-regulates $\beta 2$-integrin avidity (Kolanus et al, 1996; Nagel et al, 1998). Integrins transmit signals triggered by their clustering and multiple engagements with adhesion substrates ("outside-in signaling"). Neutrophils integrate these signals of integrin engagement and those delivered simultaneously by inflammatory cytokines or chemoattractants to activate a cascade of intracellular events resulting in cell spreading, locomotion, degranulation, and oxidative burst. These outside-in transduction pathways include the activation of various tyrosine kinases (Berton, 1999a; Fuortes et al, 1999; Lowell and Berton, 1999).

Finally, CD11b/CD18 integrin interacts in cis with GPI-anchored membrane proteins, such as Fc $\gamma$ RIIlb (CD16b), the LPS receptor CD14 or the urokinase receptor UPAR (CD87). Integrins behave as promiscuous transducers mediating signals triggered by these GPI-linked receptors (Petty and Todd, 1996). Fc $\gamma$ RIIIb interaction with CD11bCD18 promotes antibodydependent phagocytosis (Todd and Petty, 1997), while CD14 interaction with CD11bCD18 only occurs in the presence of LPS and LPS-binding protein and may play a role in the generation of proinflammatory mediators (Zarewych et al 1996, Todd and Petty, 1997).

\section{I.A.3. Extravasation and Diapedesis Toward Inflammatory Stimuli}

\section{Transendothelial Migration}

Neutrophil transmigration occurs prominently at the borders of endothelial cells, where discontinuities of tight junctions are observed. P-selectin has been shown to be concentrated along endothelial borders and may target there neutrophil adhesion (Burns et al, 1999). Extravasation requires, however, modifications of endothelial cell-to-cell adherent junctions. Indeed, disorganization of the junctional components VEcadherin, $\beta$-catenin, and plakoglobin has been observed in the vicinity of regions of firm adhesion between neutrophils and endothelial cells (Del Maschio et al, 1996).

Two cell adhesion molecules of the Ig-superfamily (CAMs) have been shown to be involved in leukocyte transmigration, the platelet endothelial cell adhesion molecule-1 (PECAM-1 or CD31) and, more recently, the junctional adhesion molecule (JAM) (MartinPadura et al, 1998; Muller et al, 1993; Vaporciyan et al, 1993). PECAM-1 is expressed both on the neutrophil surface and at the endothelial cell junction and mediates neutrophil extravasation via PECAM-1/PECAM-1 homophilic interactions. A "zipper" model has been proposed to account for a transmigration of leuko- cytes that maintains the permeability barrier of the endothelial cell monolayer (Muller et al, 1993). The JAM is selectively concentrated at inter-endothelial tight junctions but is not present on neutrophils. Antibodies to JAM inhibit in vitro leukocyte transmigration but the leukocyte counter-receptor of JAM is not known (Dejana et al, 1999; Martin-Padura et al, 1998). Finally, PECAM-1 is able to transduce signals into the cell, and its dimerization, by antibody cross-linking, increases CD11b/CD18 binding capacity via an inside-out signal transduction that involves PI3-kinase (Berman and Muller, 1995; Pellegatta et al, 1998).

\section{Migration Within Interstitial Tissues}

Neutrophils migrate in tissues by haptotaxis, ie, up a gradient of immobilized, rather than soluble (chemotaxis) chemoattractants. These chemoattractants, produced by bacteria, by dying cells, or by various stromal and epithelial cells of inflamed tissues, are bound to extracellular matrix components because of their negative charge. In vitro models show that leukocytes navigate through complex chemoattractant fields by migrating in a multistep process in response to one agonist source after the other (Fig. 1). Crosstalks between chemoattractant receptors and their signaling pathways may result in desensitization to one chemoattractant by another. In particular, signals delivered by "end target-derived" chemoattractantssuch as formyl peptides, released by bacteria or by mitochondria from dying cells, or complement C5a, produced in their immediate surrounding-are dominant and override "regulatory cell-derived" attractants, such as bioactive peptides (LTB4) or chemokines (IL8) (Foxman et al, 1999; Kitayama et al, 1997). This will allow, for example, leukocytes recruited by endothelial-derived chemoattractants to migrate away from the endothelial agonist source towards their final target within a tissue.

Neutrophil migration through the extracellular matrix is mediated by $\beta 2$ integrins, in concert with $\beta 1$ and $\beta 3$ integrins: the laminin-, fibronectin-, and vitronectin receptors $\alpha 6 \beta 1, \alpha 5 \beta 1$ and $\alpha \mathrm{v} \beta 3$ are mostly stored in neutrophil granules and rapidly expressed on the plasma membrane upon stimulation by chemoattractants and during transendothelial migration (Bohnsack et al, 1995; Hendey et al, 1996; Loike et al, 1999; Roussel and Gingras, 1997). Leukocyte locomotion requires the continuous formation of new adhesive contacts at the cell front, while the cell rear detaches from the adhesive substrate (Lauffenburger and Horwitz, 1996). During neutrophil locomotion on vitronectin, $\alpha v \beta 3$ integrins, which are mainly expressed at the leading edge, have been shown to be endocytosed when reaching the cell rear and finally recycled at the front (Lawson and Maxfield, 1995). This $\alpha \mathrm{v} \beta 3$ polarized distribution involves the activation of the $\left(\mathrm{Ca}^{2+}\right)_{i}{ }^{-}$ dependent phosphatase calcineurin, possibly resulting in integrin de-activation at the cell rear (Hendey et al, 1996). Similarly, a tyrosine-containing motif of the 


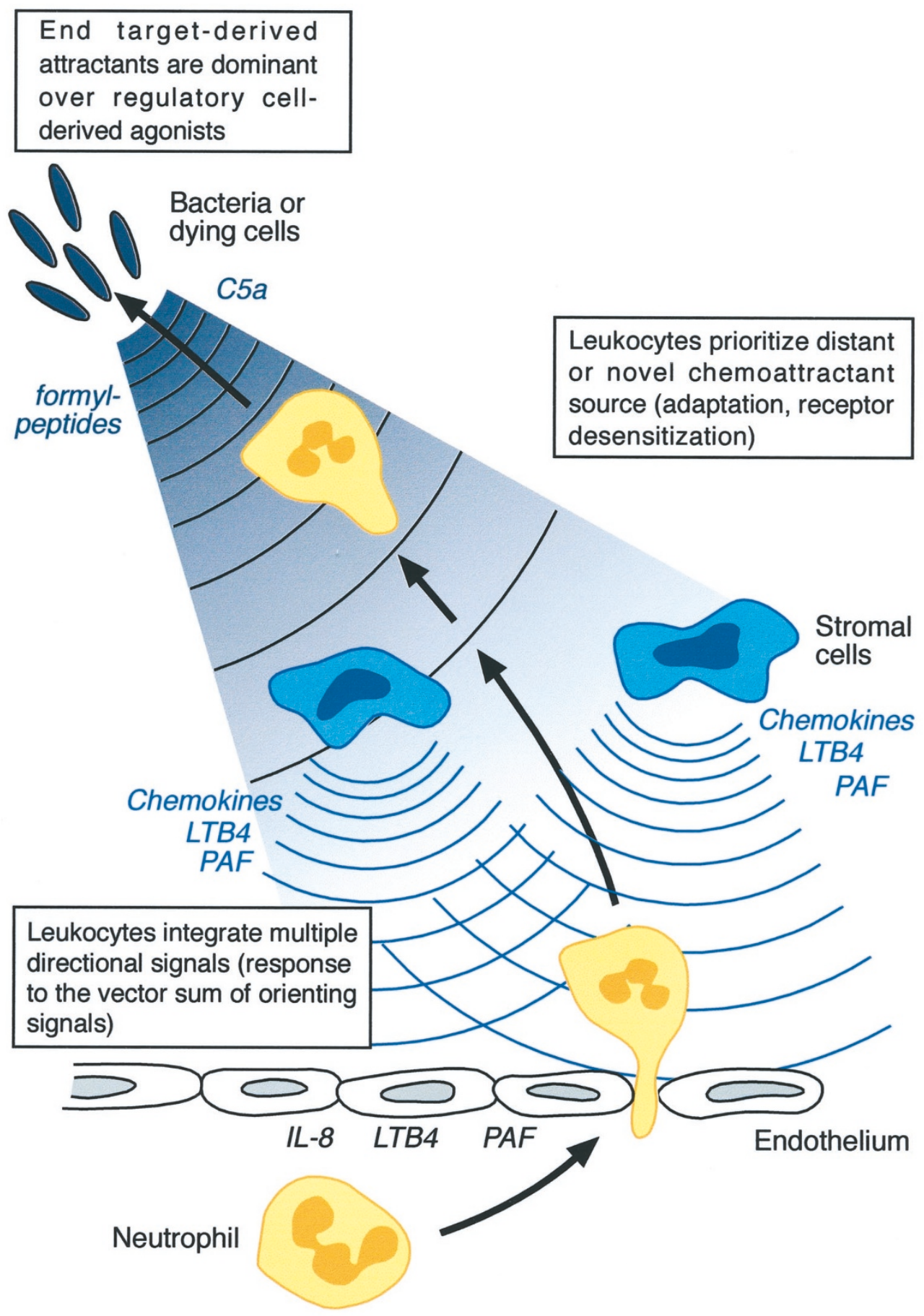

\section{Figure 1.}

Schematic view of the chemotactic migration of leukocytes towards an inflammation site. Neutrophils move through the endothelium and within tissues by responding to successive combinations of chemoattractant gradients. Chemoattractants are released by endothelial cells, by activated stromal cells (macrophages, epithelial cells... ), and by the inflammatory targets, ie, bacteria or dying cells. The direction of neutrophil movement is first guided by the steepest local chemoattractant gradient and is then regulated by successive receptor desensitization and attraction by secondary distant agonists. Finally, end-target attractants are dominant over regulatory cell-derived agonists (adapted from Foxman et al, 1999)

$\beta 2$ integrin cytoplasmic domain, involved in spontaneous receptor recycling, is required for cell migration (Fabbri et al, 1999). Detachment from the adhesion substrate could also be favored by the clustering in the cell rear of anti-adhesive membrane molecules, such as leukosialin (CD43) (Seveau et al, 2000). Dynamic 3-D imaging of neutrophils migrating through the matrix has revealed that cells crawl along matrix fibers, sometimes pulling elastic portions of these fibers to move through openings, but with no proteolytic degradation of the matrix (Mandeville et al, 1997). Such proteolytic degradation appears, however, to be required for the crossing of basement membranes (Huber and Weiss, 1989; Mandeville et al, 1997). 


\section{Signaling by Chemoattractants}

Neutrophils display multiple structurally related receptors for chemoattractants that can trigger adhesion, direct cell migration, and promote degranulation and oxidative responses. These G-protein-coupled seventransmembrane glycoproteins, also called "serpentines," include receptors for complement C5a, for formylpeptides, for the PAF, for leukotriene B4 (Yokomizo et al, 1997), and receptors for C-X-C or $\alpha$-chemokines (mainly CXCR1 and CXCR2 receptors for IL-8) (Premack and Schall, 1996). Ligation of chemoattractants to such receptors activates phospholipases, via heterodimeric G proteins, resulting in intracellular $\mathrm{Ca}^{2+}$ release, $\mathrm{Ca}^{2+}$ channel opening, and activation of conventional proteine kinase C isoforms (Bokoch, 1995; Premack and Schall, 1996). Tyrosine kinases (mainly Lyn of the Srk-family) (Berton, 1999a; Ptasznik et al, 1996; Welch and Maridonneau-Parini, 1997) and the GTP-binding protein Ras (Worthen et al, 1994) are also activated. Ras activation triggers the MAPK/ERK cascade, which appears to be involved in various chemoattractant-induced neutrophil functions (Krump et al, 1997; Nick et al, 1997; Pillinger et al, 1996). Activation of small GTP-binding proteins of the Ras, Rac, and Rho families regulate actin-dependent processes such as membrane ruffling, formation of filopodia and stress fibers, mediating cell adhesion and motility (Benard et al, 1999; Cox et al, 1997; Nobes and Hall, 1999). Moreover, Rho family members relay signals from chemokine receptors to the outside-in activation of integrins. The $\mathrm{Ca}^{++}-$and DAGindependent protein kinase $\mathrm{C}-\zeta$ has recently been proposed as a downstream effector of Rho signaling in this process (Laudanna et al, 1996, 1998). Finally, chemoattractant receptors, via their coupled G-protein heterodimers, activate PI3-Kinase, which is involved in the pathways leading to degranulation and NADPH-oxidase activation (Klippel et al, 1996; Okada et al, 1994; Thelen and Didichenko, 1997). The role of PI3-Kinase in neutrophil adhesion promoted by G-protein-coupled receptors is not clearly defined (Akasaki et al, 1999; Shimizu and Huntiii, 1996). Specific PI3-Kinase inhibitors block chemoattractant-induced neutrophil locomotion or homotypic aggregation, but have no effect on integrin CD11b/CD18 expression and activation triggered by these agonists (Capodici et al, 1998; Jones et al, 1998; Niggli and Keller, 1997).

\section{Transepithelial Migration}

In many inflammatory diseases (gastrointestinal, respiratory, urinary) neutrophils finally transmigrate across a polarized epithelium to accumulate within a lumen (Parkos, 1997). Transepithelial migration involves a disruption of intercellular tight junctions, which modifies the epithelial barrier and allows the entry of noxious lumenal contents and microorganisms. Complex signaling events lead to cortical restructuration of epithelial F-actin (Hofman et al, 1996) and the reversible disruption of tight junctions, followed by their resealing after passage of neutrophils (Nash et al, 1987; Parsons et al, 1987). The basolateral-to-apical crossing of an epithelium layer, which is often more than two times higher than the size of a neutrophil, involves a complex series of adhesive and de-adhesive events driven by mechanical forces-as shown by neutrophils squeezing through tight junctions and triggered by potent chemoattractants. Specifically, $\mathrm{N}$-formyl peptides are released by bacteria in the lumen and transported across epithelial cells (Chadwick et al, 1988; Merlin et al, 1998), while chemokines such as IL-8 are secreted by infected epithelia on their basolateral side (Eckmann et al, 1993; Kunkel et al, 1991; RichmanEisenstat et al, 1993). Finally, recent studies with Salmonella typhi have shown that pathogen interactions with the lumenal epithelial surface result in the release of an additional, currently undefined, "transcellular" chemotactic factor(s), which could drive neutrophil migration across epithelium (McCormick et al, 1998). Neutrophil transepithelial migration is mediated by $\beta 2$ integrin CD11b/CD18 interaction with unknown epithelial ligand(s) distinct from ICAM-1, which might include members of the proteoglycan family (Parkos, 1997). Integrin-associated protein CD47 appears to be involved in neutrophil transepithelial migration as shown by the delayed neutrophil recruitment to infectious sites in the presence of anti-CD47 blocking antibodies or in CD47 knock-out mice (Lindberg et al, 1996; Parkos, 1997). Although this could suggest involvement of $\alpha v \beta 3$ integrin, whose functions are regulated by CD47, no evidence has been reported for a role of $\beta 3$ integrins in transepithelial migration.

Finally, neutrophils may modify the epithelial electrolyte secretion and thus hydration of lumenal surfaces. Indeed, upon activation by bacterial products in the lumen, neutrophils release 5'AMP, which, in the intestine, has been shown to be rapidly converted to adenosine and to interact with an A2b type epithelial receptor, resulting in vectorial secretion of chloride ions into the lumenal compartment (Parkos, 1997; Strohmeier et al, 1995).

\section{I.B. Phagocytosis, Degranulation, and Bacteria Killing}

\section{I.B.1. Phagocytosis}

Neutrophil phagocytosis involves two different receptor classes, Fc $\gamma$ Receptors-Fc $\gamma$ RIIA (CD32), and Fc $\gamma$ RIIIB (CD16)-and complement receptors CR1 (CD35) and CR3 (or CD11b/CD18 integrin). Among these, the functional phagocytic receptors are Fc $\gamma$ RII and CR3, while CR1 and Fc $\gamma$ RIIIB appear mostly as co-receptors facilitating the function of the former receptors. Signaling pathways triggered by these two classes of receptors are different, as are the phagocytic processes themselves.

The ingestion of IgG-coated targets is promoted by the aggregation of Fc $\gamma \mathrm{RII}$ receptors and the phosphorylation of their cytoplasmic ITAMS (immunoreceptor tyrosine-based activation motifs) via the activation of Src-tyrosine kinases. Src kinase (Hck, Fgr, Lyn)-deficient mice exhibit poor Syk activation upon 
Fc $\gamma \mathrm{R}$ engagement, which results in a delay in phagocytosis (Crowley et al, 1997). Phosphorylated ITAMS indeed serve as docking sites for SH2 domains of Syk tyrosine kinase, which triggers various pathways involving the activation of PI3-kinase and of Rho proteins. As a result of Rho protein activation, membrane protrusions extend over the surface of the opsonized particle to form a "phagocytic cup" which engulfs the particle (Greenberg et al, 1996; Massol et al, 1998; Swanson and Baer, 1995). Phagocytes from Sykdeficient mice, or treated with a PI-3 kinase inhibitor, form actin-rich phagocytic cups that fail to proceed to particle engulfment (Crowley et al, 1997; Kiefer et al, 1998). Analysis of transfectants expressing GTPases defective in binding guanine nucleotides allowed to specify the involvement of Rho proteins: RhoA appears to be involved in the early F-actin recruitment and phagocytic cup formation, but may not be absolutely required for FcR-mediated phagocytosis (Caron and Hall, 1998; Hackam et al, 1997); CDC42 would regulate the extension of membrane over the particle edges, and Rac1, together with PI3-kinase, would allow membrane fusion and the final closure of the phagocytic cup (Cox et al, 1997; Massol et al, 1998). PI3-kinase is indeed involved in the myosin-induced "purse-string-like" contraction of pseudopods that closes phagosomes (Swanson et al, 1999).

The exact role of the Fc $\gamma \mathrm{RIII}$ receptor, anchored via a C-terminus-linked GPI moiety in the neutrophil membrane, is not yet clear. It has been recently proposed that, upon cross-linking by immunoglobulin ligands, Fc $\gamma$ RIII receptors would recruit Fc $\gamma$ RII receptors in "signaling raft-like" membrane domains and allow the clustering of ITAMS (Chuang et al, 2000).

Phagocytosis of C3bi-opsonized targets by complement receptor 3 (CR3) involves a different process: complement-opsonized targets sink into the cell, which produces little protrusions. CR3-mediated phagocytosis has recently been shown, in macrophages, to involve Rho but neither Rac nor Cdc42 (Caron and Hall, 1998). Unlike Fc $\gamma$ R-mediated phagocytosis, the ingestion of C3bi-opsonized particles occurs independently of a rise of cytosolic-free $\mathrm{Ca}^{++}$ and of increased inositol phosphate production (Fällman et al, 1989). While FcR-mediated phagocytosis is accompanied by the activation of the respiratory burst and by the production of arachidonic metabolites and cytokines, this does not occur during C3bi-dependent uptake (Wright and Silverstein, 1983; Yamamoto and Johnston, 1984).

Adhesion of neutrophil CR1 and CR3 to particles exclusively coated with $\mathrm{C} 3 \mathrm{~b} / \mathrm{iC} 3 \mathrm{~b}$ is not sufficient to promote phagocytosis, unless neutrophils are activated by PMA or by formyl-peptides and a contact with fibronectin or laminin (Brown, 1986; Wright and Meyer, 1986). These stimuli result in the phosphorylation of CR1 and trigger the "inside-out" signaling that activates CR3 binding capacity. Cooperativity between $\mathrm{Fc} \gamma$ - and complement-receptors occurs when $\mathrm{C} 3 \mathrm{~b} / \mathrm{iC} 3 \mathrm{~b}-$ bearing targets are also opsonized by antibodies or display glycosylated CR3 ligands (Ehlenberger and Nussenzweig, 1977). Cross-talks between phagocytic receptors are suggested by the observation that neutrophils from CR3-deficient (CD18deficient $L A D$ ) patients display an impaired antibodydependent phagocytosis (Dana et al, 1984) and that Fc $\gamma$ RIIIB interacts in cis with CR3, via a lectincarbohydrate interaction (Todd and Petty, 1997). Complex signaling pathways promoted by the engulfment of opsonized targets lead to the fusion of protease-rich granules with the phagosome and the triggering of the oxydative burst, as described in detail below.

\section{I.B.2. Degranulation}

\section{Granule Biogenesis}

Neutrophil-derived microbicidal molecules are packed in granules that are released upon cell activation (Elsbach, 1998; Lehrer and Ganz, 1999; Spitznagel, 1990) (Fig. 2). Granule biogenesis follows the granulocyte differentiation pathway (Borregaard and Cowland, 1997). The azurophilic granules first emerge at the stage of promyelocytes and contain myeloperoxidase, serine proteases, and antibiotic proteins (Fouret et al, 1989). Azurophil granules are thus considered as the true microbicidal compartment mobilized upon phagocytosis. Still, morphological heterogeneity has been described within azurophil granules (Egesten et al, 1994). According to the observation that azurophil granules do not contain lysosome-associated membrane proteins (LAMP), they cannot be classified as lysosome, but rather appear to have the functional characteristics of a regulated secretory granule (Cieutat et al, 1998). Later in differentiation, at the metamyelocyte stage, specific granules containing lactoferrin and collagenase emerge, followed by the tertiary granule population containing gelatinase. A fourth type of granules, called the secretory vesicles, appears at the stage of mature neutrophil. Their origin might be endocytic, because they contain plasma proteins such as albumin. However, recent findings have shown that this strict compartmentalization is not a dogma. For instance, proteinase 3, a serine protease described in azurophil granules is also localized in the membrane of secretory vesicles, the most mobilizable compartment of neutrophils (Witko-Sarsat et al, 1999a). The mechanisms underlying the secretion of the four morphologically distinct populations of granules may be under separate control. The order of exocytosis observed after ionophore-induced progressive elevation of cytosolic calcium was secretory vesicles, gelatinase granules, specific granules, and lastly azurophilic granules (Sengelov et al, 1993).

Two inherited defects affect neutrophil granule structure, as reviewed in Malech and Nauseef (1997) . The first is the specific granule deficiency, which is a rare congenital disorder marked by frequent and severe bacterial infections. Neutrophils are characterized by a lack of specific granules and defensins, abnormalities in neutrophil migration, and impaired bactericidal activity. The molecular basis of this defect 


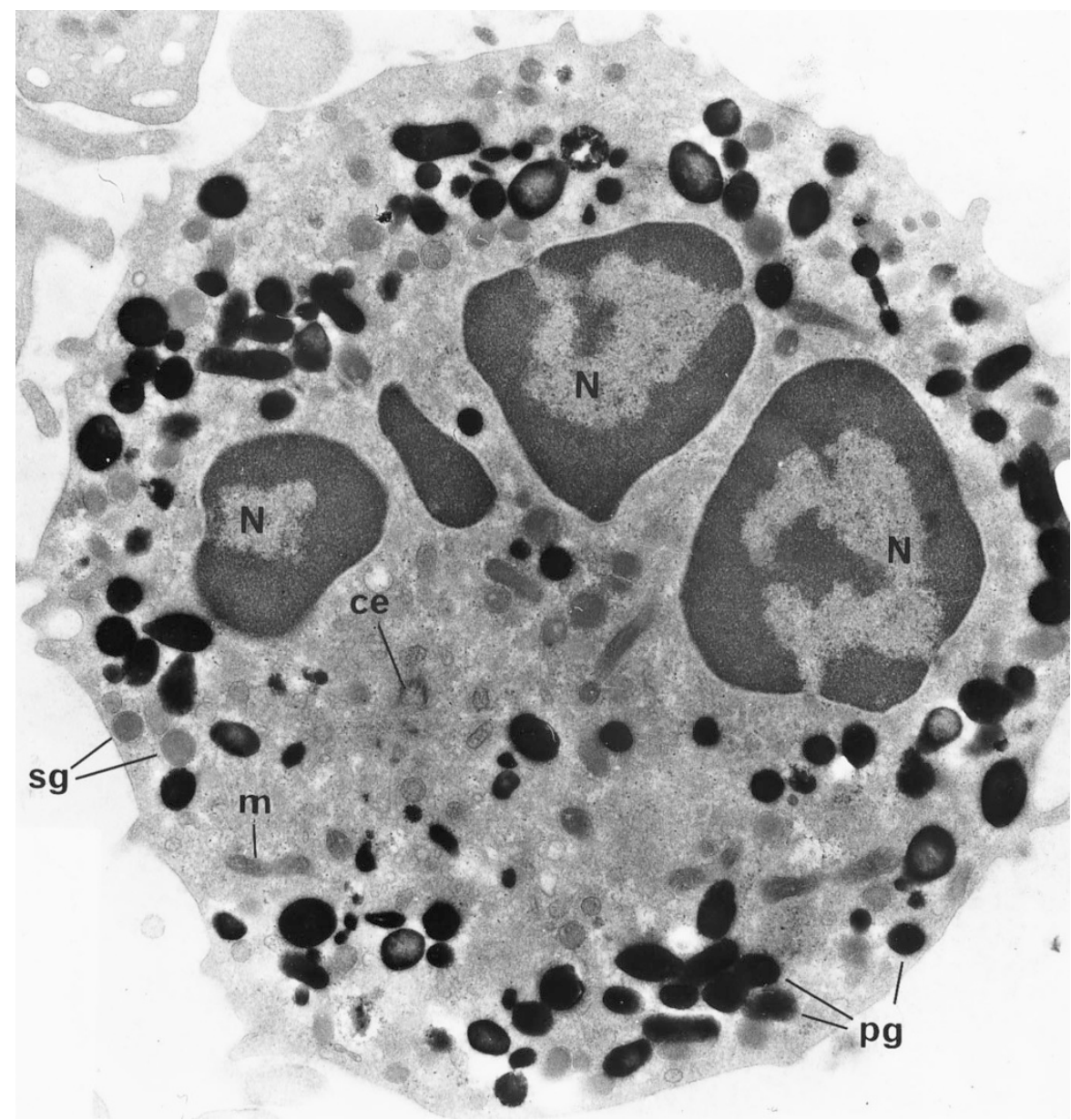

\section{Figure 2.}

Electron microscopy showing the various intracytoplasmic granules of a resting neutrophil. Resting neutrophils were first fixed in $1.25 \%$ glutaraldehyde in $0.1 \mathrm{~m}$ phosphate buffer followed by an incubation in diaminobenzidine to label peroxidase-positive granules. Neutrophils were then post-fixed with 0s04. Peroxidase-positive granules are azurophil granules (or primary granules, $p g$ ), which appear as large dark granules. Specific granules (or secondary granules, $s g$ ) are $s m a l l e r$ in size. Nucleus ( $M$; ; centriole (ce); mitochondri $(m)$. (Courtesy of Dr Elizabeth Cramer, INSERM U474, Cochin Hospital, Paris.)

has been recently characterized in one patient and involves a deletion in the CCAAT/enhancer binding protein ([C/EBP] $\epsilon$ ) gene, encoding for a member of the leucine zipper family of transcription factor primarily expressed in myeloid cells (Lekstrom-Himes et al, 1999). The second inherited granule deficiency is the Chediak-Higashi syndrome (CHS), which is a rare autosomal recessive disorder associated with an immune deficiency leading to increase susceptibility to infection and a life-threatening lymphoma-like syndrome. A lack of natural killer cell function and a neutropenia may be found, with a prominent defect in formation of neutrophil granules. The gene for $\mathrm{CHS}$ has been cloned, based on its homology to the murine gene responsible for the Beige phenotype that corresponds to the mouse CHS (Nagle et al, 1996). The CHS protein has structural features homologous to a yeast vacuolar sorting protein thought to be associated with vesicle transport. In fact, the CHS abnormalities are not restricted to neutrophils and all cell types show some oversized lysosomes, the disease affecting thus several organ systems.

\section{Mechanisms of Degranulation}

Intracellular transport of proteins, their delivery to various compartments, and their eventual secretion in the extracellular milieu represent crucial mechanisms in the activity of neutrophils. Degranulation of vesicles into the phagolysosome or in the extracellular space are key events for microbicidal activity (Berton, 1999b). With the exception of secretory vesicles, which are of endocytic origin, fusion of neutrophil granules with the plasma membrane represents a heterotypic fusion event. This fusion involves proteinprotein interactions that dock a vesicle to its final destination and proteins that favor the interaction between the phospholipid bilayer of the vesicle and its target membrane.

\section{I.B.3. Microbicidal Molecules}

The antimicrobial efficiency of human neutrophils depends on two concurrent events occurring in the nascent phagolysosome of stimulated neutrophils: the generation of ROS by assembly and activation of the 


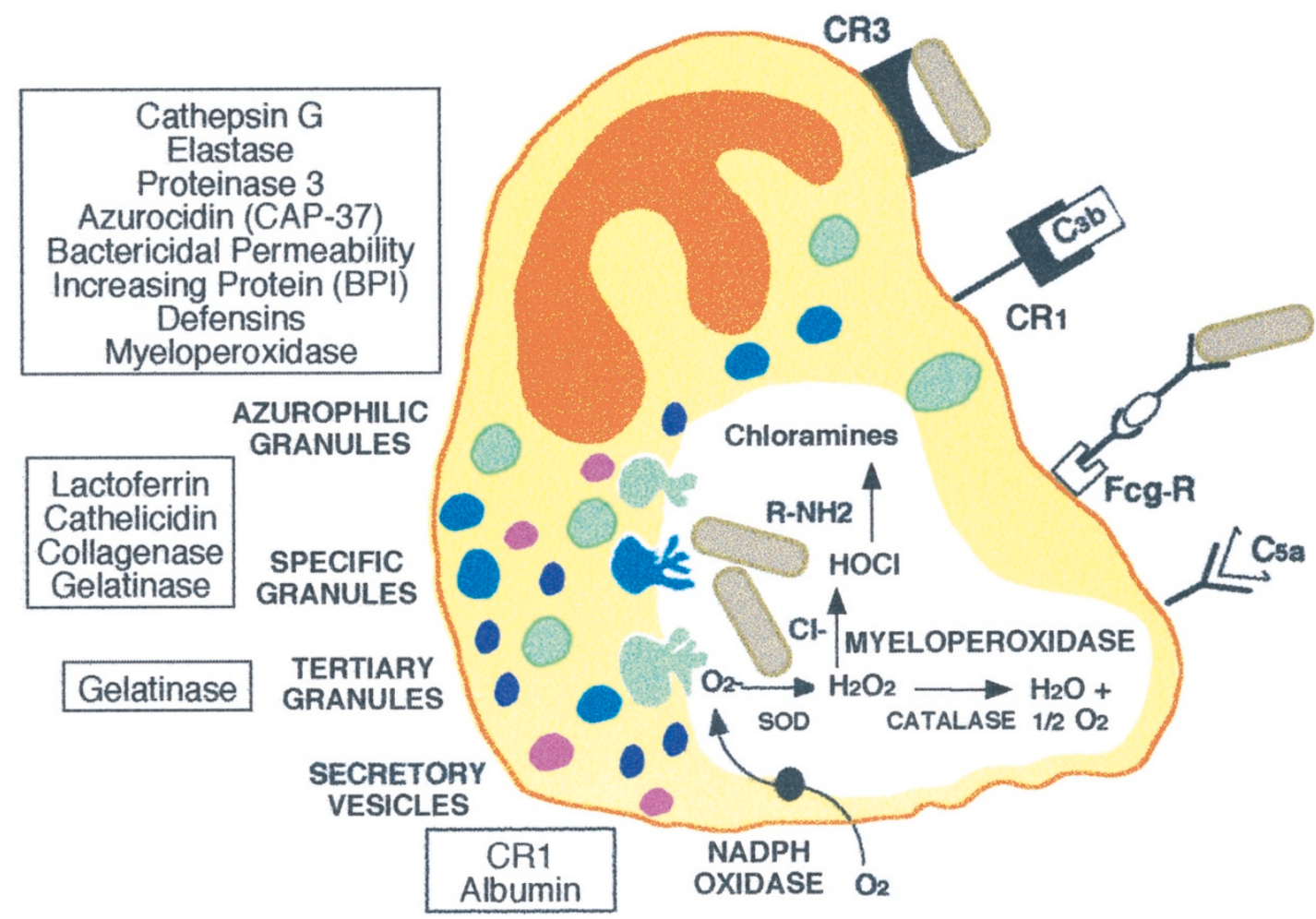

Figure 3.

Neutrophil effector mechanisms involved in the defense against pathogens and in the inflammatory process. Neutrophil effector systems are mobilized following phagocytosis of a pathogen. Complement opsonins C3b and C4b are recognized by CR1 and CR3. IgG opsonins are recognized via the immunoglobulin receptors $(\mathrm{F} c \gamma \mathrm{R})$. The first microbicidal pathway is the oxidative reponse, which consists of the production of radical oxygen species following NADPH-oxidase complex activation, including superoxide anion $\left(\mathrm{O}_{2}{ }^{-}\right)$, hydrogen peroxide $\left(\mathrm{H}_{2} \mathrm{O}_{2}\right)$, and, via myeloperoxidase, hypochlorous acid (HOCl) and chloramines. The second microbicidal pathway is non-oxygen-dependent and consists of the release in the phagolysosome or in the extracellular medium of preformed proteins stored in granules. Serine proteases, antibiotic proteins, as well as myeloperoxidase are contained in azurophilic granules. Metalloproteinases (collagenase and gelatinase) and antimicrobial proteins (lactoferrin and cathelicidin) are contained in specific granules. Gelatinase is also contained in tertiary granules, also called gelatinase granules. (Adapted from Witko-Sarsat and Descamps-Latscha, 1994.)

NADPH-dependent oxidase and the release of enzymatic or antimicrobial protein content in the granules. These responses are triggered by numerous agonists promoting adhesion or by phagocytic targets (Fig. 3).

\section{NADPH-Derived Oxidants}

The activation of the oxidative metabolism, known as the respiratory burst, first involves NADPH oxidase, an enzymatic complex composed of cytosolic (p40phox, p47phox, and p67phox) and membrane proteins (p22phox and gp91phox), which constitute a heterodimeric flavohemoprotein known as cytochrome b558, as reviewed in Babior (1999), Clark (1999), and Deleo and Quinn (1996). Two low-molecular weight guanine nucleotide-binding proteins are involved: Rac2, which is located in the cytoplasm in a dimeric complex with RhoGDI (Guanine nucleotide Dissociation Inhibitor), and Rap1A, which is located in membranes. Upon activation of neutrophils, p47phox becomes phosphorylated and cytosolic components migrate to the plasma membrane where they associate with cytochrome b558 to assemble the active oxidase. This enzymatic complex is thus able to generate superoxide anion $\left(\mathrm{O}_{2}{ }^{-}\right)$, which can dismutate into $\mathrm{H}_{2} \mathrm{O}_{2}$ (Babior, 1984 ; Nathan, 1987). There are three intermediates in the reduction of $\mathrm{O}_{2}$ to $\mathrm{H}_{2} \mathrm{O}_{2}$, namely $\mathrm{O}_{2}{ }^{-}, \mathrm{H}_{2} \mathrm{O}_{2}$, and the hydroxyl radical $\left(\mathrm{OH}^{\circ}\right)$, which are formed by successive one electron additions. Despite numerous studies, the formation of $\mathrm{OH}^{\circ}$ in phagocytes is still controversial (Britigan et al, 1986; Rosen and Klebanoff, 1979; Tauber and Babior, 1977; Ward et al, 1983). The formation of singlet oxygen appears to be an important event in the microbicidal potential of neutrophils (Allen et al, 1972; Harrison et al, 1978).

Much of what is known about the NADPH oxidase has come from studies of patients deficient in the system, who have chronic granulomatous disease (CGD). Due to a genetic defect in any of the four phox subunit genes, phagocytes of CGD patients fail to mount a respiratory burst (Gallin et al, 1991; Segal and Abo, 1993). With regard to molecular defect, $60 \%$ to $80 \%$ of cases are due to the X-linked gp91phox deficiency, $30 \%$ of cases are due to the autosomal recessive $\mathrm{p} 47$ phox, and $2 \%$ to $3 \%$ are due to the autosomal recessive p22phox or p67phox deficiency (Roos et al, 1996). Although their phagocytic capacity is normal, CGD phagocytes are incapable of producing ROS and subsequently of killing ingested targets. Patients with CGD experience recurrent and often life-threatening bacterial and fungal infections, as well 
as a granulomatous response in affected tissues. One exception to this rule is the normal killing of microorganisms that themselves produce significant quantities of $\mathrm{H}_{2} \mathrm{O}_{2}$ (eg, pneumococci), thereby supplying a missing ingredient used by the CGD neutrophils to reconstitute the activity of the myeloperoxidase$\mathrm{H}_{2} \mathrm{O}_{2}$-halide antimicrobial system that we describe below. The severe clinical picture observed in CGD clearly demonstrates the vital importance of NADPH oxidase in host defense against infection. Two distinct murine animal models of CGD-p47phox gene knockout (Jackson et al, 1995) and gp91phox gene knockout (Pollock et al, 1995) have been developed and show a phenotype resembling human CGD. Circulating neutrophils in these mice lack NADPH activity and CGD mice die prematurely from bacterial or fungal infections. These animal models are potentially interesting for the investigation of gene therapy protocols for CGD (Bjorgvinsdottir et al, 1997; Dinauer et al, 1999; Mardiney et al, 1997). The human gene therapy for the correction of the p47phox-deficient form of CGD is currently under study (Malech, 1999). The cell targets for p47phox gene transfer are hematopoietic progenitor/stem cells (CD34+) using retroviral vectors (Malech et al, 1997). In a phase I clinical trial of ex vivo gene therapy of p47phox-deficient CGD using retroviral vectors, prolonged production (2-6 months) of a low number (1:5000) of oxidase-normal neutrophils was achieved. Although the correction of the defect was transient, this therapy might provide beneficial effects in increasing host defense potential.

\section{The $\mathrm{H}_{2} \mathrm{O}_{2}$-Myeloperoxidase System}

The generation of superoxide anion via the activation of NADPH oxidase is the starting material for the production of a vast assortment of reactive oxidants, including halogenated oxidants generated through the myeloperoxidase (MPO) pathway (Klebanoff, 1969, 1999). MPO is a heme protein present in azurophil granules of neutrophils and monocytes, which is released upon cell activation into the phagolysosome or into the extracellular space. MPO amplifies the toxic potential of $\mathrm{H}_{2} \mathrm{O}_{2}$ by producing reactive intermediates. At plasma concentrations of chloride ion, the major product of MPO is hypochlorous acid $(\mathrm{HOCl})$. This potent oxidant chlorinates electron-rich substrates and oxidatively bleaches heme proteins and nucleotides. MPO has a wide range of substrates leading to a wide variety of byproducts. Amino acids, especially taurine, can be chlorinated to yield chloramines, the so-called long-lived oxidants (Rotrosen, 1992; Winterbourn, 1990). Several studies have demonstrated that the $\mathrm{MPO}-\mathrm{H}_{2} \mathrm{O}_{2}$ system results in the formation of tyrosyl radical and chlorination products, the generation of tyrosine peroxide, reactive aldehydes (Hazen et al, 1998), and the oxidation of serum proteins and lipoproteins (Heinecke, 1999; Leeuwenburgh et al, 1997). Interestingly, MPO can utilize nitrite and hydrogen peroxide as substrate to catalyze tyrosine nitration in proteins (Sampson et al, 1998) and can react with peroxinitrite (Floris et al, 1993; Podrez et al, 1999), thus providing a link with the nitric oxide-synthase system, as described below.

The importance of MPO in microbicidal activity has historically been the focus of studies. Given the important role of this system in the antimicrobial activity of circulating neutrophils, it seemed predictable that inherited deficiency of MPO would be severe and likely to be uncommon in the general population. Several inherited MPO deficiencies were described with severe infections with Candida (Nauseef, 1998). Likewise, knock-out MPO mice, which have recently been described (Koyama et al, 1999), show increased susceptibility to Candida infection. However, the use of flow cytochemistry to quantitate leukocytes in clinical samples revealed a large population of asymptomatic subjects with MPO deficiency (Nauseef et al, 1996; Petrides, 1998). MPO-derived oxidants have also been implicated in other processes unrelated to host defense, including carcinogenesis ( London et al, 1997; Pero et al, 1996), atherosclerosis (Heinecke, 1999), and chronic renal failure (Witko-Sarsat et al, 1998). In this latter condition, high levels of advanced oxidized protein products, derived from MPO activity, circulate in the plasma of uremic patients and can mediate inflammatory functions.

One should mention that an allelic polymorphism in the SP1 binding site in MPO promoter (Sp/Sp genotype leading to higher MPO mRNA expression) has been recently associated with an increased frequency of acute promyelocytic leukemia (Reynolds et al, 1997), as well as with gender-specific risk for Alzheimer's disease (Reynolds et al, 1999). In a study pointing out the influence of host defense molecule polymorphisms in CGD complications, it has clearly been demonstrated that CGD patients having the $\mathrm{Sp} / \mathrm{Sp}$ genotype had significantly increased frequency of gastrointestinal complications (Foster et al, 1998). It thus appears that MPO-derived oxidants have important regulatory functions in various pathophysiological conditions, not restricted to the field of inflammation. Although neutrophils remain the main source of MPO, it is also present in monocytes that could also be involved in MPO-mediated biological activity.

\section{Nitric Oxide-Synthase-Derived Reactive Nitrogen Intermediates}

NO-synthases (NO) are unique among eukaryotic enzymes in being dimeric, calmodulin-dependent or calmodulin-containing cytochrome P450-like hemoproteins that combine reductase and oxygenase catalytic domains in one monomer. They bear both FAD and FMN, and carry out a 5-electron oxidation of a non-aromatic amino acid (L-arginine) with the aid of tetrahydrobiopterin (Marletta, 1993; Nathan and Xie, 1994). Reactive nitrogen intermediates include nitric oxide (NO), which can react with oxygen to form much stronger oxidants such as nitrogen dioxide (NO2). The direct toxicity of $\mathrm{NO}$ is modest, but is greatly enhanced by reacting with superoxide to form peroxynitrite (ONOO-) (Beckman and Koppenol, 1996). 
The large amounts of NO produced by murine macrophages may contribute to their microbicidal activity. Because human phagocytes and especially neutrophils, appear to generate so little nitric oxide (Klebanoff and Nathan, 1993; Padgett and Pruett, 1995), the microbicidal role of NO in the human remains controversial (Albina, 1995). However, in urinary tract infection, neutrophils isolated from urine showed a dramatic increase in nitric oxide synthase activity, the major isoform being the inducible NOsynthase (Wheeler et al, 1997). NOS knockout mice have demonstrated the enzyme's essential contribution to host defense only against a restricted set of pathogens, including Mycobacterium tuberculosis and Leishmania major. Mice doubly deficient in both NO and NADPH-oxidase (gp91phox-knockout) formed massive abscesses containing commensal organisms, mostly enteric bacteria, even when reared under specific pathogen-free conditions with antibiotics, whereas neither parental strain showed such infections. No data on neutrophil functions in these mice are yet available (Shiloh et al, 1999).

\section{Granule Proteins}

Antimicrobial Proteins. Neutrophils use an array of antimicrobial peptides and proteins to destroy invading microorganisms. This has been reviewed in (Lehrer and Ganz, 1999; Levy, 1996). The azurophilic granules contain the majority of the antimicrobial proteins that should be released in the phagolysosome. One of the most active participants in host defense against Gram-negative bacterial infections is bactericidal/permeability increasing protein (BPI), a 50- kDa protein stored in azurophil granules but also expressed at the plasma membrane of neutrophils ( Elsbach, 1998; Weersink et al, 1993). The selective toxicity of BPI for Gram-negative bacteria relies on the binding capacity of its 21-25 kDa aminoterminal fragment to LPS (Ooi et al, 1987). This property of BPI has prompted preclinical and subsequent clinical testing of recombinant amino-terminal fragments of BPI. Phase I trials in healthy human volunteers and multiple clinical trials have now well proven that BPI is neither toxic nor immunogenic in normal individuals or in seriously ill patients (Von Der Mohlen et al, 1995). Trials of BPI administration have been or are being performed in various pathologic conditions including severe pediatric meningococcemia, hemorrhagic trauma, peritoneal infections, and cystic fibrosis (Elsbach, 1998).

Another important group of antimicrobial peptides is the group of beta-sheet defensins that comprises four members: HNP1 to NHP4 (Ganz and Lehrer, 1995). Defensins are small cationic, antibiotic peptides that contain six cysteines in disulfide linkage. They are active against Gram-positive and Gram-negative bacteria and act by inducing microbial membrane permeabilization. Besides their bactericidal role, defensins appear to have the ability to regulate the inflammatory process through binding to protease inhibitors such as alpha-1-antitrypsin and alpha-1-antichymotrypsin. At high concentration, defensins can ablate the inhibitory effect of normal human serum on cathepsin $G$ and human neutrophil elastase (Panyutich et al, 1995). Defensins are mitogenic for fibroblasts, thus suggesting a role in wound healing (Murphy et al, 1993).

Specific granules also contain antimicrobial molecules destined predominantly for extracellular release. Among them, hCAP-18 is a cathelicidin. This family of antimicrobial peptides has a conserved N-terminal precursor segment named "cathelin" and a highly variable carboxy-terminal microbicidal peptide. In neutrophils, they are stored in specific granules in an inactive form (Cowland et al, 1995; Sorensen et al, 1997). LL-37, a 37-residue peptide at the carboxyterminal domain of hCAP-18, is released after processing by elastase (Zanetti et al, 1997), thus pointing to a cooperation with azurophil granules. Synthetic LL-37 was active against Gram-negative and Grampositive microorganisms (Turner et al, 1998). Interestingly, LL-37 may act synergistically with lactoferrin, which indeed possesses its own antimicrobial activity (Zanetti et al, 1997). Lactoferrin is a well studied example of an antimicrobial peptide generated by limited proteolysis of a longer protein. Lactoferrin is an $80 \mathrm{kDa}$ iron-binding protein whose antimicrobial amino-terminal domain (lactoferricin) is liberated by pepsin cleavage (Hwang et al, 1998). Other proteins stored in specific granules, such as phospholipase A2 and lysozyme, may account for bactericidal activities, as demonstrated in biological fluids (Harwig et al, 1995; Weinrauch et al, 1996).

Secretory leukoproteinase inhibitor (SLPI) is a $12 \mathrm{kD}$ nonglycosylated protein which is present in neutrophils (Sallenave et al, 1997) and produced by cells of mucosal surfaces. This two-domain polypeptide has a carboxy-terminal domain expressing antiproteinase activity, whereas its aminoterminal domain has broadspectrum antimicrobial properties (Tomee et al, 1997). LPS and lipoteichoic acid from Gram-positive bacteria cell walls have also been shown to induce SLPI synthesis in murine macrophages (Jin et al, 1998).

Studies of antimicrobial peptides are providing new insights into the complex interactions between microbes and their hosts. Characterization of structural antimicrobial motifs of peptides isolated from neutrophils or from other sources (plants, insects) might offer novel templates for pharmaceutical compounds that could be effective against increasingly resistant microbes. For instance, protegrins are stored in granules from pig neutrophils as cathelin-containing precursors and are processed by elastase in a 16-18 amino-acid active peptide (Shi and Ganz, 1998). Protegrins display a strong toxic activity against bacteria, fungi, and enveloped viruses (Cho et al, 1998; Lehrer and Ganz, 1999). These small peptides are particularly well suited for chemical peptide synthesis. A clinical trial on prevention of oral mucositis caused by cancer therapy has been undertaken (Ganz and Lehrer, 1999).

Proteases. Neutrophil-derived proteases have the ability to degrade the majority of extracellular matrix components and, as a result, play fundamental roles in physiological processes, reviewed in Owen and Campbell (1999). According to the biochemistry of the 
active site, four distinct classes of proteinases can be identified, namely, serine-proteases, metalloproteases, thiol-proteases, and aspartate proteases. The two first classes, most active at neutral $\mathrm{pH}$, play a major role in degradation of extracellular proteins, whereas the two others, most active at acidic $\mathrm{pH}$, are involved in intracellular protein digestion.

Serine Proteinases. Neutrophil-derived proteases are packed in azurophil granules. Serine proteases are a large family of enzymes characterized by their active site, the so-called "catalytic triad" composed of histidine, aspartic acid, and serine. The group of the neutral serine protease homologs stored in the azurophilic granules of the neutrophil includes cathepsin G (Salvesen et al, 1987), elastase (Takahashi et al, 1988), proteinase 3 (Bories et al, 1989; Campanelli et al, 1990b), and the enzymatically inactive azurocidin or CAP-37 (Almeida et al, 1991; Campanelli et al, 1990a; Morgan et al, 1991), which are cationic glycoproteins of similar size (25-29 kD) which have been cloned. Neutrophil serine proteinases exhibit sequence homologies between each other and with $\mathrm{T}$ cell proteases, human lymphocyte proteases, granzyme B, and rat mast cell proteases (Hudig et al, 1993). Genomic cloning has revealed that neutrophil elastase, proteinase 3 , and azurocidin genes form a cluster of genes, located in the terminal region of the short arm of chromosome 19 and coordinately regulated in the promonocytic cell line U937 during induced terminal differentiation (Sturrock et al, 1992; Zimmer et al, 1992). The gene of cathepsin $G$ belongs to another cluster of genes encoding hematopoietic serine proteases along with granzyme $\mathrm{H}$ and granzyme $\mathrm{B}$ genes on chromosome 14q11.2 (Haddad et al, 1991; Hanson et al, 1990).

Elastase and PR3 display very similar patterns of proteolytic activities (Kam et al, 1992). They are both capable of cleaving insoluble elastin and a variety of matrix proteins, including fibronectin, laminin, vitronectin, and collagen type IV They show minimal activity against interstitial collagens, type I and III (Rao et al, 1991). The main physiologic defense against elastase and proteinase 3 is plasma $\alpha 1$-antitrypsin ( $\alpha 1-\mathrm{AT})$ and $\alpha 2-$ macroglobulin (Mason et al, 1991; Travis and Salvesen, 1983). Several intracellular elastase inhibitors have been characterized, including the human monocyte/neutrophil elastase inhibitor, a 42 kD glycoprotein, and member of the serpin family (RemoldO'Donnell et al, 1992). Cathepsin G displays a different pattern of inhibition, inasmuch as the serpin which accounts for the greatest inhibition is $\alpha 1$ antichymotrypsin. Elastase and PR3 have been implicated in pulmonary pathology including emphysema (Janoff et al, 1977; Kao et al, 1988), chronic bronchitis, and cystic fibrosis (last section of this review). Current concepts on the pathogenesis of emphysema emphasize the role of unrestrained proteolytic activity in the lung extracellular matrix. Because $\alpha 1-\mathrm{AT}$ provides almost all the protective screen of the lower respiratory tract against neutrophil elastase, emphysema might result from inactive $\alpha 1-\mathrm{PI}$ unable to inhibit neutrophil elastase in the lung (Janoff, 1985; Stockley,
1987). Of particular interest is $\alpha 1$-AT deficiency, an autosomal hereditary disorder characterized by reduced levels of $\alpha 1$-AT in plasma and lung fluids, thereby leading to unopposed proteinase activity and culminating in pulmonary emphysema (Crystal et al, 1989). In this condition, quantum proteolytic events in neutrophils are large and prolonged, leading directly to an increased risk of tissue injury in the immediate vicinity of neutrophils (Campbell et al, 1999). SLPI may be important for local anti-elastase protection in the lung, but it has antiproteinase activity against neutrophil elastase and cathepsin G, but not against proteinase 3 (Rao et al, 1993).

Neutrophil serine proteinases, especially cathepsin G, can mediate platelet aggregation (Renesto and Chignard, 1993). Serine proteinase homologs have been shown to exert immunomudulatory effects. Azurocidin (CAP-37) has a chemotactic activity for monocytes and stimulates PKC in endothelial cells (Pereira et al, 1990, 1996). Elastase can cleave monocyte CD14, thus inhibiting lipopolysaccharidemediated cell activation (Le-Barillec et al, 1999). Both elastase and proteinase 3 are able to induce the synthesis of IL-8 in endothelial cells (Berger et al, 1996) and to process IL8 into more potent N-terminal truncated forms of IL8 (Padrines et al, 1994). Similarly, PR3 can process the membrane-bound TNF- $\alpha$ precursor into its mature form (Robache-Gallea et al, 1995). Elastase and PR3 could play a significant role in pulmonary inflammation through their secretagogue activity on goblet cells. They are so far the most potent agonist for goblet cell secretory activity that is dependent on their catalytic activity (Sommerhoff et al, 1990; Witko-Sarsat et al, 1999b).

Several groups have investigated the conditions required for plasma membrane expression of serine proteases that could be of great relevance in the pathophysiology of inflammatory disease. Both elastase and cathepsin $\mathrm{G}$ can be expressed at the plasma membrane of activated neutrophils, where they appear to be bound via an ionic interaction (Owen et al, 1995). In contrast, proteinase 3 , also expressed at the plasma membrane, is bound via a covalent interaction (Witko-Sarsat et al, 1999a). It has been described that in the case of elastase and cathepsin G, this tight association of serine-proteinases with the plasma membrane confers resistance to physiological inhibitors such as $\alpha 1$-AT via a steric mechanism. The use of inhibitors seems to be the only means to regulate the activity of neutrophil serine proteinases, inasmuch as these proteases are probably functional in their packaged forms, and specific serine protease inhibitors could be of potential interest as anti-inflammatory drugs.

Among purified neutrophil-derived proteases, those that so far appear to have significant in vitro antimicrobial potential independent of their enzymatic action are cathepsin G (Bangalore et al, 1990; Shafer et al, 1991), PR3, and azurocidin (Campanelli et al, 1990b). Their antimicrobial activity is widely distributed because they are active against Gram-positive, Gramnegative, yeast, and fungi. Although in vitro studies did 
not reveal antimicrobial activity of elastase, knock-out elastase mice show an impaired host defense against Gram-negative bacterial sepsis (Belaaouaj et al, 1998). The discrepancy between in vitro and in vivo studies suggests that the antimicrobial potential of elastase could be via an indirect mechanism involving the proteolytic activation of antimicrobial peptides synthesized as proforms, such as defensin (Daher et al, 1988) and cathelicidin (Zanetti et al, 1997).

Metalloproteinases. Matrix metalloproteinases (MMPs) constitute a family of closely related enzymes that play important roles in a variety of physiological and pathological processes of matrix degradation (Owen and Campbell, 1999; Shapiro, 1998; Weiss and Peppin, 1986). Neutrophils contain metalloproteinases such as collagenase (MMP-8), which are stored in the specific granules and specifically cleave type I collagen, whereas the $92 \mathrm{kDa}$-gelatinase (MMP-9), which is stored in separate secretory vesicles, degrades native type $\mathrm{V}$ collagen. In addition, neutrophil metalloproteinases have been involved in the modulation of neutrophil functions such as the shedding of Fc $\gamma$ receptor (Middelhoven et al, 1997).

Comparison of the primary structures of MMP shows that they are structurally homologous with defined functional domains (Sanchez-Lopez et al, 1988; Wilhelm et al, 1989). All of these enzymes contain an essential catalytic zinc-binding domain, an $\mathrm{NH} 2$-terminal domain that preserves the latent state of the enzyme and a $\mathrm{COOH}$-terminal domain that plays a major role in substrate specificity.

Metalloproteinases are stored in latent form within granules. When neutrophils are stimulated to release them, these latent enzymes must be activated before they can attack their substrate, by mechanisms that are still not completely understood. In vitro experiments have shown the involvement of serine proteinases, chlorinated oxidants, chemicals such as organomercurials, and SH-modifying agents. Latent collagenase can be directly activated by $\mathrm{HOCl}$, whereas progelatinase seems to require both oxidantand serine protease-dependent pathways (Knauper et al, 1996; Murphy et al, 1992; Peppin and Weiss, 1986). Secretion of metalloproteinase inhibitors in an inactive precursor form is an important feature that regulates their activity in the extracellular milieu.

Further regulation of the activity of metalloproteinases in the extracellular milieu is achieved by specific inhibitors interacting with the activated enzymes. Three tissue inhibitors of metalloproteases (TIMP) have been characterized and cloned (Murphy and Docherty, 1992). TIMP-1 and TIMP-2 are soluble inhibitors that are present in many tissues and biological fluids. They are secreted by several mammalian cell types, including fibroblasts, endothelial cells, smooth muscle cells, and chondrocytes (Cawston et al, 1981; Declerck et al, 1991; Stricklin and Welgus, 1983). TIMP-3 is an insoluble inhibitor that is bound to extracellular matrix (Moses, 1997). The activity of TIMP can be oxidatively regulated and is blocked by various serine proteinases, including human neutrophil elastase, trypsin, and $\alpha$-chymotrypsin (Okada et al, 1988). In addition, metalloproteinases can be inhibited by $\alpha 2$-macroglobulin and by complexing agents such as EDTA. Targeted disruption of metalloprotease genes has pointed out specific roles for metalloproteases in physiological processes (Shapiro, 1998). For instance, gelatinase B knock-out mice show an impaired primary angiogenesis in bone growth plates and a resistance to bullous pemphigoid. No investigation of neutrophil functions has been performed in this model (Vu et al, 1998).

\section{I.C. Cytokine Synthesis}

A great body of evidence has accumulated that the human neutrophil is both a target and a source of various proinflammatory cytokines, chemokines, and growth factors, and therefore often exerts its proinflammatory functions through an autoregulatory pathway. Neutrophils are exquisite targets of proinflammatory cytokines, eg, IL-1 and TNF- $\alpha$, of chemokines such as IL-8, and growth factors such as granulocyte/ monocyte colony stimulating factor (G-CSF and GMCSF). Indeed, these cytokines have been shown to amplify several functions of neutrophils, including their capacity of adhering to endothelial cells and to produce ROS, as described above; likewise, chemokines act as potent attractants and favor their orientated migration toward the inflammatory site. An important issue is that both cytokines and chemokines may also act as priming agents of neutrophils.

The concept that neutrophils can be a source of cytokines has only recently emerged and has recently been reviewed (Cassatella, 1999). Indeed, neutrophils were long considered to be devoid of transcriptional activity and capable of performing no or little protein synthesis. However, convincing molecular evidence has now been afforded that neutrophils either constitutively or in an inducible manner can synthesize and release a wide range of proinflammatory cytokines, antiinflammatory cytokines, and other cytokines and growth factors (Table 1). The production of cytokines by activated neutrophils is striking in its diversity. However, it remains much lower in its degree than that produced by the mononuclear phagocytes, namely the monocytes (Cassatella, 1995). This important discrepancy between the two cell types leads to the use of extremely purified neutrophil preparations when studying their cytokine production. However, this appears less evident in vivo if one considers that (i) the number of circulating neutrophils is almost 20 times higher than that of monocytes, and (ii) at the site of inflammation, neutrophils are the first to be recruited and largely predominate over monocytes. The production of cytokines is also largely influenced by the stimulating agents and among these, cytokines and bacterial endotoxins (LPS) are the most potent inducers (Table 2). The pattern of cytokines produced by neutrophils also greatly differs depending on the agonist, and for some cytokines co-stimulation by at least two of agonists is required, eg, IFN- $\gamma+$ LPS in the case of IL-12 (Cassatella et al, 1995). Another important feature is that cytokine production is pre- 
Table 1. Cytokine Expression by Neutrophils In Vitro

\begin{tabular}{|c|c|}
\hline Cytokines that are Expressed by Neutrophils In Vitro & $\begin{array}{c}\text { Cytokines that are not Expressed by } \\
\text { Neutrophils In Vitro }\end{array}$ \\
\hline $\begin{array}{l}\text { Proinflammatory cytokines } \\
\text { TNF- } \alpha \\
\text { IL-1- } \alpha \text {, IL-1- } \beta \\
\text { IL-12 } \\
\text { Antiinflammatory cytokines } \\
\text { IL-1 receptor antagonist (IL-1Ra) } \\
\text { Chemokines } \\
\text { IL-8 } \\
\text { Growth-related gene product- } \alpha \text { (GR0- } \alpha \text { ) } \\
\text { Macrophage infiltrating protein-1 } \alpha \text { (MIP-1 } \alpha \text { ), MIP-1 } \beta \\
\text { Cytokine-induced chemoattractants (CINC) } \\
\text { Other cytokines and growth factors } \\
\text { Interferon- } \alpha \text { (IFN- } \alpha \text { ), IFN- } \beta \\
\text { Granulocyte colony-stimulating factor (G-CSF) } \\
\text { Fas ligand (FasL), CD30 ligand (CD30L) } \\
\text { Vascular endothelial growth factor (VEGF) } \\
\text { Hepatocyte growth factor (HGF) } \\
\text { Release under certain conditions } \\
\text { Macrophage-CSF (M-CSF), IL-3, GRO- } \beta \\
\text { IL-18 (IFN- } \gamma \text { inducible factor) } \\
\text { TGF- } \alpha \\
\text { Oncostatin (0SM) and neurotrophins } \\
\text { Secretion still debated } \\
\text { IL-6, monocyte chemotactic protein-1 (MCP-1), } \\
\text { granulocyte-macrophage CSF (GM-CSF), stem cell } \\
\text { factor (SCF), and IFN- } \gamma\end{array}$ & $\begin{array}{l}\text { T-cell-derived cytokines } \\
\text { IL-10 } \\
\text { IL-13 } \\
\text { Other cytokines } \\
\text { RANTES, } \\
\text { MCP-2, MCP-3 }\end{array}$ \\
\hline
\end{tabular}

Adapted from Cassatella, 1999.

ceded by a consistent accumulation of the corresponding mRNA cytokines. Finally, the production of cytokines by neutrophils can easily be modulated by immunomodulatory cytokines such as IFN- $\gamma$, IL-4, IL-10, and IL-13, suggesting that T helper-1 (Th-1) or Th-2 cells may influence neutrophil cytokine production (Romagnani, 1994).

Given the limited space, our description will be restricted to $\mathrm{TNF} \alpha$, IL-1 $\beta$, and IL-1Ra as representatives of pro- or anti-inflammatory cytokines, and IL-8 as representative of chemokines. Detailed description of the other cytokines produced by neutrophils is given in Cassatella (1999).

\section{I.C.1. TNF- $\alpha$ as a Proinflammatory Cytokine}

TNF- $\alpha$, a homotrimer of $17 \mathrm{Kda}$ subunits, was originally described as a product of activated monocytes and macrophages displaying tumoricidal activity. It is a highly pleiotropic cytokine belonging to the superfamily of membrane-anchored and soluble cytokines that are notably involved in $\mathrm{T}$ cell-mediated immunity. Although it inhibits the growth of tumor cells, it has an enhancing effect on the proliferation of certain normal cells and has a great variety of nontumoral target cells, for example, monocytes, macrophages, lymphocytes, eosinophils, and neutrophils. TNF- $\alpha$ is involved in septic shock, cachexia, autoimmunity, and inflammatory diseases. Its potent proinflammatory effects mainly result from its capacity to increase expression of endothelial cell adhesion molecules and subsequently promote neutrophil adherence to vascular endothelium (see above). Finally, TNF- $\alpha$ is also a priming agent for neutrophils that notably increases their phagocytosis, degranulation, and oxidative responses.

However, activated neutrophils have been shown to have the capacity to express TNF- $\alpha$ mRNA (Lindemann et al, 1989). Using GM-CSF as a stimulus, no secretion of the related TNF protein was detected. Soon after, the dual observation of expression of TNF- $\alpha$ mRNA and protein secretion was reported with LPS as a stimulating agent. This observation was substantiated by other reports showing that Candida albicans also induces a potent extracellular release of TNF- $\alpha$ (Djeu et al, 1990; Mandi et al, 1991). It is also now generally accepted that cytokines, for example, TNF- $\alpha$ itself, IL- $1 \beta$, GM-CSF, and IL-2, are also potent inducers of TNF- $\alpha$ mRNA expression and secretion by neutrophils.

As already mentioned, neutrophils are exquisite targets of TNF- $\alpha$ that under certain conditions enhances their expression of adhesion molecules, induces their degranulation and subsequent release of lysosomal enzymes, and primes them for oxidative activity, leading to the production of highly reactive oxygen species. These effects are mediated via TNF- $\alpha$ 
Table 2. Agents Able to Trigger Cytokine Production by Neutrophils

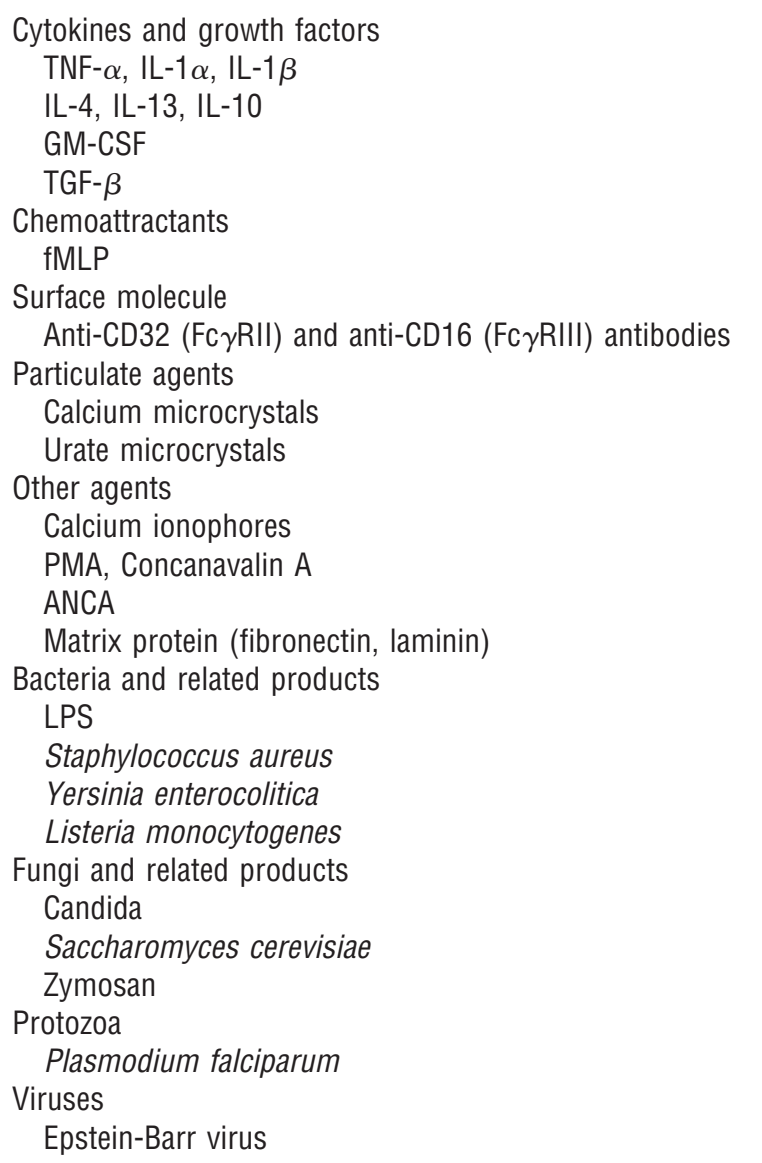

Adapted from Cassatella, 1999.

receptors that have been cloned and are expressed in two types: the type $\mathrm{A}$ of $75 \mathrm{kDa}$ (also referred to as $\mathrm{p} 75)$ and the type B of $55 \mathrm{kDa}$ (p55). Both types are expressed on a wide variety of cells, but it is generally accepted that, whereas the p75 is mainly expressed on cells of myeloid origin, the p55 predominates on epithelioid cells. Even though both receptors display similar architecture, most of the sequence homology is displayed in the extracellular domain and almost no homology is observed in the cytoplasmic domain, suggesting that the two receptors activate distinct intracellular signaling pathways. Soluble forms of p55 and p75 that bind to TNF- $\alpha$ and have similar neutralizing effects have been described (Brockhaus et al, 1990; Tartaglia and Goeddel, 1992). The underlying mechanisms of shedding of TNF receptors are still unclear, but neutrophil elastase has been shown to participate in the shedding of p75 (Porteu et al, 1991). Both soluble receptors are present in blood and urine of normal individuals (Aderka et al, 1992). Elevated circulating levels of these molecules have already been reported in patients with inflammatory diseases such as rheumatoid arthritis (Dayer and Fenner, 1992; Lopez et al, 1995) and in chronic renal failure patients (Descamps-Latscha et al, 1995; Pereira et al, 1994). The biologic functions of these soluble forms of TNF receptors present in plasma are still speculative. One might expect that they play a role in neutralizing circulating TNF- $\alpha$ resulting in a decrease of an inflammatory reaction. However, a role of these receptors as possible "reservoirs" of biologically active TNF- $\alpha$ has also been suggested. In vivo, an imbalance between TNF soluble receptors and TNF- $\alpha$ has been observed in severe meningococcemia (Girardin et al, 1992; Villard et al, 1993).

\section{I.C.2. IL-1 and IL-1 Receptor Antagonist (IL-1-Ra)}

The issue of whether or not neutrophils synthesize and secrete IL-1 has been a matter of debate for several years, but molecular studies have now clearly demonstrated that neutrophils indeed express the mRNA of both IL- $1 \alpha$ and $\mathrm{IL}-1 \beta$ and release the related IL-1 proteins. However, the amount of IL-1 $\beta$ is up to 10 times more than that of IL-1 $\alpha$. The stimuli listed in Table 2 are in general all capable of inducing IL-1 production by neutrophils, although, among the cytokines, it appears that only IL-1 $\beta$ itself and TNF- $\alpha$ induce IL-1 production by neutrophils. Interestingly, anti-neutrophil cytoplasm autoantibodies (ANCA) have been shown to induce IL-1 $\beta$ mRNA expression in neutrophils. IL-1 is usually released in concert with TNF- $\alpha$ and exerts similar effects on neutrophils (see above).

Two classes of IL-1 receptors (IL-1-RI and IL-1-RII) expressed on a wide variety of cells have been described. IL-1Ra is a $23-$ to $25-\mathrm{kDa}$ protein made by the same cells as those that produce IL-1. It exerts its inhibitory action on IL-1 by binding to IL-1 receptors without triggering any signal transduction or biological activity. The demonstration of a constitutive secretion of IL-1Ra by neutrophils using GM-CSF combined with TNF- $\alpha$ as agonists (McColl et al, 1992) has been followed by the demonstration that neutrophil-derived products have an inhibitory activity on monocyte derived IL-1 production (Tiku et al, 1986). The expression of IL-1Ra mRNA in LPS-treated neutrophils appears to be greater than that of LPS-treated monocytes and an almost 100 -fold excess of IL-1Ra over IL-1 is usually produced by activated neutrophils. More recent studies have shown that IL-4, IL-13, and TGF- $\beta$ are potent inducers of IL-1Ra mRNA. It has thus become evident that neutrophil-derived IL-1Ra could contribute to modulate the IL-1 induced inflammatory and immune responses.

\section{I.C.3. IL-8 as a Prototype of Chemokines}

Chemokines are usually classified as $\mathrm{C}-\mathrm{X}-\mathrm{C}$ or $\mathrm{C}-\mathrm{C}$ chemokines on the basis of the position of the first two cysteine residues, and IL-8 is a prototype of the C-X-C family (Baggiolini et al, 1994). It was first described as a potent neutrophil chemoattractant and activator (Baggiolini and Clark-Lewis, 1992). It is expressed in response to LPS, mitogens such as PHA, cytokines, eg, TNF- $\alpha$, and IL-1 $\beta$ or aggregated immune complexes (Deforge et al, 1992). It is secreted by a variety of cells including $\mathrm{T}$ lymphocytes, epithelial cells, keratinocytes, fibroblasts, endothelial cells, and neutro- 
phils. Interestingly, IL-8 is the most abundantly secreted cytokine by neutrophils, and on the other hand neutrophils are the primary cellular target of IL-8 (Gainet et al, 1998). The presence of IL-8 mRNA in freshly isolated neutrophils has been widely reported. However, whether it is constitutive or induced by isolation procedure is still debated.

The list of agents capable of triggering IL-8 production by neutrophils never ceases to increase and comprises all the products listed in Table 2. Among these, opsonized zymosan, which involves CR1 and CR3 complement receptors, appears as the most potent agonist of IL-8 production. The potent chemotactic effect of IL-8 on neutrophils is also abundantly documented. Two sulfhydryl groups participate in the binding of the ligand to the receptor and consequently regulate receptor-mediated cell functions (Samanta et al, 1993).

\section{I.C.4. Modulation of Cytokine Expression by Neutrophils}

As for other cytokine producing cells, cytokine expression by neutrophils can easily be modulated by the T-cell-derived regulatory cytokines, ie, positively by Th1 type cytokines such as IFN $\gamma$, and negatively by Th2 type cytokines such as IL-10, IL-4, and IL-13, reviewed in Cassatella (1999). Given the pathophysiological importance of such regulatory pathways, we will briefly consider each of these cytokines.

\section{IFN- $\gamma$}

IFN- $\gamma$ exerts a strong enhancing effect on the production of cytokines, regardless of the agonist used. This priming effect can be further enhanced in the presence of GM-CSF. IFN- $\gamma$ also up-regulates both the production of IL-1Ra and the accumulation of IL-1Ra mRNA. This positive effect of IFN- $\gamma$ on neutrophil cytokine production might have important consequences in vivo and may also represent one of the important mechanisms contributing to improve host defense to pathogens.

\section{$I L-10$}

Contrary to IFN- $\gamma$, IL-10 exerts an inhibitory effect on neutrophil cytokine production. This negative effect of IL-10 was initially reported on TNF- $\alpha$, IL-1- $\beta$, and IL-8 production (Cassatella et al, 1993), and is now expanded to almost all cytokines and chemokines produced by neutrophils, including IL-8, MIP-1 $\alpha$, MIP- $1 \beta$, and GRO- $\alpha$. Interestingly, IL-10 totally abrogated LPS-induced production of the p40 chain of the heterodimeric IL-12. Given the central role of this latter cytokine on Th-1 cells, this effect of IL-10 could contribute to the prevention of Th1 cell mobilization and attraction during infections. In contrast, IL-10 potentiates the expression of IL-1Ra induced by LPS, but not by opsonized zymosan. Taken together, these findings contribute to reinforcing the role of IL-10 as a biological antiinflammatory compound.

\section{IL-4 and IL-13}

These two immunomodulatory $\mathrm{T}$ cell-derived cytokines have also recently been shown to decrease LPS-induced neutrophil production of cytokines, in particular IL-8. As mentioned above for IL-10, IL-4 also induced an up-regulation of $\mathrm{IL}-1 \mathrm{Ra}$ synthesis in neutrophils, but this effect was not shared with IL-13. Finally, GM-CSF, which is known to exert a priming effect on neutrophil production of TNF- $\alpha$ and IL-8 induced by LPS, may also potentiate the neutrophil synthesis of IL- $1 \alpha$ and IL-1 $\beta$, but without affecting that of IL-1Ra.

\section{I.C.5. Molecular Regulation of Cytokine Production}

The very low transcriptional activity of neutrophils renders difficult the investigation of the regulation of their cytokine gene transcription. Nevertheless, an active transcription of the IL-1 $\beta$ gene in response to IL-1 $\beta$, TNF- $\alpha$ LPS, and GM-CSF has been demonstrated (Cassatella, 1999). Moreover, recent studies have shown that a wide variety of agonists induce the nuclear accumulation of NF- $\kappa \mathrm{B} /$ Rel proteins and their inhibitor $\mathrm{I}-\kappa \mathrm{B}$ (McDonald et al, 1997). In contrast, numerous studies have shown that cytokine gene expression can be regulated at the level of mRNA stability. This mechanism explains the up-regulation of IL-1 $\beta$ mRNA, whereas that of IL-1Ra has been shown to occur at the post-transcriptional level. The abovementioned inhibitory effects of IL-10 on neutrophil IL-8 production also result from both an inhibition of IL-8 gene transcription and an enhanced IL-8 mRNA degradation. Finally, a control at the translational level has also been suggested for IL-1Ra under specific experimental conditions.

\section{I.D. Apoptosis and Resolution of Acute Inflammation}

Most acute inflammatory responses resolve spontaneously thanks to endogenous "stop programs" that switch off inflammation and limit destruction of host tissues. These include the elimination of infectious agents by phagocytosis, the progressive decrease of leucocyte recruitment promoted by endogenous "braking signals," and finally, the apoptosis and clearance of leukocytes (Liles and Klebanoff, 1995).

\section{I.D.1 Progressive Decrease of Neutrophil Recruitment}

Termination of neutrophil emigration from blood vessels presumably results from (i) changes in the pattern of cytokine/anticytokine (IL-1/IL-1Ra, TNF/soluble TNF-R) and inflammatory/anti-inflammatory cytokines (IL-10, IL-4, IL-13), secreted by tissue cells and infiltrated leukocytes; (ii) the progressive return of endothelial cells to their resting state in terms of membrane adhesion molecules-that are shed or internalizedand in terms of displayed chemokines; and (iii) the inactivation of chemoattractants by specific enzymes or via receptor-mediated endocytosis (Ayesh et al, 1995; Cao et al, 1998; Hofman et al, 1998). 
As mentioned above, IL-10, IL-4, and IL-13, synthesized by macrophages and $\mathrm{T}$ cells at the inflammation site, down-regulate chemokine synthesis by neutrophils (Cassatella et al, 1993; Wang et al, 1994), and IL-10 enhances the synthesis of IL-Ra (Cassatella et al, 1994; Marie et al, 1996). In contrast, the effects of IL-10 on endothelial cells, such as the up-regulation of E-selectin and ICAM-1 (Sironi et al, 1993; Vora et al, 1996), would favor leucocyte extravasation. The net effect of these cytokines, however, appears to slow down neutrophil recruitment, because anti-IL-13 antibodies enhance the recruitment of neutrophils in the inflamed lung (Lentsch et al, 1999), and IL-10-deficient mice develop chronic enterocolitis characterized by a massive influx of neutrophils (Kuhn et al, 1993).

Other mediators that may slow down neutrophil recruitment are lipoxins, ie, lipoxygenase products generated by transcellular metabolism during host defense and inflammation. PMN-platelet transcellular pathways are a major route to lipoxin formation during PMN/platelet adhesion, PMN donating leukotriene A4 and platelet providing the lipoxin synthase to produce lipoxin LXA4. Lipoxins inhibit neutrophil chemotaxis, adhesion to endothelial cells, and migration across endothelium and epithelium. They were shown, in experimental models of glomerulonephritis, to act as "stop signals" for neutrophil-mediated tissue injury (Diamond et al, 1999; O'Meara and Brady, 1997).

\section{I.D.2. Apoptosis in Resolution of Inflammation}

Neutrophil apoptosis and subsequent ingestion by macrophages is the major mechanism for clearing neutrophils that have been recruited to the inflamed sites and thus for promoting resolution of the inflammation (Cox et al, 1995; Savill, 1997).

The constitutive apoptosis of senescent neutrophils involves proteolytic cascades-caspases, calpains, and the proteasome-that activate kinases, eg, caspase 3-mediated activation of protein kinase $\mathrm{C}-\delta$ (Pongracz et al, 1999), dissociate actin-binding proteins from filamentous actin (Knepper-Nicolai et al, 1998), and participate in cell surface as well as nuclear morphological transformations. Inflammatory mediators, such as LPS or GM-CSF, delay the apoptosis of neutrophils by increasing mitochondrial stability and reducing caspase 3 activity (Watson et al, 1999), and by down-regulating the gene expression of Bax, a pro-apoptotic member of the Bcl-2 family (Dibbert et al, 1999). In contrast, anti-inflammatory cytokines such as IL-10 accelerate the apoptosis of LPSactivated neutrophils (Cox, 1996).

Extravasation and apoptosis of inflammatory neutrophils are normal in Fas ligand- and Fas-deficient mice, showing that the FasL/Fas-mediated apoptosis is not essential in regulating the lifespan of neutrophils during an acute inflammatory response (Fecho and Cohen, 1998). Still, macrophages can trigger neutrophil apoptosis by expressing cell surface Fas ligand (FasL) and releasing soluble FasL, that reacts with the Fas "death receptor" on neutrophils. Ingestion of opsonized particles or of apoptotic neutrophils indeed promotes the release of soluble FasL by macrophages and the killing of bystander neutrophils (Brown and Savill, 1999). This may represent a negative feedback loop accelerating the resolution of inflammation by eliminating recruited leukocytes by apoptosis.

Phagocytosis of apoptotic neutrophils by human macrophages involves the $\alpha \mathrm{v} \beta 3$ integrin-CD36 complex, on macrophages, which binds thrombospondin, which itself binds an undefined ligand on apoptotic neutrophils (Savill et al, 1992). Macrophages stimulated with digestible particulate glucans lose their ability to use this recognition system, but acquire the ability to recognize exposed phosphatidylserine (PS) on the surface of apoptotic cells. CD36 appears to act as a necessary cofactor either for the $\alpha \mathrm{v} \beta 3$ system or for PS recognition (Fadok et al, 1998a). CD14 participates in the phagocytosis of apoptotic lymphocyte, but not that of apoptotic neutrophils.

Finally, phagocytosis of apoptotic neutrophils actively inhibits the production of IL-1beta, IL-8, IL-10, GM-CSF, TNF $\alpha$, leukotriene C4, and thromboxane B2 by human macrophages (Fadok et al, 1998b). This active suppression of inflammatory mediator production is presumably an important step in the resolution of inflammation.

\section{Neutrophils in Pathology}

The major role of neutrophils in host defense is a rapid response to invading microorganisms. However, neutrophils do not differentiate efficiently between foreign and host antigens without the help of soluble components of the immune system (eg, antibodies, complement, and cytokines) to select their targets. The nonspecific response and the powerful weapons of neutrophils are the two major mechanisms by which they could injure normal tissue. The host-damaging potential of the neutrophils is limited by elimination of the primary event that initiates inflammatory sequences and by mechanisms that inactivate neutrophils such as tachyphylaxis to proinflammatory mediators and apoptosis. Shut off the neutrophil influx involves inactivation of mediators and temporal change in the pattern of chemokines produced. Apoptosis mediates safe clearance of dying neutrophils from the inflammatory site. When these regulatory mechanisms are impaired or when the acute insult cannot be resolved, neutrophils become the predominant contributor to tissue injury (Fig. 4).

The role of neutrophils in pathology is exemplified in this review by different diseases, which we classified according to the stimulus or type of mechanism that activates neutrophils. However, this classification is simplistic, because neutrophils may be activated via several concomitant mechanisms when involved in inflammatory reactions.

\section{II.A. Bacterial Infection}

Tissue damage after acute bacterial infection may partly result from excessive neutrophil infiltration and activation in the infected tissue. During pyelonephritis, 

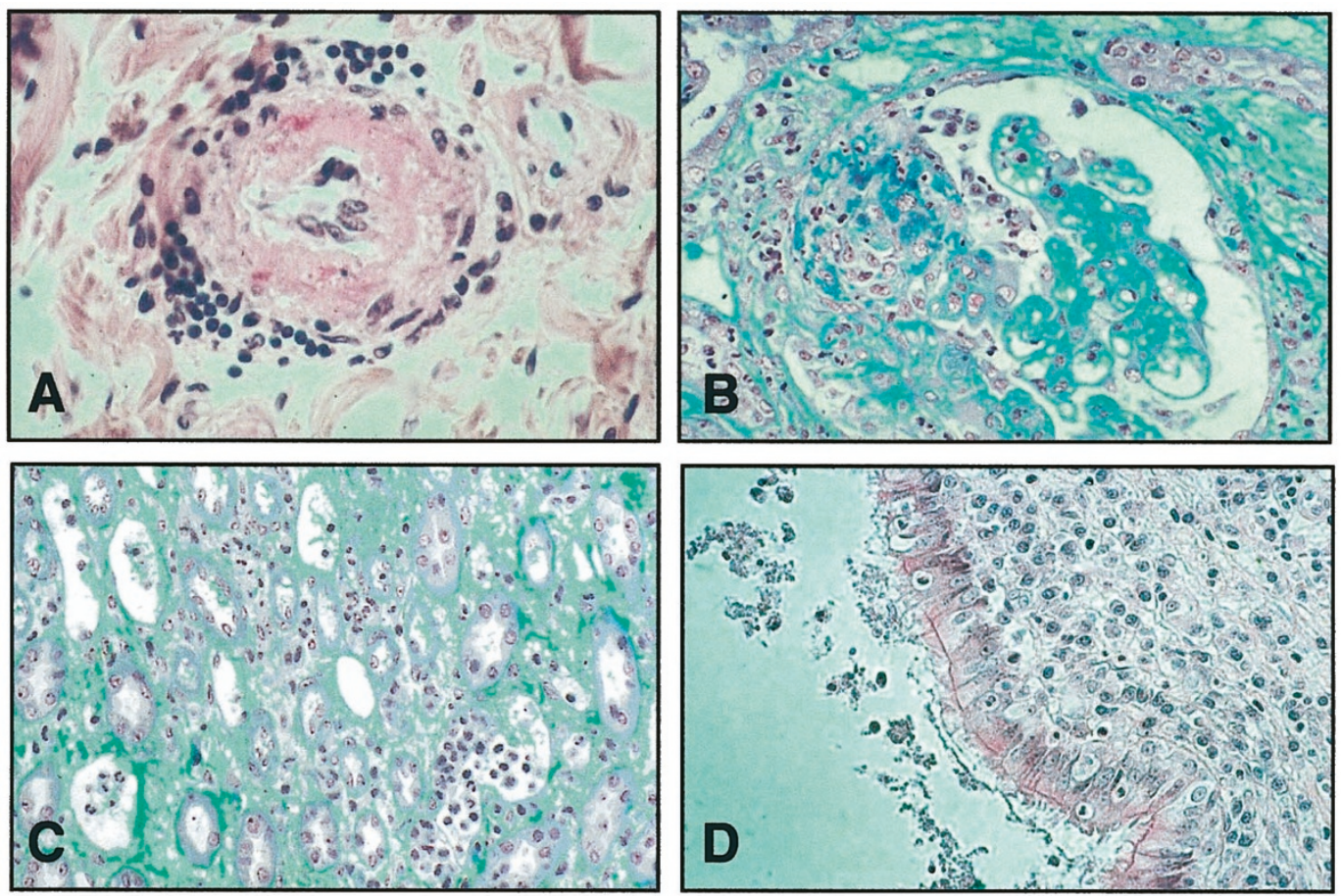

\section{Figure 4.}

Neutrophil-induced lesions. A, Leucocytoclastic vasculitis of the gut associated with cryoglobulinemia in a patient with rheumatoid arthritis. B, Necrotizing and crescentic glomerulonephritis associated with anti-proteinase 3 ANCA in a patient with Wegener's granulomatosis. C, Acute tubular necrosis secondary to renal ischemia after aortic surgery (courtesy of Drs Dominique Droz and Laure-Hélène Noël, INSERM U507, Necker Hospital). D, Bronchiolar infiltration by neutrophils in a patient with cystic fibrosis. (courtesy of Dr Claire Danel, Laennec Hospital, Paris).

the large inocula of bacteria in the kidney parenchyma triggers a burst of neutrophil extravascular migration. Microscopic examination of infected kidneys shows intensive neutrophil infiltration, degranulation of neutrophils containing phagocytozed bacteria, severe tubular destruction, and occlusion of small capillaries by leukocyte plugs (Ivanyi and Thoenes, 1987; Ivanyi et al, 1988). Studies using CT imaging indicate that patients with severe infection may develop renal scars (Meyrier, 1989). Experiments in animal models have shown that renal scarring after acute bacterial pyelonephritis results from parenchymal damage by neutrophils. Renal scarring may be prevented by neutrophil depletion or inhibition of leukocyte chemotaxis (Bille and Glauser, 1982; Tardif et al, 1994). Indirect evidence suggests that uropathogenic bacterial strains, which induce excessive neutrophil activation, contribute to tissue damage and renal scarring: strains associated with renal damage in vivo induce higher extracellular release of elastase and reactive oxygen products in vitro than bacterial strains causing pyelonephritis without renal scars (Topley et al, 1989; Monga and Roberts, 1995; Mundi et al, 1991). Some Escherichia coli strains that resist neutrophil engulfment could stimulate an extracellular oxidative metabolic burst, while those that are phagocytozed usually lead to intraphagosomal production of free radicals, minimizing their tissue-damaging effects (Iwahi and Imada, 1988; Lock et al, 1990). The bacterial load at the initiation of the inflammatory response and the phenotypic expression of bacteria, determining their ability to provoke neutrophil activation and to resist neutrophil phagocytosis, are important factors contributing to neutrophil-induced tissue damage during bacterial infection.

\section{II.B. Tissue Injury-Induced Inflammation: Ischemia-Reperfusion Injury}

Tissue injury after ischemia appears to be a consequence not only of tissue hypoxia but also of the process of reperfusion that leads to an inflammatory response. After the initial ischemic event, an array of cytokines, complement components, and cell contents are released, activating the endothelium and inducing neutrophil recruitment (Fig. 4C). Infiltrating neutrophils are a potential source of reactive oxygen species, proteolytic enzymes, and cytokines, which during reperfusion may play a detrimental role. In addition, capillaries may become obstructed by aggregated neutrophils, impairing reperfusion of the microcirculation (Bagge et al, 1980). Several studies have shown a pathogenetic role for neutrophils in ischemic insult to the myocardium, intestine, skeletal muscle, liver, and kidney, as reviewed in De Greef et al (1998). Ischemia causes neutrophil activation, retention, and worsening of renal injury in isolated kidneys (Linas et al, 1995). Neutrophil depletion attenuates ischemic renal reperfusion injury in the rat and mouse (Kelly et al, 1996). Blocking antibodies to ICAM-1 or $\beta 2$-integrin prevent the ischemia-induced renal infiltration of granulocytes and protect the kidney against 
reperfusion injury in the rat (Kelly et al, 1994; Rabb et al, 1994, 1995). The same results were obtained using antisense oligonucleotides and gene "knock-out" to block ICAM-1 (Kelly et al, 1996). In renal transplantation, neutrophil infiltration into the glomeruli approximately 30 minutes after reperfusion of the cadaveric kidney is significantly associated with long coldischemia times and delayed graft function, suggesting that graft function may be influenced by early neutrophil-mediated damage after reperfusion (Koo et al, 1998). Inhibition of leukocyte adhesion with antiICAM-1 or anti-LFA1 mAb in clinical renal transplantation trials seems to accelerate recovery of graft function (Haug et al, 1993; Hourmant et al, 1996). Such therapeutic approaches may herald the development of anti-adhesion strategies in other clinical forms of ischemia-reperfusion injury, such as resuscitation following systemic hypotension, or myocardial necrosis.

\section{II.C. Crystal-Induced Inflammation}

Acute gouty inflammation is the consequence of the deposition of monosodium urate crystals in joints. Neutrophils appear to be the major effector of acute gout. They accumulate in the joint fluid where they actively ingest urate crystals, aggregate and degranulate. Acute gouty inflammation may be prevented by neutrophil depletion or leukocyte chemotaxis inhibition (Phelps and McCarty, 1966). The considerable reactivity of the urate crystal surface allows it to bind soluble and membrane proteins (Terkeltaub et al, 1983). Precipitated urate crystals activate humoral mediator cascades such as complement and contact activation systems. The generation of C5a, kallikrein, bradykinin, and plasmin induces neutrophil chemotaxis and vascular permeability. Urate crystals also induce the production of inflammatory mediators by synovial cells (TNF $\alpha$ and IL8) and by neutrophils (LTB4 and IL8) (Matsukawa et al, 1998; Rae et al, 1982). TNF $\alpha$ and IL8 induce subsequent production by neutrophils of IL $1 \beta$ and IL8, which amplify the leukocyte influx. This autocrine mechanism appears to regulate the initiation and propagation of the inflammatory reaction.

Interestingly, urate crystals inhibit the production of C-C chemokines by neutrophils in response to TNF- $\alpha$, preventing the recruitment of mononuclear cells (Hachicha et al, 1995). Binding of urate crystals to neutrophils is followed by the release of lysosomal proteases and superoxide. In addition, phagocytosis of these highly membranolytic crystals may cause perforation of the phagolysosomal membrane leading to liberation of the lysosomal contents and to cell necrosis. However, the tissue injury induced by neutrophils during gout attack is acute and self-limited. The desensitization of neutrophils to chemotactic factors, proteolytic inactivation of soluble mediators, production of cytokine antagonists such as IL-1Ra (Matsukawa et al, 1998), and release of anti-inflammatory molecules such as TGF- $\beta$ (Brandes et al, 1991) may suppress leukocyte activation and neutrophil influx.
Change in the protein coating of the crystal surface during the evolution of acute gouty inflammation may also decrease the ability of urate crystals to activate leukocytes (Terkeltaub et al, 1991) and may partly explain why the presence of intra-articular crystals do not necessary produce arthritis between acute gouty attacks.

\section{II.D. Complement-Induced Inflammation and Oxidative Stress: Hemodialysis}

Activation of the complement cascade received much attention in the early literature on the immune system in maintenance dialysis (Craddock et al, 1977). It occurs in the early phase of each dialysis session, mainly through the alternative pathway, and closely reflects dialysis membrane biocompatibility, which is observed in dialysis with cellulose membranes such as cuprophan, but not with synthetic membranes, such as polyacrilonitrile (Cheung, 1990). Activated complement-split products, C5a and C3a, were originally ascribed to neutrophil lung sequestration (Arnaout et al, 1985; Hakim et al, 1984), and are now endowed for several indices of dialysis-induced neutrophil and/or monocyte activation, including triggering of protease (Hörl et al, 1985), reactive oxygen species (ROS) production by neutrophils (DescampsLatscha et al, 1991), and transcription (but not secretion) of the pro-inflammatory cytokines, interleukin-1 (IL-1) and TNF- $\alpha$ by monocytes (Schindler et al, 1990). The conjunction of massive generation of $\mathrm{ROI}$ in the face of a chronic deficiency of antioxidant systems (Céballos-Picot et al, 1996) and of a profound impairment in the balance between pro-inflammatory cytokines and their specific inhibitors (Descamps-Latscha et al, 1995) largely contribute to dialysis-related complications such as an increased rate of atherosclerosis and $\beta 2$-microglobulin amyloidosis arthropathy (Descamps-Latscha, 1993). In this setting chlorinated oxidants derived from MPO seem to play a critical role (Witko-Sarsat et al, 1998).

In acute ischemic renal failure in rats, chronic activation of the complement system by daily exposure of the blood to cuprophane dialysis membranes is associated histologically with increased neutrophil infiltration in the renal parenchyma, and functionally with a delay in the resolution of the acute renal failure (Schulman et al, 1991). Among patients with acute renal failure requiring hemodialysis, the use of the cuprophane membrane, as compared with the synthetic membrane, leads to a slower resolution of renal failure and a lower survival rate (Hakim et al, 1994; Schiffl et al, 1994). These findings suggest that preactivation of neutrophils by hemodialysis exacerbates the detrimental role of these cells in ischemia-reperfusion injury and in endotoxemia.

\section{II.E. Immune Complex-Induced Inflammation: Antibody-Mediated Glomerunephritis}

Immune complex deposition in tissues triggers an inflammatory reaction and is a key pathogenic factor 
in numerous clinical conditions such as glomerulonephritis, immune vasculitis, arthritis, and systemic lupus (Fig. 4A). Antibodies may deposit in the glomerulus either because they circulate in the form of immune complexes and are passively entrapped, or because they bind to targets fixed in the glomerulus. Among the experimental models developed to study the pathogenesis of antibody-mediated glomerulonephritis, the most extensively studied is the model of antiglomerular basement membrane (anti-GBM)nephritis, which is induced by injection of heterologous anti-GBM antibodies. In this experimental model, the injection of sufficient heterologous antiserum against the GBM leads to acute (heterologous) and delayed (autologous) phases of injury. The autologous phases result from the host's immune response to heterologous Ig anti-GBM. Most studies have concentrated on the heterologous phase of anti-GBMnephritis. This phase is characterized by immediate deposition of nephrotoxic mAb along the GBM (within minutes), transient neutrophil infiltration (maximal at 2 hours) in the glomerular capillaries, a swelling of endothelial cells that may detach from the underlying basement membrane, and the presence of thrombotic lesions. At Day 1 to 4, many glomeruli show segmental and global thrombosis and necrosis. Development of proteinuria starts 2 to 4 hours after injection and is maximal at 8 to 12 hours. Neutrophils play a critical role in glomerular injury in the heterologous phase because neutrophil-depleted mice or beige mice (that are deficient in leukocytic neutral proteinase elastase and cathepsin $\mathrm{G}$ ) do not develop proteinuria (Schrijver et al, 1990). ICAM-1 or P-selectin deficiency does not impair neutrophil influx in these models (Tang et al, 1997). CD11b/CD18 (CR3) deficiency reduces but does not abolish neutrophil infiltration. The recruitment of neutrophils is Fc $\gamma$-dependent and the use of $F\left(a b^{\prime}\right) 2$ fragments of the anti-GBM antibody markedly reduces the neutrophil influx. Immune complex deposits under the fenestrated endothelium are easily accessible to circulating cells. It has therefore been suggested that the initial accumulation of neutrophils is driven by neutrophil Fc receptor engagement with immobilized immune complexes in the glomerular capillary walls. The putative role of complement in pathogenesis of the heterologous phase of the antiGBM disease is suggested by the deposition of complement components in a distribution matching that of the antibody. C5a may have a role in the chemoattraction and activation of neutrophils; the deposition of iC3b on the GBM may enhance neutrophil adhesion while the deposition of sublytic concentration of C5b-9 on the endothelial surface may promote the surface expression of P-selectin. However, the contribution of complement is dependent on the dose of antibody used (Sheerin et al, 1997). Under a certain threshold level of antibody, complement acts synergistically with anti-GBM antibodies to induce neutrophil infiltration and albuminuria. At higher doses, neutrophil accumulation is complement-independent, but proteinuria remains partially complement-dependent, as shown in an experimental model using $\mathrm{C} 3, \mathrm{C} 4$, and
C5-deficient mice (Sheerin et al, 1997; Schrijver et al, 1988). Complement dependent proteinuria may be related to the interaction of CR3 (CD11b/CD18) on neutrophils with complement fragment iC3b, which probably stabilizes neutrophil interaction with immune complexes and favors the release of azurophilic granules (Tang et al, 1997). Indeed, proteinuria is absent in CR3-deficient mice, whereas initial neutrophil infiltration is only partly reduced. Neutrophils, once attracted to the glomeruli, make close contacts of varying extent with the inner side of the GBM, pushing aside the endothelial cells. In the zones of contact of neutrophils with their adhesion partners, neutrophil proteinases are known to be functional, in spite of the presence of powerful circulating inhibitors (Campbell and Campbell, 1988). Neutrophil enzymes can thus fragment GBM and degrade heparan sulfate proteoglycans in vitro and ex vivo (Heeringa et al, 1996). Heparan sulfate constitutes the majority of anionic sites of the capillary permeability barrier and also contributes to the anticoagulant properties of GBM exposed through the glomerular endothelium fenestrae. Experiments performed in Beige mice, which have a congenital defect in neutrophil granules, have demonstrated the involvement of neutrophil proteinases in the induction of albuminuria in the heterologous phase of anti-GBM nephritis (Schrijver et al, 1989). While the importance of neutrophils in mediating glomerular injury has been well demonstrated in this experimental model, the pathogenetic role of these cells in human immune complex mediated glomerunephritis remains to be elucidated.

\section{II.F. Cytokine-Induced Inflammation: Rheumatoid Arthritis}

Rheumatoid arthritis (RA) is known to be a predominantly $\mathrm{T}$ cell/macrophage driven process in the early stage of the disease, but the cell with the greatest capacity to inflict damage within joints is the neutrophil (Edwards and Hallett, 1997). Neutrophils are numerous in the synovial fluid and joint tissues during the early stages of rheumatoid arthritis and during acute exacerbation of the disease (Mohr et al, 1984). Neutrophils concentrate at the pannus-cartilage junction, which is the site of early cartilage erosion. They are thought to contribute directly to the cartilage damage, through their serine- and metalloproteases (Chatham et al, 1993; Larbre et al, 1995), as well as through the production of ROS and chlorinated oxidants (Edwards and Hallett, 1997). One should emphasize the importance of neutrophil- and macrophage-derived cytokines, found in large quantities in synovial fluids [eg IL-1 $\beta$, IL-6, TNF- $\alpha$, TGF- $\beta$, and IL-8]. In vitro, neutrophil-mediated cartilage injury is modulated by cytokines such as TNF- $\alpha$ (Kowanko et al, 1990). In vivo, the major role of TNF- $\alpha$ in the pathogenesis of RA has been demonstrated by a successful clinical trial using anti-TNF antibodies (Elliott et al, 1994). TNF- $\alpha$ is therefore likely to be an important stimulator of neutrophils within the joints of RA patients, resulting in 
amplification of the inflammatory response and contributing to the tissue damage caused by neutrophils.

Another cytokine playing a crucial role in the attraction of neutrophils is IL-8. Abundantly released by chondrocytes, it diffuses toward the joint surface, causing a chemotactic gradient. Although IL-8 alone does not exert a direct effect on cartilage, it induces a rapid cartilage destruction when cocultured with neutrophils (Pillinger and Abramson, 1995) probably due to neutrophil release of oxidants and proteases. Human chondrocytes are also a major source of $\mathrm{NO}$. They express the inducible isoform of NO synthase (iNOS) and NO, in conjunction with ROS, might theoretically contribute to promote cartilage degradation. However, this was not verified in a recent report showing that the inhibition of chondrocyte production enhances neutrophil-induced cartilage breakdown (Clancy et al, 1993).

The question of whether neutrophils in RA differ either functionally or in their molecular expression from non-rheumatoid neutrophils is still a matter of debate. Some studies have reported that the circulating rheumatoid neutrophil exhibits evidence of prior activation, with enhanced expression of receptors including $\mathrm{Fc} \gamma \mathrm{RI}, \mathrm{CR} 1, \mathrm{CR} 3$, and CR4, increased capacities of migration, degranulation, and superoxide anion production (Pillinger and Abramson, 1995). However, other studies have shown that the only neutrophils that show activation characteristics are within the joints (Lopez et al, 1995). Because there is consensus for considering RA as a major T-celldriven disease, it is likely that the differences between rheumatoid and non-rheumatoid circulating neutrophils are a subsequent rather than a primary event in RA.

With regard to therapeutic strategies developed in $\mathrm{RA}$, it is of interest to note that (i) most of the commonly used antiinflammatory drugs eg, corticosteroids and non-steroidal antiinflammatory drugs, gold salts, sulfasalazine, or D-penicillamine, exert profound effects on neutrophil effector functions; and (ii) among the drugs under trial in RA, several are specifically aimed at targeting neutrophil molecules eg, anti-adhesion molecules and/or neutrophil activation, eg, anticytokine antibodies (Arend and Dayer, 1995). Taken together, these observations derived from RA underscore the importance of considering the neutrophil as a pleiad of actors, each one a potential candidate for targeting future therapeutic strategies.

\section{II.G. Antineutrophil Cytoplasmic Antibodies and Vasculitis: Autoimmunity Against Neutrophil Components}

Neutrophil granule proteins are now recognized as target antigens for antineutrophil cytoplasmic antibodies (ANCA) found in sera of patients with systemic necrotizing vasculitides. The pathogenesis of ANCAassociated vasculitis is unknown. However, there is no immunologic evidence for vascular immune complex localization (Csernok et al, 1999; Falk and Jennette, 1997).
The diagnosis of ANCA is based on the pattern of fluorescence observed by indirect immunofluorescence microscopy on alcohol-fixed PMN. ANCA can be divided into a group displaying a cytoplasmic staining pattern (C-ANCA) and a second group displaying perinuclear staining (P-ANCA) (Hoffman and Specks, 1998; Wieslander, 1991). Investigations of antigen specificity have been aimed at identifying the proteins recognized by these ANCA (Lesavre, 1991). It appears that the majority of C-ANCA react with PR3, although in a few cases C-ANCA could be directed against BPI, elastase (Nassberger et al, 1989), or cathepsin G (Halbwachs-Mecarelli et al, 1992). Despite difficulties in classifying vasculitic syndromes, the correlation between clinical expression of Wegener's granulomatosis and ANCA reactivity has now established that PR3 is the target autoantigen (Ewert et al, 1991; Jenne et al, 1990). Wegener's granulomatosis is a multisystem disease characterized by granuloma of the respiratory tract and systemic necrotizing vasculitis (Hagen et al, 1993) (Fig. 4B). The major target antigen of P-ANCA is myeloperoxidase (Falk and Jennette, 1988). Anti-MPO was originally described in patients with microscopic polyangiitis and idiopathic necrotizing crescentic glomerulonephritis, which can be considered as a renal limited form of systemic vasculitis. Also presenting anti-MPO is the Churg-Strauss syndrome, which has a history of asthma and hypereosinophilia in conjunction with small vessel vasculitis (Falk and Jennette, 1997; Kallenberg and Tervaert, 1999). Whether ANCA are serologic epiphenomena or play a pathogenic role in the course of the disease is still a matter of debate (Salant, 1999). The correlation of ANCA titers with disease activity suggests that ANCA may be directly involved in the clinical course of the disease.

Many studies have focused on in vitro ANCAinduced activation of neutrophils and consequent damage to endothelial cells. Binding of ANCA to their target results in activation of an oxidative burst (Falk et al, 1990; Keogan et al, 1992), degranulation, and cytokine secretion in neutrophils and in monocytes (Ralston et al, 1997). The binding of ANCA involves the engagement of Fc $\gamma$ receptors (Kocher et al, 1998). However, hypotheses that postulate a pathogenic role for ANCA must explain how ANCA are able to interact in vivo with target antigens that are sequestered within the cytoplasm of neutrophils. Several mechanisms leading to translocation of intracellular antigens have been proposed, including cytokine priming (Csernok et al, 1994) and apoptosis of neutrophils (Gilligan et al, 1996). Interestingly, PR3 is expressed at the plasma membrane of stimulated neutrophils (Muller Kobold et al, 1998), but also in a constant subset of unstimulated neutrophils. A large subset of neutrophils expressing membrane PR3 is a risk factor for vasculitis (WitkoSarsat et al, 1999c).

Despite several studies using synthetic peptides or recombinant proteins aiming at mapping ANCA epitopes, no precise information is available. Anti-PR3 recognize conformational epitopes (Bini et al, 1992). Of note, both anti-MPO (Short et al, 1995) and anti- 
PR3 (Sun et al, 1998) seem to recognize a pro-form that is not completely processed. The relevance of such findings in the pathophysiological mechanisms of vasculitis are still unknown. Moreover, the question of whether ANCA can be a direct target for treatment has still to be elucidated (Kallenberg and Tervaert, 1999).

\section{II.H. Genetic Disorders of Neutrophil Regulations: Hereditary Periodic Fever Syndromes}

The hereditary periodic fever syndromes are a group of disorders characterized by self-limited episodes of fever accompanied by localized inflammation. Of these syndromes, Familial Mediterranean Fever (FMF) has been the longest recognized (Sohar et al, 1967). It is an autosomal recessive disease occurring primarily among populations originating in the Mediterranean basin (Arabs, Armenians, Turks, and Sephardic Jews). The inflammatory episodes of FMF affect mainly the serosal or synovial membranes. They are characterized by massive influx of neutrophils into the affected tissues. These recurrent and reversible attacks are brief (1 to 3 days). Secondary amyloidosis, a consequence of long-standing inflammation, is the most severe complication of the disease. The acute attacks and the development of amyloidosis can be prevented by daily oral colchicine (Zemer et al, 1986). The FMF gene has recently been identified by positional cloning (Anonymous, 1997a, 1997b). It encodes a transcript expressed predominantly in neutrophils. The predicted product is a 781 amino acid protein (called pyrin or marenostrin) with homology to several transcription factors. Restriction of marenostrin/pyrin message expression to neutrophils has confirmed that FMF is a genetic disorder of these cells. The function of this protein is still unknown, and the pathogenic basis of the inflammatory attack is not yet understood. It is tempting to suggest that marenostrin/pyrin is an inhibitory regulator of the inflammatory response, controlling for example a chemotaxin-inactivating enzyme (Babior, 1998; Matzner et al, 1984). Another point that is not yet settled is why FMF attacks involve serosal and synovial membranes. One may argue that serosal and synovial surfaces suffer minor injuries that are too mild to cause symptoms but are serious enough to locally activate neutrophils. Physical traumas seems to initiate inflammatory episodes, because many patients report the appearance of a short synovial attack involving the lower extremities after prolonged standing or walking. However, other tissues such as mucous membranes that are more exposed to trivial injury are not affected by the inflammatory episodes of FMF, showing that the regulatory dysfunction of neutrophils from these patients is not implicated in all pathways leading to neutrophil stimulation.

Familial Hibernian Fever (FHF), also termed dominant periodic fever, familial periodic fever, or TRAPS (TNF receptor-associated periodic syndromes), is an autosomal dominant disease occurring primarily among the populations originating in Northern Europe
Table 3. Clinical Conditions Associated with Neutrophil-Induced Injury Classified According to their Main Mechanism

Bacterial infection

Acute and chronic pyelonephritis, osteomyelitis, endocarditis...

Endotoxic shock

Acute respiratory distress syndrome

Tissue injury/Ischemia-reperfusion injury

Transplantation

Myocardial ischemia and necrosis

Resuscitation following systemic hypotension

Prerenal acute renal failure

Crystal deposition

Gout

Articular chondrocalcinosis

Silicosis

Soft tissue calcium deposits in patients with chronic renal failure

Complement

Classical pathway; Immune complex-induced inflammation

Mannose-binding lectin pathway: Poststreptococcal glomerulonephritis

Bacterial infection-induced inflammation

Alternative pathway:

Hemodialysis

Bacterial infection-induced inflammation

Tissue injury-induced inflammation

Crystal deposition-induced inflammation

Immune complex

Henoch-Schönlein purpura

Essential cryoglobulinemic vasculitis

Lupus

Goodpasture's syndrome

Serum-sickness vasculitis

Drug or infection-induced immune complex vasculitis

Cytokines

Rheumatoid arthritis

Inflammatory bowel diseases

ANCA (anti-neutrophil cytoplasmic antibody)

Wegener's granulomatosis

Microscopic polyangiitis

Pauci-immune necrotizing crescentic glomerulonephritis

Genetic disorders of neutrophil regulations

Familial Mediterranean fever

Familial Hibernian fever

(McDermott et al, 1997). The clinical picture of FHF is recurrent attacks of fever with abdominal pain and severe localized myalgia. Presence of erythematous skin lesions, conjunctivitis, unilateral periorbital edema, and scrotal pain are noted with high frequency. Pleuretic and nonpleuretic chest pain may occur. True arthritis is rare but oligoathralgia is a frequent symptom. Lymphadenopathy is common. Attacks tend to last longer (2 to 3 weeks) than the inflammatory episodes of FMF. Patients tend to respond to corticosteroids rather than colchicine. Amy- 
loidosis has also been documented but with a widely divergent incidence among families. Mutations that cause this disease are point substitutions within cystein-rich motifs of the extracellular domains of the $55 \mathrm{kDa}$ TNF receptor (TNFR1, p55, or CD120a) (McDermott et al, 1999). These mutations impair metalloprotease-mediated shedding of membrane TNFR1. Cleavage of TNF receptors from the membrane of activated monocytes and neutrophils is thought to attenuate the inflammatory response by desensitization of phagocytes to further "juxtacrine" TNF stimulation and by producing a pool of soluble receptors that competes with membrane-bound receptors and inhibits TNF systemic effects. It is therefore likely that impaired post-stimulatory TNFR1 clearance and subsequent reduced levels of shed soluble receptors are responsible for prolonged systemic inflammatory episodes triggered by mild injury in FHF.

\section{II.I. Cystic Fibrosis: The Paradox of Exacerbation of Neutrophil-Mediated Tissue Damage and Concomitant Persistence of Infection}

Cystic fibrosis is a hereditary disorder caused by mutations of the cystic fibrosis transmembrane conductance regulator (CFTR), the product of which is a membrane protein thought to function as a chloride channel (Stern, 1997). The lethal clinical manifestations are clearly related to the thick, infected mucous and chronic neutrophil-dominated airway inflammation (Jennings and Crystal, 1992; Mclntosh and Cutting, 1992; Welsh and Fick, 1987). It has been suggested that CFTR itself may be a major receptor for binding and internalization of Pseudomonas aeruginosa and that CFTR-mediated ingestion of Pseudomonas aeruginosa is critical for early and effective clearance from the lung (Pier et al, 1997). This pathogen can never be permanently eradicated despite intensive antibiotic treatment and leads invariably to respiratory failure, which is the cause of death in most patients with cystic fibrosis. Although the genetic basis of cystic fibrosis, as well as the molecular structure of CFTR, have been extensively studied, a clear relationship between the genetic defect and the pulmonary pathophysiology, especially chronic infections and neutrophil-dominated airway inflammation, has not been established. A current hypothesis stresses the possibility of impairment in the innate immune system (Bals et al, 1999).

Neutrophils are considered responsible for the early onset and the promotion of the inflammatory process in CF, which starts within the first year of a CF patient's life (Khan et al, 1995). Several studies investigating the complex relationships between infection and inflammation in CF support the concept that the host inflammatory response is not necessarily proportional to the burden of pathogens in the respiratory tract, although these pathogens may provide the primary stimulus for such responses (Regelmann et al, 1995). Numerous neutrophils are present in the airways (Fig. 4D) and high concentrations of neutrophil- derived mediators have been found, eg, long-lived oxidants (Witko-Sarsat et al, 1995); inflammatory cytokines, such as IL-8 (Richman-Eisenstat et al, 1993), which correlates with disease activity, and TNF- $\alpha$ (Bonfield et al, 1995); metalloproteases such as gelatinase; serine proteases including elastase, cathepsin G (Goldstein and Döring, 1986; Suter et al, 1984), and recently, proteinase 3 (Witko-Sarsat et al, 1999b) with a clear imbalance between proteinases and antiproteinases (Birrer et al, 1994); and antibiotic peptides, defensins. It has been shown that the antibiotic activity of beta-defensins (hBD-1 and hBD-2) might be decreased in the CF lung because of the modification in the ionic concentrations of the bronchial secretions (Bals et al, 1998; Goldman et al, 1997).

With regard to neutrophil functions, myeloperoxidasedependent oxygenation activities appear to be significantly higher not only in CF homozygotes, but also in heterozygote parents of CF patients (Prince, 1998), providing some evidence for a genetic component in the altered neutrophil function in CF (Witko-Sarsat et al, 1996). Likewise, it has been described as a decrease in the shedding of L-selectin in stimulated CF neutrophils, which was not observed in either stable or acutely infected non-CF bronchiectasis patients, thus suggesting a disturbed control of the migration process in CF neutrophils (Russell et al, 1998).

As CF involves chronic active inflammation and recurrent infections ultimately resulting in inflammation, clinical management of CF presents a paradox combining antibiotherapy and antiinflammatory drugs such as the non-steroidal antiinflammatory agent ibuprofen (Konstan et al, 1995). Antiproteinase therapy has also been proposed and aerosolization of $\alpha 1$ antitrypsin or secretory leukoproteinase inhibitor (SLPI) has proven to exert a beneficial effect on pulmonary function (McElvaney et al, 1991, 1992). New antiinflammatory therapeutic approaches in CF rely on better knowledge of the link between the CFTR mutation and the mechanisms of the neutrophildominated airway inflammation function that constitutes a very recent and exciting area of research. For instance, CFTR belongs to the family of ATP-binding cassette $(A B C)$ proteins. The idea is that other $A B C$ proteins-Multi-Drug Resistance (MDR) protein or the Multidrug Resistance-associated Protein (MRP)might complement CFTR (Lallemand et al, 1997). Interestingly, colchicine, which is both an ABC protein inducer and an antiinflammatory agent with direct effects on neutrophils, has thus been proposed as a good antiinflammatory drug candidate (SermetGaudelus et al, 1999).

\section{Conclusion}

Until approximately two decades ago, neutrophils were viewed as short-lived cells having a destructive hardware but no software. This notion has changed since it became clear that neutrophils were able to integrate complex arrays of adhesion-, chemoattractant-, and cytokine-driven signals and were able to synthesize cytokine in response to inflammatory stimuli. 
The neutrophil itself appears to be well equipped with an unusual combination of contrasting molecules: ROS, small, ubiquitous and short-lived molecules, and proteases, macromolecules with specific long-lasting activity. The neutrophil safely keeps them apart through separate intracellular compartmentalization under basal conditions. These mediator activities regulate pathophysiological processes not exclusively aimed at the destruction of invading microorganisms. Finally, neutrophils are activated by a great variety of stimuli and are involved in diseases that may be classified, as shown in Table 3, according to the major neutrophil-activating event.

\section{Acknowledgements}

We are grateful to Eric Blouin for reviewing the manuscript and to Marie Netter for the figure drawing.

\section{References}

Adams DH, and Shaw S (1994). Leucocyte-endothelial interaction and regulation of leukocyte migration. Lancet 343 : 831-836.

Aderka D, Engelmann H, Shemer-Avni Y, Hornik V, Galil A, Sarov B, and Wallach D (1992). Variation in serum levels of the soluble TNF receptors among healthy individuals. Lymphokine Cytokine Res 11:157-159.

Akasaki T, Koga H, and Sumimoto H (1999). Phosphoinositide 3-kinase-dependent and -independent activation of the small GTPase Rac2 in human neutrophils. J Biol Chem 274:18055-18059.

Albina JE (1995). On the expression of nitric oxide synthase by human macrophages. Why no NO? J Leukocyte Biol 58:643-649.

Allen RC, Stjernholm RL, and Steele RH (1972). Evidence for the generation of an electronic excitation state(s) in human polymorphonuclear leukocytes and its participation in bactericidal activity. Biochem Biophys Res Commun 47:679-684.

Almeida RP, Melchior M, Campanelli D, Nathan C, and Gabay JE (1991). Complementary DNA sequence of human neutrophil azurocidin, an antibiotic with extensive homology to serine proteases. Biochem Biophys Res Commun 177: 688-695.

Alon R, Fuhlbrigge RC, Finger EB, and Springer TA (1996). Interactions through L-selectin between leukocytes and adherent leukocytes nucleate rolling adhesions on selectins and VCAM-1 in shear flow. J Cell Biol 135:849-865.

Anderson DC, Schmalstieg FC, Arnaout MA, Kohl S, Tosi MF, Dana N, Buffone GJ, Hughes BJ, Brinkley BR, Dickey WD, Abramson JS, Springer T, Boxer LA, Hollers JM, Wayne, and Smith C (1984). Abnormalities of polymorphonuclear leukocyte function associated with a heritable deficiency of high molecular weight surface glycoproteins (GP138): Common relationship to diminished cell adherence. $\mathrm{J}$ Clin Invest 74 : $536-551$.

Anonymous (1997a). A candidate gene for familial Mediterranean fever. The French FMF Consortium. Nature Gen 17:25-31.

Anonymous (1997b). Ancient missense mutations in a new member of the RoRet gene family are likely to cause familial
Mediterranean fever. The International FMF Consortium. Cell 90:797-807.

Arend WP, and Dayer JM (1995). Inhibition of the production and effects of interleukin-1 and tumor necrosis factor alpha in rheumatoid arthritis. Arthritis Rheum 38:151-160.

Arnaout MA, Hakim RM, Todd RF, Dana N, and Colten HR (1985). Increased expression of an adhesion-promoting surface glycoprotein in the granulocytopenia of hemodialysis. N Engl J Med 312:457-462.

Ayesh SK, Azar Y, Barghouti II, Ruedi JM, Babior BM, and Matzner $Y$ (1995). Purification and characterization of a C5a-inactivating enzyme from human peritoneal fluid. Blood. 85:3503-9

Babior BM (1984). The respiratory burst of phagocytes. J Clin Invest 73:599-601.

Babior BM (1998). Familial Mediterranean fever and the control of inflammation. Curr Op Hematol 5:1-2.

Babior BM (1999). NADPH oxidase: An update. Blood 93: 1464-1476.

Bagge U, Amundson B, and Lauritzen C (1980). White blood cell deformability and plugging of skeletal muscle capillaries in hemorrhagic shock. Acta Physiol Scand 108:159-163.

Baggiolini M, and Clark-Lewis I (1992). Interleukin-8, a chemotactic and inflammatory cytokine. FEBS Lett 307:97-101.

Baggiolini M, Dewald B, and Moser B (1994). Interleukin-8 and related chemotactic cytokines-CXC and CC chemokines. Advances Immunol 55:97-179.

Bals R, Wang X, Wu Z, Freeman T, Bafna V, Zasloff M, and Wilson JM (1998). Human beta-defensin-2 is a salt-sensitive peptide antibiotic expressed in human lung. J Clin Invest 102:874-880.

Bals R, Weiner DJ, and Wilson JM (1999). The innate immune system in cystic fibrosis lung disease. J Clin Invest 103:303307.

Bangalore N, Travis J, Onunka VC, Pohl J, and Shafer WM (1990). Identification of the primary antimicrobial domains in human neutrophil cathepsin G. J Biol Chem 265:1358413588.

Bargatze RF, Kurk S, Butcher EC, and Jutila MA (1994). Neutrophils roll on adherent neutrophils bound to cytokineinduced endothelial cells via L-selectin on the rolling cells. $J$ Exp Med 180:1785-1792.

Beckman JS, and Koppenol WH (1996). Nitric oxide, superoxide, and peroxynitrite: The good, the bad, and ugly. Am J Physiol 271:C1424-C1437.

Belaaouaj A, McCarthy R, Baumann M, Gao Z, Ley TJ, Abraham SN, and Shapiro SD (1998). Mice lacking neutrophil elastase reveal impaired host defense against gram negative bacterial sepsis. Nature Med 4:615-618.

Benard V, Bohl BP, and Bokoch GM (1999). Characterization of rac and cdc42 activation in chemoattractant-stimulated human neutrophils using a novel assay for active GTPases. J Biol Chem 274:13198-13204.

Berger SP, Seelen MAJ, Hiemstra PS, Gerritsma JSJ, Heemskerk E, Van Der Woude FJ, and Daha MR (1996). Proteinase 3 , the major autoantigen of Wegener's granulomatosis, enhances IL-8 production by endothelial cells in vitro. J Am Soc Nephrol 7:694-701. 
Berman ME, and Muller WA (1995). Ligation of platelet/ endothelial cel adhesion molecule 1 (PECAM-1/CD31) on monocytes and neutrophils increases binding capacity of leukocyte CR3 (CD11b/CD18). J Immunol 154:299-307.

Berton G (1999a). Tyrosine kinases in neutrophils. Curr Opin Hematol 6:51-58.

Berton G (1999b) Degranulation, 3rd ed. In: Gallin Jl and Snyderman R (editors). Inflammation: Basic principles and clinical correlates. Philadelphia: Lippincott Williams and Wilkins, 703.

Bille J, and Glauser MP (1982). Protection against chronic pyelonephritis in rats by suppression of acute suppuration: Effect of colchicine and neutropenia. J Infect Dis 146:220226.

Bini P, Gabay JE, Teitel A, Melchior M, Zhou JL, and Elkon KB (1992). Antineutrophil cytoplasmic autoantibodies in Wegener's granulomatosis recognize conformational epitope(s) on proteinase 3. J Immunol 149:1409-1415.

Birrer P, McElvaney NG, Rudeberg A, Sommer CW, LiechtiGallati S, Kraemer R, Hubbard R, and Crystal RG (1994). Protease-antiprotease imbalance in the lungs of children with cystic fibrosis. Am J Respir Crit Care Med 150:207-213.

Bjorgvinsdottir H, Ding C, Pech N, Gifford MA, Li LL, and Dinauer MC (1997). Retroviral-mediated gene transfer of gp91phox into bone marrow cells rescues defect in host defense against Aspergillus fumigatus in murine $\mathrm{X}$-linked chronic granulomatous disease. Blood 89:41-48.

Blouin E, Halbwachs-Mecarelli L, and Rieu P (1999). Redox regulation of b2-integrin $\mathrm{CD} 11 \mathrm{~b} / \mathrm{CD} 18$ activation. Eur $\mathrm{J} \mathrm{Im}$ munol 29:3419-3431.

Bohnsack JF, Chang J, Zhou X, and Yednock TA (1995). Mechanisms of beta 1 integrin-dependent adherence of granulocytic HL60 to fibronectin. J Leukocyte Biol 57:592599.

Bokoch GM (1995). Chemoattractant signaling and leukocyte activation. Blood 86:1649-1660.

Bonfield TL, Panuska JR, Konstan MW, Hilliard KA, Hilliard JB, Ghnaim H, and Berger M (1995). Inflammatory cytokines in cystic fibrosis lungs. Am J Respir Crit Care Med 152:21112118.

Borges E, Eytner R, Moll T, Steegmaier M, Campbell MA, Ley K, Mossmann H, and Vestweber D (1997). The P-selectin glycoprotein ligand-1 is important for recruitment of neutrophils into inflamed mouseperitoneum. Blood 90:1934-1942.

Bories D, Raynal MC, Solomon DH, Darzynkiewicz Z, and Cayre YE (1989). Down-regulation of a serine protease, myeloblastin, causes growth arrest and differentiation of promyelocytic leukemia cells. Cell 59:959-968.

Borregaard N, and Cowland JB (1997). Granules of the human neutrophilic polymorphonuclear leukocyte. Blood 89: 3503-3521.

Brandes ME, Allen JB, Ogawa Y, and Wahl SM (1991). Transforming growth factor beta 1 suppresses acute and chronic arthritis in experimental animals. J Clin Invest 87: 1108-1113.

Brenner B, Gulbins E, Schlottmann K, Koppenhoefer U, Busch GL, Walzog B, Steinhausen M, Coggeshall KM, Linderkamp O, and Lang $F$ (1996). L-selectin activates the Ras pathway via the tyrosine kinase p56lck. Proc Natl Acad Sci USA 93:15376-15381.
Britigan BE, Rosen GM, Chai Y, and Cohen MS (1986). Do human neutrophils make hydroxyl radical? Determination of free radicals generated by human neutrophils activated with a soluble or particulate stimulus using electron paramagnetic resonance spectrometry. J Biol Chem 261:4426-4431.

Brockhaus M, Schoenfeld HJ, Schlaeger EJ, Hunziker W, Lesslauer W, and Loetscher H (1990). Identification of two types of tumor necrosis factor receptors on human cell lines by monoclonal antibodies. Proc Natl Acad Sci USA 87:31273131.

Brown EJ (1986). The role of extracellular matrix proteins in the control of phagocytosis. J Leukoc Biol 39:579-591.

Brown SB, and Savill J (1999). Phagocytosis triggers macrophage release of Fas ligand and induces apoptosis of bystander leukocytes. J Immunol 162:480-485.

Bullard DC, Kunkel EJ, Kubo H, Hicks MJ, Lorenzo I, Doyle NA, Doerschuk CM, Ley K, and Beaudet AL (1996). Infectious susceptibility and severe deficiency of leukocyte rolling and recruitment in E-selectin and $\mathrm{P}$-selectin double mutant mice. J Exp Med 183:2329-2336.

Burns AR, Bowden RA, Abe Y, Walker DC, Simon SI, Entman $\mathrm{ML}$, and Smith CW (1999). P-selectin mediates neutrophil adhesion to endothelial cell borders. J Leukoc Biol 65:299306.

Campanelli D, Detmers PA, Nathan CF, and Gabay JE (1990a). Azurocidin and a homologous serine protease from neutrophils. Differential antimicrobial and proteolytic properties. J Clin Invest 85:904-915.

Campanelli D, Melchior M, Fu Y, Nakata M, Shuman H, Nathan C, and Gabay JE (1990b). Cloning of cDNA for proteinase 3: A serine protease, antibiotic, and autoantigen from human neutrophils. J Exp Med 172:1709-1715.

Campbell EJ, and Campbell MA (1988). Pericellular proteolysisby neutrophilsin the presence of proteinase inhibitors: Effects of substrate opsonization. J Cell Biol 106:667-676.

Campbell EJ, Campbell MA, Boukedes SS, and Owen CA (1999). Quantum proteolysis by neutrophils: Implications for pulmonary emphysema in alpha1-antitrypsin deficiency. $\mathrm{J}$ Clin Invest 104:337-344.

Cao Y, Stafforini DM, Zimmerman GA, Mclntyre TM, and Prescott SM (1998). Expression of plasma platelet-activating factor acetylhydrolase is transcriptionally regulated by mediators of inflammation. J Biol Chem 273:4012-4020.

Capodici C, Hanft S, Feoktistov M, and Pillinger MH (1998). Phosphatidylinositol 3-kinase mediates chemoattractantstimulated, CD11b/CD18-dependent cell-cell adhesion of human neutrophils: Evidence for an ERK-independent pathway. J Immunol 160:1901-1909.

Caron E, and Hall A (1998). Identification of two distinct mechanisms of phagocytosis controlled by different Rho GTPases. Science 282:1717-1721.

Cassatella MA (1995). The production of cytokines by polymorphonuclear neutrophils. Immunol Today 16:21-26.

Cassatella MA (1999). Neutrophil-derived proteins: Selling cytokines by the pound. Adv Immunol 73:369-509.

Cassatella MA, Meda L, Bonora S, Ceska M, and Constantin G (1993). Interleukin 10 (IL-10) inhibits the release of proinflammatory cytokines from human polymorphonuclear leukocytes. Evidence for an autocrine role of tumor necrosis factor 
and IL-1beta in mediating the production of IL- 8 triggered by lipopolysaccharide. J Exp Med 178:2207-2211.

Cassatella MA, Meda L, Gasperini S, Calzetti F, and Bonora S (1994). Interleukin 10 (IL-10) upregulates IL-1 receptor antagonist production from lipopolysaccharide-stimulated human polymorphonuclear leukocytes by delaying mRNA degradation. J Exp Med 179:1695-1699.

Cassatella MA, Meda L, Gasperini S, D'Andrea A, Ma X, and Trinchieri G (1995). Interleukin-12 production by human polymorphonuclear leukocytes. Eur J Immunol 25:1-5.

Cawston TE, Galloway WA, Mercer E, Murphy G, and Reynolds JJ (1981). Purification of rabbit bone inhibitor of collagenase. Biochem J 195:159-165.

Céballos-Picot I, Witko-Sarsat V, Mérad-Boudia M, Nguyen AT, Thévenin $M$, Jaudon $M C$, Zingraff $J$, Jungers $P$, and Descamps-Latscha B (1996). Glutathione antioxidant system as a marker of uremia progression and oxidative stress in chronic renal failure. Free Rad Biol Med 21:845-863.

Chadwick VS, Mellor DM, Myers DB, Selden AC, Keshavarzian A, Broom MF, and Hobson CH (1988). Production of peptides inducing chemotaxis and lysosomal enzyme release in human neutrophils by intestinal bacteria in vivo and in vitro. Scand J Gastroenter 23:121-128.

Chatham WW, Swaim R, Frohsin HJR, Heck LW, Miller EJ, and Blackburn WD Jr (1993). Degradation of human articular cartilage by neutrophils in synovial fluid. Arth Rheum 36:5158.

Cheung AK (1990). Biocompatibility of hemodialysis membranes. J Am Soc Nephrol 1:150-161.

Cho Y, Turner JS, Dinh NN, and Lehrer RI (1998). Activity of protegrins against yeast-phase Candida albicans. Infect Immun 66:2486-2493.

Chuang FYS Sassaroli M and Unkeless JC (2000). Convergence of Fc gamma receptor IIA and Fc gamma receptor IIIB signaling pathways in human neutrophils. J Immunol 164: 350-360.

Cieutat AM, Lobel P, August JT, Kjeldsen L, Sengelov H, Borregaard N, Bainton DF (1998). Azurophilic granules of human neutrophilic leukocytes are deficient in lysosomeassociated membrane protein but retain the mannose6phosphate recognition marker. Blood 91:1044-1058.

Clancy RM, Leszczynska-Piziak J, and Abramson SB (1993). Nitric oxide stimulates the ADP-ribosylation of actin in human neutrophils. Biochem Biophys Res Commun 191:847-852.

Clark RA (1999). Activation of the neutrophil respiratory burst oxidase. Infect Dis 179:S309-S317.

Cowland JB, Johnsen AH, and Borregaard N (1995). hCAP18 , a cathelin/pro-bactenecin-like protein of human neutrophil specific granules. FEBS Lett 368:173-176.

Cox G (1996). (IL-10) enhances resolution of pulmonary inflammation in vivo by promoting apoptosis of neutrophils. American Journal of Physiology 271:L566-L571.

Cox D, Chang P, Zhang Q, Reddy PG, Bokoch GM, and Greenberg S (1997). Requirements for both Rac1 and Cdc42 in membrane ruffling and phagocytosis in leukocytes. J Exp Med 186:1487-1494.

Cox G, Crossley J, and Xing Z (1995). Macrophage engulfment of apoptotic neutrophils contributes to the resolution of acute pulmonary inflammation in vivo. Am $\mathrm{J}$ Resp Cell Mol Biol 12:232-237.
Craddock PR, Fehr J, Dalmasso AP, Brighan KL, and Jacob HS (1977). Hemodialysis leukopenia. Pulmonary vascular leukostasis resulting from complement activation by dialyzer cellophane membranes. J Clin Invest 59:879-888.

Crowley MT, Costello PS, Fitzer-Attas CJ, Turner M, Meng F, Lowell C, Tybulewicz VLJ, and Defranco AL (1997). A critical role for Syk in signal transduction and phagocytosis mediated by Fcg receptors on macrophages. J Exp Med 186: 1027-1039.

Crystal RG, Brantly ML, Hubbard RC, Curiel DT, States DJ, and Holmes MD (1989). The alpha 1-antitrypsin gene and its mutations. Clinical consequences and strategies for therapy. Chest 95:196-208.

Csernok E, Ernst M, Schmitt W, Bainton DF, and Gross WL (1994). Activated neutrophils express proteinase 3 on their plasma membrane in vitro and in vivo. Clin Exp Immunol 95:244-250.

Csernok E, Muller A, and Gross WL (1999). Immunopathology of ANCA-associated vasculitis. Int Med 38:759-765.

Daher KA, Lehrer RI, Ganz T, and Kronenberg M (1988). Isolation and characterization of human defensin cDNA clones. Proc Natl Acad Sci U S A 85:7327-7331.

Dana N, Todd RF 3d, Pitt J, Springer TA, and Arnaout MA (1984). Deficiency of a surface membrane glycoprotein (Mo1) in man. J Clin Invest 73:153-159.

Dayer JM, and Fenner H (1992). The role of cytokines and their inhibitors in arthritis. Baillieres Clin Rheumatol 6:485516 .

De Greef KE, Ysebaert DK, Ghielli M, Vercauteren S, Nouwen EJ, Eyskens EJ, and de Broe ME (1998). Neutrophils and acute ischemia-reperfusion injury. J Nephrol 11:110-122.

Declerck YA, Yean TD, Chan D, Shimada H, and Langley KE (1991). Inhibition of tumor invasion of smooth muscle cell layers by recombinant human metalloproteinase inhibitor. Cancer Res 51:2151-2157.

Deforge LE, Fantone JC, Kenney JS, and Remick DG (1992). Oxygen radical scavengers selectively inhibit interleukin 8 production in human whole blood. J Clin Invest 90:21232129

Dejana E, Bazzoni G, Martin-Padura I, and Del Maschio A (1999). Endothelial cell-to-cell junctions and the control of vascular permeability and leukocyte infiltration. Mediat Inflam 8:S3.

Deleo FR, and Quinn MT (1996). Assembly of the NADPHoxidase: Molecular interactions of oxidase proteins. J Leukocyte Biol 60:677-685.

Del Maschio A, Zanetti A, Corada M, Rival Y, Ruco L, Lampugnani MG, and Dejana E (1996). Polymorphonuclear leukocyte adhesion triggers the disorganization of endothelial cell-to-cell adherens junctions. J Cell Biol 135:497-510.

Descamps-Latscha B (1993). The immune system in endstage renal disease. Curr OpinNephrol Hypert 2:883-891.

Descamps-Latscha B, Goldfarb B, Nguyen AT, Landais P, London G, Haeffner-Cavaillon N, Jacquot C, Herbelin A, and Kazatchkine M (1991). Establishing the relationship between complement activation and stimulation of phagocyte oxidative metabolism in hemodialyzed patients: A randomized prospective study. Nephron 59:279-285.

Descamps-Latscha B, Herbelin A, Nguyen AT, RouxLombard P, Zingraff J, Moynot A, Verger C, Dahmane D, de 
Groote D, Jungers P, and Dayer JM (1995). Balance between IL-1 beta, TNF-alpha, and their specific inhibitors in chronic renal failure and maintenance dialysis. Relationships with activation markers of T-cells, B-cells, and monocytes. $\mathrm{J} \mathrm{Im}$ munol 154:882-892.

Diamond P, McGinty A, Sugrue D, Brady HR, and Godson C (1999). Regulation of leukocyte trafficking by lipoxins. Clin Chem Lab Med 37:293-297.

Dibbert B, Weber M, Nikolaizik WH, Vogt P, Schoni MH, Blaser K, and Simon HU (1999). Cytokine-mediated Bax deficiency and consequent delayed neutrophil apoptosis: $A$ general mechanism to accumulate effector cells in inflammation. Proc Natl Acad Sci U S A 96:13330-13335.

Dinauer MC, Li LL, Bjorgvinsdottir H, Ding CJ, and Pech N (1999). Long-term correction of phagocyte NADPH oxidase activity by retroviral-mediated gene transfer in murine X-linked chronic granulomatous disease. Blood 94:914-922.

Djeu JY, Serbousek D, and Blanchard DK (1990). Release of tumor necrosis factor by human polymorphonuclear leukocytes. Blood 76:1405-1409.

Doerschuk CM (1992). The role of CD18-mediated adhesion in neutrophil sequestration induced by infusion of activated plasma in rabbits. Am J Resp Cell Mol Biol 7:140-148.

Downey GP, Doherty DE, Schwab B, Elson EL, Henson PM, and Worthen GS (1990). Retention of leucocytes in capillaries: Role of cell size and deformability. J Appl Physiol 69:1767-1778.

Doyle NA, Bhagwan SD, Meek BB, Kutkoski GJ, Steeber DA, Tedder TF, and Doerschuk CM (1997). Neutrophil margination, sequestration, and emigration in the lungs of L-selectin-deficient mice. J Clin Invest 99:526-533.

Eckmann L, Kagnoff MF, and Fierer J (1993). Epithelial cells secrete the chemokine interleukin-8 in response to bacterial entry. Infect Immun 61:4569-4574.

Edwards SW, and Hallett MB (1997). Seeing the wood for the trees: The forgotten role of neutrophils in rheumatoid arthritis. Immunol Today 18:320-324.

Egesten A, Breton-Gorius J, Guichard J, Gullberg U, and Olsson I (1994). The heterogeneity of azurophil granules in neutrophil promyelocytes: Immunogold localization of myeloperoxidase, cathepsin G, elastase, proteinase 3, and bactericidal/permeability increasing protein. Blood 83:2985-2994.

Ehlenberger AG, and Nussenzweig V (1977). The role of membrane receptors for C3b and C3d in phagocytosis. J Exp Med 145:357-371.

Elliott MJ, Maini RN, Feldmann M, Kalden JR, Antoni C, Smolen JS, Leeb B, Breedveld FC, MacFarlane JD, Bijl H, and Woody JN (1994). Randomised double-blind comparison of chimeric monoclonal antibody to tumour necrosis factor alpha (cA2) versus placebo in rheumatoid arthritis. Lancet 344:1105-1110.

Elsbach $P$ (1998). The bactericidal/permeability-increasing protein (BPI) in antibacterial host defense. J Leukocyte Biol 64:14-18.

Erzurum SC, Downey GP, Doherty DE, Schwab B3D, Elson EL, and Worthen GS (1992). Mechanisms of lipopolysaccharideinduced neutrophil retention: Relative contributions of adhesive and cellular mechanical properties. J Immunol 149:154-162.
Ewert BH, Jennette JC, and Falk RJ (1991). The pathogenic role of antineutrophil cytoplasmic autoantibodies. Am J Kidney Dis 18:188-195.

Fabbri M, Fumagalli L, Bossi G, Bianchi E, Bender JR, and Pardi R (1999). A tyrosin-based sorting signal in the $\beta 2$ integrin cytoplasmic domain mediates its recycling to the plasma membrane and is required for ligand-supported migration. EMBO J 18:4915-4925.

Fadok VA, Warner ML, Bratton DL, and Henson PM (1998a). CD36 is required for phagocytosis of apoptotic cells by human macrophages that use either a phosphatidylserine receptor or the vitronectin receptor (alpha $v$ beta 3 ). $\mathrm{J} \mathrm{Immu-}$ nol 161:6250-6257.

Fadok VA, Bratton DL, Konowal A, Freed PW, Westcott JY, and Henson PM. (1998b). Macrophages that have ingested apoptotic cells in vitro inhibit proinflammatory cytokine production through autocrine/paracrine mechanisms involving TGF-beta, PGE2, and PAF. J Clin Invest 101:890-898.

Falk RJ, and Jennette JC (1988). Anti-neutrophil cytoplasmic autoantibodies with specificity for myeloperoxidase in patients with systemic vasculitis and idiopathic necrotizing and crescentic glomerulonephritis. N Engl J Med 318:1651-1657.

Falk RJ, and Jennette JC (1997). ANCA small-vessel vasculitis. J Am Soc Nephrol 8:314-322.

Falk RJ, Terrell RS, Charles LA, and Jennette JC (1990). Anti-neutrophil cytoplasmic autoantibodies induce neutrophils to degranulate and produce oxygen radicals in vitro. Proc Natl Acad Sci U S A 87:4115-4119.

Fällman M, Lew DP, Stendahl O, and Andersson T (1989). Receptor-mediated phagocytosis in human neutrophils is associated with increased formation of inositol phosphates and diacylglycerol. Elevation in cytosolic free calcium and formation of inositol phosphates can be dissociated from accumulation of diacylglycerol. J Clin Invest 84:886-891.

Fauve RM (1980). Inflammation and natural immunity. In: Fougereau $\mathrm{M}$ and Dausset $\mathrm{J}$, editors. Progress in immunology IV. London: Academic Press, 737.

Fecho K, and Cohen PL (1998). Fas ligand (gld)- and Fas (Ipr)-deficient mice do not show alterations in the extravasation or apoptosis of inflammatory neutrophils. J Leukocyte Biol 64:373-383.

Fischer A, Trung PH, Descamps-Latscha B, LisowskaGrospierre B, Gerota I, Perez N, Scheinmetzler C, Durandy A, Virelizier JL, and Griscelli C (1983). Bone-marrow transplantation for inborn error of phagocytic cells associated with defective adherence, chemotaxis, and oxidative response during opsonised particle phagocytosis. Lancet 2:473-476.

Floris R, Piersma SR, Yang G, Jones P, and Wever R (1993). Interaction of myeloperoxidase with peroxynitrite. A comparison with lactoperoxidase, horseradish peroxidase and catalase Eur J Biochem 215:767-775.

Folkesson HG, Matthay MA, Hebert CA, and Broaddus VC (1995). Acid aspiration-induced lung injury in rabbits is mediated by interleukin-8-dependent mechanisms. J Clin Invest 96:107-116.

Foster CB, Lehrnbecher T, Mol F, Steinberg SM, Venzon DJ, Walsh TJ, Noack D, Rae J, Winkelstein JA, Curnutte JT, and Chanock SJ (1998). Host defense molecule polymorphisms influence the risk for immune-mediated complications in chronic granulomatous disease. J Clin Invest 102:21462155. 
Fouret P, Du Bois RM, Bernaudin JF, Takahashi H, Ferrans VJ, and Crystal RG (1989). Expression of the neutrophil elastase gene during human bone marrow cell differentiation. J Exp Med 169:833-845.

Foxman EF, Kunkel EJ, and Butcher EC (1999). Integrating conflicting chemotactic signals: The role of memory in leukocyte navigation. J Cell Biol 147:577-588.

Fuortes M, Jin WW, and Nathan C (1996). Ceramide selectively inhibits early events in the response of human neutrophils to tumor necrosis factor. J Leukoc Biol 59:451-460.

Fuortes M, Melchior M, Han H, Lyon GJ, and Nathan C (1999). Role of the tyrosine kinase pyk2 in the integrindependent activation of human neutrophils by TNF. J Clin Invest 104:327-335.

Gallin Jl, Leto TL, Rotrosen D, Kwong CH, and Malech $\mathrm{HL}$ (1991). Delineation of the phagocyte NADPH oxidase through studies of chronic granulomatous diseases of childhood. Curr Opin Immunol 4:53-56.

Gainet J, Chollet-Martin S, Brion M, Hakim J, GougerotPocidalo M, and Elbim C (1998). Interleukin-8 production by polymorphonuclear neutrophils in patients with rapidly progressive periodontitis: An amplifying loop of polymorphonuclear neutrophil activation. Lab Invest 78:755-762.

Ganz T, and Lehrer RI (1995). Defensins. Pharmacol Ther 66:191-205.

Ganz T, and Lehrer RI (1999). Antibiotic peptides from higher eukaryotes: Biology and applications. Mol Med Today 5:292297.

Gilligan HM, Bredy B, Brady HR, Hebert MJ, Slayter HS, Xu Y, Rauch J, Shia MA, Koh JS, and Levine JS (1996). Antineutrophil cytoplasmic autoantibodies interact with primary granule constituents on the surface of apoptotic neutrophils in the absence of neutrophil priming. J Exp Med 184:22312241.

Girardin E, Roux-Lombard P, Grau GE, Suter P, Gallati H, and Dayer JM (1992). Imbalance between tumour necrosis factoralpha and soluble TNF receptor concentrations in severe meningococcaemia. The J5 Study Group. Immunology 76: 20-23.

Goldman MJ, Anderson GM, Stolzenberg ED, Kari UP, Zasloff M, and Wilson JM (1997). Human beta-defensin-1 is a salt-sensitive antibioticin lung that is inactivated in cystic fibrosis. Cell 88:553-560.

Goldstein W, and Doring G (1986). Lysosomal enzymes from polymorphonuclear leukocytes and proteinase inhibitors in patients with cystic fibrosis. Am Rev Respir Dis 134:49-56.

Greenberg S, Chang P, Wang DC, Xavier R, and Seed B (1996). Clustered syk tyrosine kinase domains trigger phagocytosis. Proc Natl Acad Sci USA 93:1103-1107.

Hachicha M, Naccache PH, and McColl SR (1995). Inflammatory microcrystals differentially regulate the secretion of macrophage inflammatory protein 1 and interleukin 8 by human neutrophils: A possible mechanism of neutrophil recruitment to sites of inflammation in synovitis. J Exp Med 182:2019-2025.

Hackam DJ, Rotstein OD, Schreiber A, Zhang WJ, and Grinstein S (1997). Rho is required for the initiation of calcium signaling and phagocytosis by Fc $\gamma$ receptors in macrophages. J Exp Med 186:955-966.
Haddad P, Jenne D, Tschopp J, Clement MV, Mathieu-Mahul $D$, and Sasportes M (1991). Structure and evolutionary origin of the human granzyme $\mathrm{H}$ gene. Int Immunol 3:57-66.

Hagen EC, Ballieux BE, Van Es LA, Daha MR, and Van Der Woude FJ (1993). Antineutrophil cytoplasmic autoantibodies: A review of the antigens involved, the assays, and the clinical and possible pathogenetic consequences. Blood 81:19962002.

Hakim RM, Breillatt J, Lazarus JM, and Port FK (1984). Complement activation and hypersensitivity reactions to dialysis membranes. N Engl J Med 311:878-882.

Hakim RM, Wingard RL, and Parker RA (1994). Effect of the dialysis membrane in the treatment of patients with acute renal failure. N Engl J Med 331:1338-1342.

Halbwachs-Mecarelli L, Nusbaum P, Noel LH, Reumaux D, Erlinger S, Grunfeld JP, and Lesavre P (1992). Antineutrophil cytoplasmic antibodies (ANCA) directed against cathepsin G in ulcerative colitis, Crohn's disease and primary sclerosing cholangitis. Clin Exp Immunol 90:79-84.

Hanson RD, Hohn PA, Popescu NC, and Ley TJ (1990). A cluster of hematopoietic serine protease genes is found on the same chromosomal band as the human alpha/delta T-cell receptor locus. Proc Natl Acad Sci U S A 87:960-963.

Harrison JE, Watson BD, and Schultz J (1978). Myeloperoxidase and singlet oxygen: A reappraisal. FEBS Lett 92:327331.

Harwig SS, Tan L, Qu XD, Cho Y, Eisenhauer PB, and Lehrer $\mathrm{RI}$ (1995). Bactericidal properties of murine intestinal phospholipase A2. J Clin Invest 95:603-610.

Haug CE, Colvin RB, Delmonico FL, Auchincloss H JR, Tolkoff-Rubin N, Preffer FI, Rothlein R, Norris S, Scharschmidt L, Cosimi AB (1993). A phase I trial of immunosuppression with anti-ICAM-1 (CD54) mAb in renal allograft recipients. Transplantation 55:766-772.

Hazen SL, D'Avignon A, Anderson MM, Hsu FF, and Heinecke JW (1998). Human neutrophils employ the myeloperoxidase-hydrogen peroxide-chloride system to oxidize alpha-amino acids to a family of reactive aldehydes. Mechanistic studies identifying labile intermediates along the reaction pathway. J Biol Chem 273:4997-5005.

Heeringa P, Van Den Born J, Brouwer E, Dolman KM, Klok PA, Huitema MG, Limburg PC, Bakker MA, Berden JH, Daha MR, and Kallenberg CG (1996). Elastase, but not proteinase 3 (PR3), induces proteinuria associated with loss of glomerular basement membrane heparan sulphate after in vivo renal perfusion in rats. Clin Exp Immunol 105:321-329.

Heinecke JW (1999). Is lipid peroxidation relevant to atherogenesis? J Clin Invest 104:135-136.

Hendey B, Lawson M, Marcantonio EE, and Maxfield FR (1996). Intracellular calcium and calcineurin regulate neutrophil motility on vitronectin through a receptor identified by antibodies to av and b3. Blood 87:2038-2048.

Hoffman GS, and Specks U (1998). Antineutrophil cytoplasmic antibodies. Arthritis Rheum 41:1521-1537.

Hofman P, D'Andrea L, Carnes D, Colgan SP, and Madara JL (1996). Intestinal epithelial cytoskeleton selectively constrains lumen-to-tissue migration of neutrophils. American Journal of Physiology 271:C312-C320.

Hofman P, Selva E, Le Negrate G, d'Andrea L, Guerin S, Rossi B, and Auberger P (1998). CD10 inhibitors increase 
f-Met-Leu-Phe-induced neutrophil transmigration. J Leukocyte Biol 63:312-320.

Hogg JC, and Doerschuk CM (1995). Leukocyte traffic in the lung. Annu Rev Physiol 57:97-114.

Hörl WH, Schaefer RM, and Heidland A (1985). Effect of different dialyzers on proteinases and proteinase inhibitors during hemodialysis. Am J Nephrol 5:320-326.

Hourmant M, Bedrossian J, Durand D, Lebranchu Y, Renoult E, Caudrelier P, Buffet R, Soulillou JP (1996). A randomized multicenter trial comparing leukocyte function-associated antigen-1 monoclonal antibody with rabbit antithymocyte globulin as induction treatment in first kidney transplantations. Transplantation 62:1565-1570.

Huber AR, and Weiss SJ (1989). Disruption of the subendothelial basement membrane during neutrophil diapedesis in an in vitro construct of a blood vessel wall. J Clin Invest 83:1122-1136.

Hudig D, Ewoldt GR, and Woodard SL (1993). Proteases and lymphocyte cytotoxic killing mechanisms. Curr Opin Immunol 5:90-96.

Hwang PM, Zhou N, Shan X, Arrowsmith $\mathrm{CH}$, and Vogel $\mathrm{HJ}$ (1998). Three-dimensional solution structure of lactoferricin $\mathrm{B}$, an antimicrobial peptide derived from bovine lactoferrin. Biochemistry 37:4288-4298.

Ivanyi B, Rumpelt HJ, and Thoenes W (1988). Acute human pyelonephritis: Leukocytic infiltration of tubules and localization of bacteria. Virchows Archiv - A, Pathol Anat Histopathol 414:29-37.

Ivanyi B, and Thoenes W (1987). Microvascular injury and repair in acute human bacterial pyelonephritis. Virchows Archiv - A, Pathol Anat Histopathol 411:257-265.

Iwahi T, and Imada A (1988). Interaction of Escherichia coli with polymorphonuclear leukocytes in pathogenesis of urinary tract infection in mice. Infect Immun 56:947-953.

Jackson SH, Gallin JI, and Holland SM (1995). The p47phox mouse knock-out model of chronic granulomatous disease. J Exp Med 182:751-758.

Jaeschke H, and Smith CW (1997). Mechanisms of neutrophil-induced parenchymal cell injury. J Leukoc Biol 61:647-653.

Janoff A, Sloan B, Weinbaum G, Damiano V, Sandhaus RA, Elias J, and Kimbel P (1977). Experimental emphysema induced with purified human neutrophil elastase: Tissue localization of the instilled protease. Am Rev Respir Dis 115:461-478.

Janoff A (1985). Elastases and emphysema. Current assessment of the protease-antiprotease hypothesis. Am Rev Respir Dis 132:417-433.

Jenne DE, Tschopp J, Ludemann J, Utecht B, and Gross WL (1990). Wegener's autoantigen decoded. Nature 346:520.

Jennings CA, and Crystal RG (1992). Inflammatory lung disease: Molecular determinants of emphysema, bronchitis, and fibrosis. In: Gallin JI, Goldstein IM, and Snyderman R editors. Inflammation: Basic principles and clinical correlates. New York: Raven Press, 983.

Jin F, Nathan CF, Radzioch D, and Ding A (1998). Lipopolysaccharide-related stimuli induce expression of the secretory leukocyte protease inhibitor, a macrophagederived lipopolysaccharide inhibitor. Infect Immun 66:24472452.
Jones SL, Knaus UG, Bokoch GM, and Brown EJ (1998). Two signaling mechanisms for activation of $\alpha \mathrm{M} \beta 2$ avidity in polymorphonuclear neutrophils. J Biol Chem 273:10556-10566.

Kallenberg CG, and Tervaert JW (1999). What is new with anti-neutrophil cytoplasmic antibodies: Diagnostic, pathogenetic and therapeutic implications. Curr Opin Nephrol Hypertens 8:307-315.

Kam CM, Kerrigan JE, Dolman KM, Goldschmeding R, Von Dem Borne AE, and Powers JC (1992). Substrate and inhibitor studies on proteinase 3. FEBS Lett 297:119-123.

Kao RC, Wehner NG, Skubitz KM, Gray BH, and Hoidal JR (1988). Proteinase 3. A distinct human polymorphonuclear leukocyte proteinase that produces emphysema in hamsters. J Clin Invest 82:1963-1973.

Kelly KJ, Williams WW Jr, Colvin RB, and Bonventre JV (1994). Antibody to intercellular adhesion molecule 1 protects the kidney against ischemic injury. Proc Natl Acad Sci USA 91:812-816.

Kelly KJ, Williams WW Jr, Colvin RB, Meehan SM, Springer TA, Gutierrez-Ramos JC, and Bonventre JV (1996). Intercellular adhesion molecule-1-deficient mice are protected against ischemic renal injury. J Clin Invest 97:1056-1063.

Keogan MT, Esnault VL, Green AJ, Lockwood CM, and Brown DL (1992). Activation of normal neutrophils by antineutrophil cytoplasm antibodies. Clin Exp Immunol 90:228234.

Khan TZ, Wagner JS, Bost T, Martinez J, Accurso FJ, and Riches DWH (1995). Early pulmonary inflammation in infants with cystic fibrosis. Am J Respir Crit Care Med 151:10751084.

Kiefer F, Brumell J, Al-Alawi N, Latour S, Cheng A, Veillette A, Grinstein S, and Pawson T (1998). The Syk protein tyrosine kinase is essential for $\mathrm{Fc} \gamma$ receptor signaling in macrophages and neutrophils. Mol Cell Biol 18:4209-4220.

Kitayama J, Carr MW, Roth SJ, Buccola J, and Springer TA (1997). Contrasting responses to multiple chemotactic stimuli in transendothelial migration. Heterologous desensitization in neutrophils and augmentation of migration in eosinophils. J Immunol 158:2340-2349.

Klebanoff SJ (1969). Myeloperoxidase-halide-hydrogen peroxide antibacterial system. J Bacteriol 95:2131-3138.

Klebanoff SJ (1992). Oxygen metabolites from phagocytes. In: Gallin JI, Goldstein IM, and Snyderman R editors. Inflammation: Basic principles and clinical correlates. New York: Raven Press, 541.

Klebanoff SJ, and Nathan CF (1993). Nitrite production by stimulated human polymorphonuclear leukocytes supplemented with azide and catalase. Biochem Biophys Res Commun 197:192-196.

Klebanoff SJ (1999). Myeloperoxidase. Proc Assoc Am Phys 111:383-389.

Klippel A, Reinhard C, Kavanaugh WM, Apell G, Escobedo MA, and Williams LT (1996). Membrane localization of phosphatidylinositol 3-kinase is sufficient to activate multiple signal-transducing kinase pathways. Mol Cell Biol 16:41174127.

Knauper V, Murphy G, and Tschesche H (1996). Activation of human neutrophil procollagenase by stromelysin 2. Eur J Biochem 235:187-191. 
Knepper-Nicolai B, Savill J, and Brown SB (1998). Constitutive apoptosis in human neutrophils requires synergy between calpains and the proteasome downstream of caspases. J Biol Chem 273:30530-30536.

Kocher M, Edberg JC, Fleit HB, and Kimberly RP (1998). Antineutrophil cytoplasmic antibodies preferentially engage Fc gammaRIIlb on human neutrophils. J Immunol 161:69096914.

Kolanus W, Nagel W, Schiller B, Zeitlmann L, Godar S, Stockinger $H$, and Seed B (1996). $\alpha \mathrm{L} \beta 2$ integrin LFA-1 binding to ICAM-1 induced by Cytohesin-1, a cytoplasmic regulatory molecule. Cell 86:233-242.

Konstan MW, Byard PJ, Hoppel CL, and Davis PB (1995). Effect of high-dose ibuprofen in patients with cystic fibrosis. N Engl J Med 332:848-854.

Koo DD, Welsh KI, Roake JA, Morris PJ, and Fuggle SV (1998). Ischemia/reperfusion injury in human kidney transplantation: An immunohistochemical analysis of changes after reperfusion. Am J Pathol 153:557-566.

Kowanko IC, Bates EJ, and Ferrante A (1990). Neutrophilmediated cartilage injury in vitro is enhanced by tumour necrosis factor alpha. Rheumatol Int 10:85-90.

Koyama AY, Nyui S, Suzuki K, Kura F, and Maeda N (1999). Severe impairment in early host defense against Candida albicans in mice deficient in myeloperoxidase. Infect Immun 67:1828-1836.

Krump E, Sanghera JS, Pelech SL, Furuya W, and Grinstein $S$ (1997). Chemotactic peptide N-formyl-met-leu-phe activation of p38 mitogen-activated protein kinase (MAPK) and MAPK-activated protein kinase-2 in human neutrophils. J Biol Chem 272:937-44.

Kuhn R, Lohler J, Rennick D, Rajewsky K, and Muller W (1993). Interleukin-10-deficient mice develop chronic enterocolitis. Cell 75:263-274.

Kunkel SL, Standiford T, Kashara K, and Strieter RM (1991). Interleukin 8 (IL-8): The major neutrophil chemotactic factor in the lung. Exp Lung Res 17:17-23.

Lallemand JY, Stoven V, Annereau JP, Boucher J, Blanquet S, Barthe J, and Lenoir G (1997). Induction by antitumoral drugs of proteins that functionally complement CFTR: A novel therapy for cystic fibrosis? Lancet 350:711-712.

Larbre JP, Moore AR, Da Silva JA, Iwamura H, loannou Y, and Willoughby DA (1995). Direct degradation of articular cartilage by theumatoid synovial fluid: Contribution of proteolytic enzymes. J Rheumatol 21:1796-1801.

Laudanna C, Campbell JJ, and Butcher EC (1996). Role of Rho in chemoattractant-activated leukocyte adhesion through integrins. Science 271:981-983.

Laudanna C, Mochly-Rosen D, Liron T, Constantin G, and Butcher EC (1998). Evidence of Sprotein kinase C involvement in polymorphonuclear neutrophil integrin-dependent adhesion and chemotaxis. J Biol Chem 273:30306-30315.

Lauffenburger DA, and Horwitz AF (1996). Cell migration: A physically integrated molecular process. Cell 84:359-369.

Lawrence MB, and Springer TA (1993). Neutrophils roll on E-selectin. J Immunol 151:6338-6347.

Lawson MA, and Maxfield FM (1995). Ca2+- and calcineurindependent recycling of an integrin to the front of migrating neutrophils. Nature 377:75-79.
Le-Barillec K, Si-Tahar M, Balloy V, and Chignard M (1999). Proteolysis of monocyte CD14 by human leukocyte elastase lipopolysaccharide-mediated cell activation. J Clin Invest 103:1039-1046.

Leeuwenburgh C, Rasmussen JE, Hsu FF, Mueller DM, Pennathur S, and Heinecke JW (1997). Mass spectrometric quantification of markers for protein oxidation by tyrosyl radical, copper, and hydroxyl radical in low density lipoprotein isolated from human atherosclerotic plaques. J Biol Chem 272:3520-3526.

Lehrer RI, and Ganz T (1999). Antimicrobial peptides in mammalian and insect host defence. Curr Opin Immunol 11:23-27.

Lekstrom-Himes JA, Dorman SE, Kopar P, Holland SM, and Gallin J (1999). Neutrophil-specific granule deficiency results from a novel mutation with loss of function of the transcription factor CCAAT/Enhancer binding protein epsilon. J Exp Med 189:1847-1852.

Lentsch AB, Czermak BJ, Jordan JA, and Ward PA (1999). Regulation of acute lung inflammatory injury by endogenous IL-13. J Immunology 162:1071-1076.

Lesavre P (1991). Antineutrophil cytoplasmic autoantibodies antigen specificity. Am J Kidney Dis 18:159-163.

Levy O (1996). Antibiotic proteins of polymorphonuclear leukocytes. European J Haematol 56:263-277.

Ley K, Bullard DC, Arbones ML, Bosse R, Vestweber D, Tedder TF, and Beaudet AL (1995). Sequential contribution of $\mathrm{L}-$ and P-selectin to leukocyte rolling in vivo. J Exp Med 181:669-675.

Li X, Steeber DA, Tang MLK, Farrar MA, Perlmutter RM, and Tedder TF (1998). Regulation of L-selectin-mediated rolling through receptor dimerization. J Exp Med 188:1385-1390.

Liles WC, and Klebanoff SJ (1995). Regulation of apoptosis in neutrophils-Fas trak to death? J Immunol 155:3289-3291.

Linas SL, Whittenburg D, Parsons PE, and Repine JE (1995). Ischemia increases neutrophil retention and worsens acute renal failure: Role of oxygen metabolites and ICAM 1. Kidney Int 48:1584-1591.

Lindberg FP, Bullard DC, Caver TE, Gresham HD, Beaudet $A L$, and Brown EJ (1996). Decreased resistance to bacterial infection and granulocyte defects in lap-deficient mice. Science 274:795-798.

Lindemann A, Riedel D, Oster W, Ziegler-Heitbrock HW, Mertelsmann R, and Herrmann F (1989). Granulocytemacrophage colony-stimulating factor induces cytokine secretion by human polymorphonuclear leukocytes. J Clin Invest 83:1308-1312.

Lock R, Dahlgren C, Linden M, Stendahl O, Svensbergh A, and Ohman L (1990). Neutrophil killing of two type 1 fimbriabearing Escherichia coli strains: Dependence on respiratory burst activation. Infect Immun 58:37-42.

Loike JD, Cao L, Budhu S, Marcantonio EE, El Khoury J, Hoffman S, Yednock TA, and Silverstein SC (1999). Differential regulation of beta1 integrins by chemoattractants regulates neutrophil migration through fibrin. J Cell Biol 144: 1047-1056.

London SJ, Lehman TA, and Taylor JA (1997). Myeloperoxidase genetic polymorphism and lung cancer risk. Cancer Res 57:5001-5003. 
Lopez S, Halbwachs-Mecarelli L, Ravaud P, Bessou G, Dougados M, and Porteu F (1995). Neutrophil expression of tumour necrosis factor receptors (TNF-R) and of activation markers (CD11b, CD43, CD63) Clin Exp Immunol 101:25-32.

Lowell CA, and Berton G (1999). Integrin signal transduction in myeloid leukocytes. J Leukocyte Biol 65:313-320.

Malech HL, and Nauseef WM (1997). Primary inherited defects in neutrophil function: Etiology and treatment. Semin Hematol 34:279-290.

Malech HL, Maples PB, Whiting-Theobald N, Linton GF, Sekhsaria S, Vowells SJ, Li F, Miller JA, Decarlo E, Holland SM, Leitman SF, Carter CS, Butz RE, Read EJ, Fleisher TA, Schneiderman RD, Van Epps DE, Spratt SK, Maack CA, Rokovich JA, Cohen LK, Gallin JI (1997). Prolonged production of NADPH oxidase-corrected granulocytes after gene therapy of chronic granulomatous disease. Proc Natl Acad Sci USA 94:12133-12138.

Malech HL (1999). Progress in gene therapy for chronic granulomatous disease. J Infect Dis 179:S318-S325.

Mandeville JTH, Lawson MA, and Maxfield FR (1997). Dynamic imaging of neutrophil migration in three dimensions: Mechanical interactions between cells and matrix. J Leukoc Biol 61:188-200.

Mandi Y, Endresz V, Krenacs L, Regely K, Degre M, and Beladi I (1991). Tumor necrosis factor production by human granulocytes. Int Arch Allergy Appl Immunol 96:102-106.

Mardiney M, Jackson SH, Spratt SK, Li F, Holland SM, and Malech HL (1997). Enhanced host defense after gene transfer in the murine p47phox-deficient model of chronic granulomatous disease. Blood 89:2268-2275.

Marie C, Pitton C, Fitting C, and Cavaillon JM (1996). IL-10 and IL-4 synergize with TNF-alpha to induce IL-1ra production by human neutrophils. Cytokine 8:147-151.

Marletta MA (1993). Nitric oxide synthase structure and mechanism. J Biol Chem 268:12231-12234.

Martin-Padura I, Lostaglio S, Schneemann M, Williams L, Romano M, Fruscella P, Panzeri C, Stoppacciaro A, Ruco L, Villa A, Simmons D, and Dejana E (1998). Junctional Adhesion Molecule, a novel member of the immunoglobulin superfamily that distributes at intercellular junctions and modulates monocyte transmigration. J Cell Biol 142:117-127.

Mason DY, Cramer EM, Masse JM, Crystal R, Bassot JM, and Breton-Gorius J (1991). Alpha 1-antitrypsin is present within the primary granules of human polymorphonuclear leukocytes. Am J Pathol 139:623-628.

Massol P, Montcourrier P, Guillemot JC, and Chavrier P (1998). Fc receptor-mediated phagocytosis requires CDC42 and Rac1. EMBO Journal 17:6219-6229.

Matsukawa A, Yoshimura T, Maeda T, Takahashi T, Ohkawara S, and Yoshinaga M (1998). Analysis of the cytokine network among tumor necrosis factor alpha, interleukin1 beta, interleukin-8, and interleukin-1 receptor antagonist in monosodium urate crystal-induced rabbit arthritis. Lab Invest 78:559-569.

Matsumoto T, Yokoi K, Mukaida N, Harada A, Yamashit J, Watanabe Y, and Matsushima K (1997). Pivotal role of interleukin- 8 in the acute respiratory distress syndrome and cerebral reperfusion injury. J Leukoc Biol 62:581-587.

Matzner Y, Partridge RE, Levy M, and Babior BM (1984). Diminished activity of a chemotactic inhibitor in synovial fluids from patients with familial Mediterranean fever. Blood 63:629-633.

McColl SR, Paquin R, Menard C, and Beaulieu AD (1992). Human neutrophils produce high levels of the interleukin 1 receptor antagonist in response to granulocyte/macrophage colony-stimulating factor and tumor necrosis factor alpha. $J$ Exp Med 176:593-598.

McCormick BA, Parkos CA, Colgan SP, Carnes DK, and Madara JL (1998). Apical secretion of a pathogen-elicited epithelial chemoattractant activity in response to surface colonization of intestinal epithelia by Salmonella typhimurium. J Immunol 160:455-466.

McDermott EM, Smillie DM, and Powell RJ (1997). Clinical spectrum of familial Hibernian fever: A 14-year follow-up study of the index case and extended family. Mayo Clinic Proc 72:806-817.

McDermott MF, Aksentijevich I, Galon J, McDermott EM, Ogunkolade BW, Centola M, Mansfield E, Gadina M, Karenko L, Pettersson T, McCarthy J, Frucht DM, Aringer M, Torosyan Y, Teppo AM, Wilson M, Karaarslan HM, Wan Y, Todd I, Wood G, Schlimgen R, Kumarajeewa TR, Cooper SM, Vella JP, Amos Cl, Mulley J, Quane KA, Molloy MG, Ranki A, Powell RJ, Hitman GA, O'Shea JJ, and Kastner DL (1999). Germline mutations in the extracellular domains of the $55 \mathrm{kDa}$ TNF receptor, TNFR1, define a family of dominantly inherited autoinflammatory syndromes. Cell 97:133-144.

McDonald PP, Bald A, and Cassatella MA (1997). Activation of the NF-kappaB pathway by inflammatory stimuli in human neutrophils. Blood 89:3421-3433.

McElvaney NG, Hubbard RC, Birrer P, Chernick MS, Caplan DB, Frank MM, and Crystal RG (1991). Aerosol alpha 1-antitrypsin treatment for cystic fibrosis. Lancet 337:392394.

McElvaney NG, Nakamura H, Birrer P, Hebert CA, Wong WL, Alphonso M, Baker JB, Catalano MA, and Crystal RG (1992). Modulation of airway inflammation in cystic fibrosis. In vivo suppression of interleukin-8 levels on the respiratory epithelial surface by aerosolization of recombinant secretory leukoprotease inhibitor. J Clin Invest 90:1296-1301.

McEver RP, and Cummings RD (1997). Role of PSGL-1 binding to selectins in leukocyte recruitment. J Clin Invest 100:S97-S103.

McIntosh I, and Cutting GR (1992). Cystic fibrosis transmembrane conductance regulator and the etiology and pathogenesis of cystic fibrosis. FASEB J 6:2775-2782.

Merlin D, Steel A, Gewirtz AT, Si-Tahar M, Hediger MA, and Madara JL (1998). hPepT1-mediated epithelial transport of bacteria-derived chemotactic peptides enhances neutrophilepithelial interactions. J Clin Invest 102:2011-2018.

Meyrier A (1989). Frequency of development of early cortical scarring in acute primary pyelonephritis. Kidney Int 35:696703.

Middelhoven PJ, Ager A, Roos D, and Verhoeven AJ (1997). Involvement of a metalloprotease in the shedding of human neutrophil Fc gammaRIIIB. FEBS Letters 414:14-18.

Middleton J, Neil S, Wintle J, Clark-Lewis I, Moore H, Lam C, Auer M, Hub E, and Rot A (1997). Transcytosis and surface presentation of IL-8 by venular endothelial cells. Cell 91:385395.

Mizgerd JP, Kubo H, Kutkoski GJ, Bhagwan SD, Scharffetter-Kochanek K, Beaudet AL, and Doerschuk CM 
(1997). Neutrophil emigration in the skin, lungs, and peritoneum: Different requirements for CD11/CD18 revealed by CD18-deficient mice. J Exp Med 186:1357-1364.

Mizgerd JP, Meek BB, Kutkoski GJ, Bullard DC, Beaudet AL, and Doerschuk CM (1996). Selectins and neutrophil traffic: Margination and Streptococcus pneumoniae-induced emigration in murine lungs. J Exp Med 184:639-645.

Mohr W, Pelster B, and Wessinghage D (1984). Polymorphonuclear granulocytes in rheumatic tissue destruction. VI. The occurrence of PMNs in menisci of patients with rheumatoid arthritis. Rheumatol Int 5:39-44.

Monga M, and Roberts JA (1995). The possible role of granulocyte elastase in renal damage from acute pyelonephritis. Pediatric Nephrol 9:583-586.

Moore KL, Patel KD, Bruehl RE, Li F, Johnson DA, Lichenstein HS, Cummings RD, Bainton DF, and McEver RP (1995). $\mathrm{P}$-selectin glycoprotein ligand-1 mediates rolling of human neutrophils on P-selectin. J Cell Biol 128:661-671.

Morgan JG, Sukiennicki T, Pereira HA, Spitznagel JK, Guerra ME, and Larrick JW (1991). Cloning of the cDNA for the serine protease homolog CAP37/azurocidin, a microbicidal and chemotactic protein from human granulocytes. J Immunol 147:3210-3214.

Moses MA (1997). The regulation of neovascularization by matrix metalloproteinases and their inhibitors. Stem Cells 15:180-189.

Muller WA, Weigl SA, Deng X, and Phillips DM (1993). PECAM-1 is required for transendothelial migration of leukocytes. J Exp Med 178:449-460.

Muller Kobold AC, Kallenberg CG, and Tervaert JW (1998). Leucocyte membrane expression of proteinase 3 correlates with disease activity in patients with Wegener's granulomatosis. Brit J Rheumatol 37:901-907.

Mundi H, Bjorksten B, Svanborg C, Ohman L, and Dahlgren C (1991). Extracellular release of reactive oxygen species from human neutrophils upon interaction with Escherichia coli strains causing renal scarring. Infect Immun 59:41684172.

Murphy CJ, Foster BA, Mannis MJ, Selsted ME, and Reid TW (1993). Defensins are mitogenic for epithelial cells and fibroblasts. J Cell Physiol 155:408-413.

Murphy G, Ward R, Gavrilovic J, and Atkinson S (1992). Physiological mechanisms for metalloproteinase activation. Matrix Suppl.1:224-230.

Murphy G, and Docherty AJP (1992). The matrix metalloproteinases and their inhibitors. Am J Resp Cell Mol Biol $7: 120-125$.

Nagel W, Zeitlmann L, Schilcher P, Geiger C, Kolanus J, and Kolanus W (1998). Phosphoinositide 3-OH Kinase activates the b2 integrin adhesion pathway and induces membrane recruitment of Cytohesin-1. J Biol Chem 273:14853-14861.

Nagle DL, Karim MA, and Woolf EA (1996). Identification and mutationanalysis of the complete gene for Chediak-Higashi syndrome. Nat Genet 14:307-311.

Nash S, J Stafford J, and Madara JL (1987). Effects of polymorphonuclear leukocyte transmigration on barrier function of cultured intestinal epithelial monolayers. J Clin Invest 10:1104-1113.
Nassberger L, Jonsson $H$, Sjoholm AG, Sturfelt $G$, and Heubner A (1989). Circulating anti-elastase in systemic lupus erythematosus letter. Lancet 1:509.

Nathan CF (1987). Neutrophil activation on biological surfaces. Massive secretion of hydrogen peroxide in response to products of macrophages and lymphocytes. J Clin Invest 80:1550-1560.

Nathan C, and Xie QW (1994). Regulation of biosynthesis of nitric oxide. J Biol Chem 269:13725-13728.

Nauseef WM (1998). Insights into myeloperoxidase biosynthesis from inherited deficiency. J Mol Med 76:661-668.

Nauseef WM, Cogley M, and McCormick S (1996). Effect of the R569 missense mutation on the biosynthesis of myeloperoxidase. J Biol Chem 271:9546-9549.

Nick JA, Avdi NJ, Toung NK, Knall C, Gerwins P, Johnson GL, and Worthen GS (1997). Common and distinct intracellular signaling pathways in human neutrophils utilized by platelet activating facror and FMLP. J Clin Invest 99:975-986.

Niggli V, and Keller H (1997). The phosphatidylinositol 3-kinase inhibitor wortmannin markedly reduces chemotactic peptide-induced locomotion and increases in cytoskeletal actin in human neutrophils. Eur J Pharmacol 335:43-52.

Nobes CD, and Hall A (1999). Rho GTPases control polarity, protrusion, and adhesion during cell movement. J Cell Biol 144:1235-1244.

O'Meara YM, and Brady HR (1997). Lipoxins, leukocyte recruitment and the resolution of acute glomerulonephritis. Kidney Int 51:S56-S61.

Okada T, Sakuma L, Fukui Y, Hazeko I, and Ui M (1994). Blockage of chemotactic peptide-induced stimulation of neutrophils by Wortmannin as a result of selective inhibition of phosphatidylinositol 3-kinase. J Biol Chem 269:35633567.

Okada Y, Watanabe S, Nakanishi I, Kishi J, Hayakawa T, Watorek W, Travis J, and Nagase H (1988). Inactivation of tissue inhibitor of metalloproteinases by neutrophil elastase and other serine proteinases. FEBS Lett 229:157-160.

Ooi CE, Weiss J, Elsbach P, Frangione B, and Mannion B (1987). A 25-kDa NH2-terminal fragment carries all the antibacterial activities of the human neutrophil $60-\mathrm{kDa}$ bactericidal/permeability-increasing protein. J Biol Chem 262:14891-14894.

Owen CA, and Campbell EJ (1999). The cell biology of leukocyte-mediated proteolysis. J Leukocyte Biol 65:137150.

Owen CA, Campbell MA, Sannes PL, Boukedes SS, and Campbell EJ (1995). Cell surface-bound elastase and cathepsin $G$ on human neutrophils: A novel, non-oxidative mechanism by which neutrophils focus and preserve catalytic activity of serine proteinases. J Cell Biol 131:775-789.

Padgett EL, and Pruett SB (1995). Rat, mouse and human neutrophils stimulated by a variety of activating agents produce much less nitrite than rodent macrophages. Immunology 84:135-141.

Padrines M, Wolf M, Walz A, and Baggiolini M (1994). Interleukin-8 processing by neutrophil elastase, cathepsin $\mathrm{G}$ and proteinase-3. FEBS Lett 352:231-235.

Panyutich AV, Hiemstra PS, Van Wetering S, and Ganz T (1995). Human neutrophil defensin and serpins form com- 
plexes and inactivate each other. Am J Resp Cell Mol Biol 12:351-357.

Parkos CA (1997). Molecular events in neutrophil transepithelial migration. BioEssays 19:865-873.

Parsons PE, Sugahara K, Cott GR, Mason RJ, and Henson PM (1987). The effect of neutrophil migration and prolonged neutrophil contact on epithelial permeability. Am J Pathol 129:302-312.

Patel KD, Moore KL, Nollert MU, and McEver RP (1995). Neutrophils use both shared and distinct mechanisms to adhere to selectins under static and flow conditions. J Clin Invest 96:1887-1895.

Pellegatta F, Chierchia SL, and Zocchi MR (1998). Functional association of platelet endothelial cell adhesion molecule-1 and phosphoinositide 3-kinase in human neutrophils. J Biol Chem 273:27768-27771.

Peppin GJ, and Weiss SJ (1986). Activation of the endogenous metalloproteinase, gelatinase, by triggered human neutrophils. Proc Natl Acad Sci U S A 83:4322-4326.

Pereira HA, Shafer WM, Pohl J, Martin LE, and Spitznagel JK (1990). CAP-37 a human neutrophil -derived chemotactic factor with monocyte specificity. J Clin Invest 85:1468-1476.

Pereira HA, Moore P, and Grammas P (1996). CAP-37, a neutrophil granule-derived protein stimulates protein kinase C activity in endothelial cells. J Leukocyte Biol 60:415-422.

Pereira BJG, Shapiro L, King AJ, Falagas ME, Strom JA, and Dinarello CA (1994). Plasma levels of IL $1 \beta$, TNF $\alpha$ and their specific inhibitors in undialyzed chronic renal failure, CAPD and hemodialysis patients. Kidney Int 45:890-896.

Pero RW, Sheng Y, Olsson A, Bryngelsson C, and Lund-Pero $M$ (1996). Hypochlorous acid/N-chloramines are naturally produced DNA repair inhibitors. Carcinogenesis 17:13-18.

Peters AM (1998). Just how big is the pulmonary granulocyte pool? Clin Sci 94:7-19.

Petrides PE (1998). Molecular genetics of peroxidase deficiency. J Mol Med 76:688-698.

Petty HR, and Todd RF (1996). Integrins as promiscuous signal transduction devices. Immunol Today 17:209-212.

Phelps P, and McCarty JR (1966). Crystal-induced inflammation in canine joints. Importance of polymorphonuclear leukocytes. J Exp Med 124:150-162.

Phillips ML, Schwartz BR, Etzioni A, Bayer R, Ochs HD, Paulson JC, and Harlan JM (1995). Neutrophil adhesion in leukocyte adhesion deficiency syndrome type 2. J Clin Invest 96:2898-2906.

Pier GB, Grout M, and Zaidi TS (1997). Cystic fibrosis transmembrane regulator is an epithelial cell receptor for clearance of £Pseudomonas aeruginosa from the lung. Proc Natl Acad Sci U S A 4:12088-12093.

Pillinger $\mathrm{MH}$, and Abramson SB (1995). The neutrophil in rheumatoid arthritis. Rheum Dis Clin North Am 21:691-714.

Pillinger MH, Feoktistov AS, Capodici C, Solitar B, Levy J, Oei TT, and Philips MR (1996). Mitogen-activated protein kinase in neutrophils and enucleate neutrophil cytoplasts: Evidence for regulation of cell-cell adhesion. J Biol Chem 271:12049-12056.

Podrez EA, Schmitt D, Hoff HF, and Hazen SL (1999). Myeloperoxidase-generated reactive nitrogen species con- vert LDL into an atherogenic form in vitro. J Clin Invest 103:1547-1560.

Pollock JD, Williams DA, Gifford MA, Li LL, Du X, Fisherman J, Orkin SH, Doerschuk CM, and Dinauer MC (1995). Mouse model of $X$-linked chronic granulomatous disease, an inherited defect in phagocyte superoxide production. Nat Genet 9:202-209.

Pongracz J, Webb P, Wang KQ, Deacon E, Lunn OJ, and Lord JM (1999). Spontaneous neutrophil apoptosis involves caspase 3-mediated activation of protein kinase C-delta. J Biol Chem 274:37329-37334.

Porteu F, Brockhaus M, Wallach D, Engelmann H, and Nathan CF (1991). Human neutrophil elastase releases a ligand-binding fragment from the $75-\mathrm{kDa}$ tumor necrosis factor (TNF) receptor. Comparison with the proteolytic activity responsible for shedding of TNF receptors from stimulated neutrophils. J Biol Chem 266:18846-18853.

Premack BA, and Schall TJ (1996). Chemokine receptors: Gateways to inflammation and infection. Nat Med 2:11741178.

Prince A (1998). The CFTR advantage-capitalizing on a quirk of fate. Nature Med 4:663-664.

Ptasznik A, Prossnitz ER, Yoshikawa D, Smrcka A, TraynorKaplan AE, and Bokoch GM (1996). A tyrosine kinase signaling pathway accounts for the majority of phosphatidylinositol 3:4,5-trisphosphate formation in chemoattractant-stimulated human neutrophils. J Biol Chem 271:25204-25207.

Rabb H, Mendiola CC, Dietz J, Saba SR, Issekutz TB, Abanilla F, Bonventre JV, and Ramirez G (1994). Role of $\mathrm{CD} 11 \mathrm{a}$ and $\mathrm{CD} 11 \mathrm{~b}$ in ischemic acute renal failure in rats. Am J Physiol 267:F1052-F1058.

Rabb H, Mendiola CC, Saba SR, Dietz JR, Smith CW, Bonventre JV, and Ramirez G (1995). Antibodies to ICAM-1 protect kidneys in severe ischemic reperfusion injury. Biochem Biophys Res Comm 211:67-73.

Rae SA, Davidson EM, and Smith MJ (1982). Leukotriene B4, an inflammatory mediator in gout. Lancet 2:1122-1124.

Ralston DR, Marsh CB, Lowe MP, and Wewers MD (1997). Antineutrophil cytoplasmic antibodies induce monocyte IL-8 release. Role of surface proteinase-3, alpha1-antitrypsin, and Fcgamma receptors. J Clin Invest 100:1416-1424.

Rao NV, Wehner NG, Marshall BC, Gray WR, Gray BH, and Hoidal JR (1991). Characterization of proteinase-3 (PR-3), a neutrophil serine proteinase. Structural and functional properties. J Biol Chem 266:9540-9548.

Rao NV, Marshall BC, Gray BH, and Hoidal JR (1993). Interaction of secretory leukocyte protease inhibitor with proteinase-3. Am J Respir Cell Mol Biol 8:612-616.

Regelmann WE, Siefferman CM, Herron JM, Elliott GR, Clawson CC, and Gray BH (1995). Sputum peroxidase activity correlates with the severity of lung disease in cystic fibrosis. Pediatr Pulmonol 19:1-9.

Remold-O'Donnell E, Chin J, and Alberts M (1992). Sequence and molecular characterization of human monocyte/ neutrophil elastase inhibitor. Proc Natl Acad Sci U S A 89:5635-5639.

Renesto and Chignard (1993). Enhancement of cathepsin G-inducedplatelet activationby leukocyte elastase: Consequence for the neutrophil-mediated platelet activation. Blood $82: 139-144$ 
Reynolds WF, Chang E, Douer D, Ball ED, and Kanda V (1997). An allelic association implicates myeloperoxidase in the etiology of acute promyelocytic leukemia. Blood 90: 2730-2737.

Reynolds WF, Rhees J, Maclejewski D, Paladino T, Sieburg H, Maki RA, and Masliah E (1999). Myeloperoxidase polymorphism is associated with gender specific risk for Alzheimer's disease. Experimental Neurology 155:31-41.

Richman-Eisenstat JB, Jorens PG, Hebert CA, Ueki I, and Nadel JA (1993). Interleukin-8: An important chemoattractant in sputum of patients with chronic inflammatory airway disease. Am J Physiol 264:L413-L418.

Rieu P, and Arnaout MA (1996). The structural basis and regulation of $\beta 2$ integrin interactions. In: Ward $P$, Fantone JC, and Lenfant $\mathrm{C}$, editors. Lung biology in health and disease. New York, 89:1-42.

Robache-Gallea S, Morand V, Bruneau JM, Schoot B, Tagat E, Realo E, Chouaib S, and Roman-Roman S (1995). In vitro processing of human tumor necrosis factor-alpha. $\mathrm{J}$ Biol Chem 270:23688-23692.

Rollins BJ (1997). Chemokines. Blood 90:909-928.

Romagnani S (1994). Lymphokine production by human T cells in disease state. Annu Rev Immunol 12:227-257.

Roos D, de Boer M, Kuribayashi F, Meischl C, Weening RS, Segal AW, Ahlin A, Nemet K, Hossle JP, BernatowskaMatuszkiewicz E, and Middleton-Price H (1996). Mutations in the $\mathrm{X}$-linked and autosomal recessive forms of chronic granulomatous disease. Blood 87:1663-1681.

Rosen H, and Klebanoff SJ (1979). Hydroxyl radical generation by polymorphonuclear leukocytes measured by electron spin resonance spectroscopy. J Clin Invest 64:1725-1729.

Roth SJ, Carr MW, and Springer TA (1995). C-C chemokines, but not the C-X-C chemokines interleukin-8 and interferongamma inducible protein-10, stimulate transendothelial chemotaxis of T lymphocytes. Eur J Immunol 25:3482-3488.

Rotrosen D (1992). The respiratory burst oxidase. In: Gallin JI, Goldstein IM, and Snyderman R editors. Inflammation: Basic principles and clinical correlates. New York: Raven Press, 589.

Roussel E, and Gingras MC (1997). Transendothelial migration induces rapid expression on neutrophils of granulerelease VLA6 used for tissue infiltration. $J$ Leukocyte Biol 62:356-362.

Russell KJ, McRedmond J, Mukherji N, Costello C, Keatings V, Linnane S, Henry M, Fitzgerald MX, and O'Connor CM (1998). Neutrophil adhesion molecule surface expression and responsiveness in cystic fibrosis. Am J Resp Crit Care Med 157:756-761.

Salant DJ (1999). ANCA: Fuel for the fire or the spark that ignites the flame? Kidney Int 55:1125-1127.

Sallenave JM, Si-Ta Har M, Cox G, Chignard M, and Gauldie $J$ (1997). Secretory leukocyte proteinase inhibitor is a major leukocyte elastase inhibitor in human neutrophils. J Leukoc Biol 61:695-702.

Salvesen G, Farley D, Shuman J, Przybyla A, Reilly C, and Travis J (1987). Molecular cloning of human cathepsin G: Structural similarity to mast cell and cytotoxic T lymphocyte proteinases. Biochemistry 26:2289-2293.

Samanta AK, Dutta S, and Ali E (1993). Modification of sulfhydryl groups of interleukin-8 (IL-8) receptor impairs binding of IL-8 and IL-8-mediated chemotactic response of human polymorphonuclear neutrophils. J Biol Chem 268: 6147-6153.

Sampson JB, Ye Y, Rosen H, and Beckman JS (1998). Myeloperoxidase and horseradish peroxidase catalyze tyrosine nitration in proteins from nitrite and hydrogen peroxide. Arch Biochem Biophys 356:207-213.

Sanchez-Lopez R, Nicholson R, Gesnel MC, Matrisian LM, and Breathnach R (1988). Structure-function relationships in the collagenase family member transin. J Biol Chem 263: 11892-11899.

Savill J, Hogg N, Ren Y, and Haslett C (1992). Thrombospondin cooperates with CD36 and the VnR in macrophage recognition of neutrophils undergoing apoptosis. J Clin Invest 90:1513-1520.

Savill J (1997). Apoptosis in resolution of inflammation. J Leukoc Biol 61:375-380.

Schiffl H, Lang SM, Konig A, Strasser T, Haider MC, and Held E (1994). Biocompatible membranes in acute renal failure: Prospective case-controlled study. Lancet 344:570-2.

Schindler R, Lonnemann G, Shaldon S, Koch KM, and Dinarello CA (1990). Transcription, not synthesis, of interleukin-1 and tumor necrosis factor by complement. Kidney Int 37:85-93.

Schrijver G, Assmann KJ, Bogman MJ, Robben JC, de Waal RM, and Koene RA (1988). Antiglomerular basement membrane nephritis in the mouse. Study on the role of complement in the heterologous phase. Lab Invest 59:484-491.

Schrijver G, Bogman MJ, Assmann KJ, de Waal RM, Robben HC, Van Gasteren H, and Koene RA (1990). Anti-GBM nephritis in the mouse: Role of granulocytes in the heterologous phase. Kidney Int 38:86-95.

Schrijver G, Schalkwijk J, Robben JC, Assmann KJ, and Koene RA (1989). Antiglomerular basement membrane nephritis in beige mice. Deficiency of leukocytic neutral proteinases prevents the induction of albuminuria in the heterologous phase. J Exp Med 169:1435-1448.

Schulman G, Fogo A, Gung A, Badr K, and Hakim R (1991). Complement activation retards resolution of acute ischemic renal failure in the rat. Kidney Int 40:1069-1074.

Segal AW, and Abo A (1993). The biochemical basis of the NADPH oxidase of phagocytes. Trends Biochem Sci 18:4347.

Sekido N, Mukaida N, Harada A, Nakanishi I, Watanabe Y, and Matsushima K (1993). Prevention of lung reperfusion injury in rabbits by a monoclonal antibody against interleukin-8. Nature 365:654-657.

Sengelov H, Kjeldsen L, and Borregaard N (1993). Control of exocytosis in early neutrophil activation. J Immunol 150: 1535-1543.

Sermet-Gaudelus I, Stoven V, Annereau JP, Witko-Sarsat V, Reinert P, Guyot M, Descamps-Latscha B, Lallemand JY, and Lenoir $G$ (1999). Interest of colchicine for the treatment of cystic fibrosis patients. Preliminary report. Mediat Inflamm 8:13-15.

Seveau S, Keller H, Maxfield FR, Piller F, and HalbwachsMecarelli (2000). Neutrophil polarity and locomotion are associated with surface redistribution of leukosialin (CD43), an anti-adhesive membrane molecule. Blood 95:2462-2470. 
Shafer WM, Pohl J, Onunka VC, Bangalore N, and Travis J (1991). Human lysosomal cathepsin $G$ and granzyme B share a functionally conserved broad spectrum antibacterial peptide. J Biol Chem 266:112-116.

Shapiro SD (1998). Matrix metalloproteinase degradation of extracellular matrix: Biological consequences. Curr Opin Cell Biol 10:602-608.

Sheerin NS, Springall T, Carroll MC, Hartley B, and Sacks SH (1997). Protection against anti-glomerular basement membrane (GBM)-mediated nephritis in C3- and C4-deficient mice. Clin Exp Immunol 110:403-409.

Shi J, and Ganz T (1998). The role of protegrins and other elastase-activated polypeptides in the bactericidal properties of porcine inflammatory fluids. Infect Immun 66:3611-3617.

Shiloh MU, MacMicking JD, Nicholson S, Brause JE, Potter S, Marino M, Fang F, Dinauer M, and Nathan C (1999). Phenotype of mice and macrophages deficient in both phagocyte oxidase and inducible nitric oxide synthase. Immunity $10: 29-38$.

Shimizu Y, and Huntiii SW (1996). Regulating integrinmediated adhesion: One more function for PI 3-kinase? Immunol Today 17:565-573.

Short AK, Lockwood CM, Bollen A, and Moguilevsky N (1995). Neutrophil and recombinant myeloperoxidase as antigens in ANCA positive systemic vasculitis. Clin Exp Immunol 102:106-111.

Simon SI, Burns AR, Taylor AD, Gopalan PK, Lynam EB, Sklar LA, and Smith CW (1995). L-selectin (CD62L) crosslinking signals neutrophil adhesive functions via the Mac-1 (CD11b/CD18) beta 2-integrin. J Immunol 155:1502-1514.

Sironi M, Munoz C, Pollicino T, Siboni A, Sciacca FL, Bernasconi S, Vecchi A, Colotta F, and Mantovani A (1993). Divergent effects of interleukin-10 on cytokine production by mononuclear phagocytes and endothelial cells. Eur J Immunol 23:2692-2695.

Sligh JE Jr, Ballantyne CM, Rich SS, Hawkins HK, Smith CW, Bradley A, and Beaudet AL (1993). Inflammatory and immune responses are impaired in mice deficient in intercellular adhesion molecule 1. Proc Natl Acad Sci U S A 90:85298533.

Sohar E, Gafni J, Pras M, and Heller H (1967). Familial Mediterranean fever. A survey of 470 cases and review of the literature. Am J Med 43:227-253.

Sommerhoff CP, Nadel JA, Basbaum CB, and Caughey GH (1990). Neutrophil elastase and cathepsin G stimulate secretion from cultured bovine airway gland serous cells. J Clin Invest 85:682-689.

Sorensen O, Arnljots K, Cowland JB, Bainton DF, and Borregaard $N$ (1997). The human antibacterial cathelicidin, hCAP-18, is synthesized in myelocytes and metamyelocytes and localized to specific granules in neutrophils. Blood 90:2796-2803.

Spitznagel JK (1990). Antibiotic proteins of human neutrophils. J Clin Invest 86:1381-1386.

Springer TA (1994). Traffic signals for lymphocyte recirculation and leukocyte emigration: The multistep paradigm. Cell 76:301-314.

Steeber DA, Campbell MA, Basit A, Ley K, and Tedder TF (1998). Optimal selectin-mediated rolling of leukocytes during inflammation in vivo requires intercellular adhesion molecule-1 expression. Proc Natl Acad Sci USA 95:75627567.

Steeber DA, Engel P, Miller AS, Sheetz MP, and Tedder TF (1997). Ligation of L-selectin through conserved regions within the lectin domain activates signal transduction pathways and integrin function in human, mouse, and rat leukocytes. J Immunol 159:952-63.

Steegmaier M, Borges E, Berger J, Schwarz H, and Vestweber D (1997). The E-selectin-ligand ESL-1 is located in the Golgi as well as on microvilli on the cell surface. J Cell Science 110:687-694.

Stern RC (1997). The diagnosis of cystic fibrosis. N Engl J Med 336:487-491.

Stewart M, and Hogg N (1996). Regulation of leukocyte integrin function: Affinity vs. avidity. J Cell Biochem 61:554561.

Stockley RA (1987). Alpha-1-Antitrypsin and the pathogenesis of emphysema. Lung 165:61-77.

Stricklin GP, and Welgus HG (1983). Human skin fibroblast collagenase inhibitor. Purification and biochemical characterization. J Biol Chem 258:12252-12258.

Strohmeier GR, Reppert SM, Lencer WI, and Madara JL (1995). The A2b adenosine receptor mediates cAMP responses to adenosine receptor agonists in human intestinal epithelia. J Biol Chem 270:2387-2394.

Sturrock AB, Franklin KF, Rao G, Marshall BC, Rebentisch MB, Lemons RS, and Hoidal JR (1992). Structure, chromosomal assignment, and expression of the gene for proteinase-3. The Wegener's granulomatosis autoantigen. J Biol Chem 267:21193-21199.

Sun J, Fass DN, Viss MA, Hummel AM, Tang H, Homburger HA, and Specks U (1998). A proportion of proteinase 3 (PR3)-specific anti-neutrophil cytoplasmic antibodies (ANCA) only react with $\mathrm{PR} 3$ after cleavage of its $\mathrm{N}$-terminal activation dipeptide. Clin Exp Immunol 114:320-326.

Suter S, Schaad UB, Roux L, Nydegger UE, and Waldvogel FA (1984). Granulocyte neutral proteases and Pseudomonas elastase as possible causes of airway damage in patients with cystic fibrosis. J Infect Dis 149:523-531.

Swanson JA, and Baer SC (1995). Phagocytosis by zippers and triggers. Trends Cell Biol 5:89-93.

Swanson JA, Johnson MT, Beningo K, Post P, Mooseker M, and Araki N (1999). A contractile activity that closes phagosomes in macrophages. J Cell Science 112:307-316.

Takahashi H, Nukiwa T, Yoshimura K, Quick CD, States DJ, Holmes MD, Whang-Peng J, Knutsen T, and Crystal RG (1988). Structure of the human neutrophil elastase gene. J Biol Chem 263:14739-14747.

Tang T, Rosenkranz A, Assmann KJM, Goodman MJ, Gutierrez-Ramos JC, Carroll MC, Cotran RS, and Mayadas TN (1997). A role for Mac-1 (CDIlb/CD18) in immune complex-stimulated neutrophil function in vivo: Mac-1 deficiency abrogates sustained Fcgamma receptor-dependent neutrophil adhesion and complement-dependent proteinuria in acute glomerulonephritis. J Exp Med 186:1853-1863.

Tardif M, Beauchamp D, Bergeron Y, Lessard C, Gourde P, and Bergeron MG (1994). L-651,392, a potent leukotriene inhibitor, controls inflammatory process in Escherichia coli pyelonephritis. Antimicrobial Agents Chemother 38:15551560 . 
Tartaglia LA, and Goeddel DV (1992). Two TNF receptors. Immunol Today 13:151-153.

Tauber Al, and Babior BM (1977). Evidence for hydroxyl radical production by human neutrophils. J Clin Invest 60 : 374-379.

Tedder TF, Steeber DA, and Pizcueta P (1995). L-selectindeficient mice have impaired leukocyte recruitment into inflammatory sites. J Exp Med 181:2259-2264.

Terkeltaub R, Tenner AJ, Kozin F, and Ginsberg MH (1983). Plasma protein binding by monosodium urate crystals. Analysis by two-dimensional gel electrophoresis. Arth Rheum 26:775-783.

Terkeltaub RA, Dyer CA, Martin J, and Curtiss LK (1991). Apolipoprotein (apo) E inhibits the capacity of monosodium urate crystals to stimulate neutrophils. Characterization of intraarticular apo $E$ and demonstration of apo $E$ binding to urate crystals in vivo. J Clin Invest 87:20-26.

Thelen M, and Didichenko SA (1997). G-protein coupled receptor-mediated activation of $\mathrm{PI}$ 3-kinase in neutrophils. Ann of the New York Academy of Sciences 832:368-382.

Tiku K, Tiku ML, and Skosey Jl (1986). Interleukin-1 production by human polymorphonuclear neutrophils. J Immunol 136:3677-3685.

Todd RFRD, and Petty HR (1997). Beta 2 (CD11/CD18) integrins can serve as signaling partners for other leukocyte receptors. J Lab Clin Med 129:492-498.

Tomee JF, Hiemstra PS, Heinzel-Wieland R, and Kauffman HF (1997). Antileukoprotease: An endogenous protein in the innate mucosal defense against fungi. J Infect Dis 176:740747.

Topley N, Steadman R, MacKenzie R, Knowlden JM, and Williams JD (1989). Type 1 fimbriate strains of Escherichia coli initiate renal parenchymal scarring. Kidney Int 36:609616.

Travis J, and Salvesen GS (1983). Human plasma proteinase inhibitors. Annu Rev Biochem 52:655-709.

Tu L, Delahunty MD, Ding H, Luscinskas FW, and Tedder TF (1999). The cutaneous lymphocyte antigen is an essential component of the L-selectin ligand induced on human vascular endothelial cells. J Exp Med 189:241-252.

Turner J, Cho Y, Dinh NN, Waring AJ, and Lehrer RI (1998). Activities of LL-37, a cathelin-associated antimicrobial peptide of human neutrophils. Antimicrobial Agents Chemother 42:2206-2214.

Utgaard JO, Jahnsen FL, Bakka A, Brandtzaeg P, and Haraldsen $G$ (1998). Rapid secretion of prestored Interleukin 8 from Weibel-Palade bodies of microvascular endothelial cells. J Exp Med 188:1751-1756.

Van Kooyk Y, Van Vliet SJ, and Figdor CG (1999). The actin cytoskeleton regulates LFA-1 ligand binding through avidity rather than affinity changes. J Biol Chem 274:26869-26877.

Vaporciyan AA, Delisser HM, Yan H, Mendiguren II, Thom SR, Jones ML, Ward PA, and Albelda SM (1993). Involvement of platelet endothelial cell adhesion molecule-1 in neutrophil recruitment in vivo. Science 262:1580-1582.

Villard J, Roux-Lombard P, Hugli A, and Dayer JM (1993). Could natural inhibitors of tumor necrosis factor-alpha modify the clinical course of fulminant meningococcemia? Crit Care Med 21:1396-1400.
Von Der Mohlen MA, Kimmings AN, Wedel NI, Mevissen ML, Jansen J, Friedmann N, Lorenz TJ, Nelson BJ, White ML, Bauer R, and Et AL (1995). Inhibition of endotoxin-induced cytokine release and neutrophil activation in humans by use of recombinant bactericidal/permeability-increasing protein. $\mathrm{J}$ Infect Dis 172:144-151.

Vora M, Romero LI, and Karasek MA (1996). Interleukin-10 induces E-selectin on small and large blood vessel endothelial cells. J Exp Med 184:821-829.

Vu TH, Shipley JM, Bergers G, Berger JE, Helms JA, Hanahan D, Shapiro SD, Senior RM, and Werb Z (1998). MMP-9/ gelatinase $B$ is a key regulator of growth plate angiogenesis and apoptosis of hypertrophic chondrocytes. Cell 93:411422.

Wang P, Wu P, Anthes JC, Siegel MI, Egan RW, and Billah MM (1994). Interleukin-10 inhibits interleukin-8 production in human neutrophils. Blood 83:2678-2683.

Ward PA, Till GO, Kunkel R, and Beauchamp C (1983). Evidence for role of hydroxyl radical in complement and neutrophil-dependent tissue injury. J Clin Invest 72:789-801.

Ward PA (1999). The acute inflammatory response and its regulation. Arch Surg 134:666-669.

Watson RW, O'Neill A, Brannigen AE, Coffey R, Marshall JC, Brady HR, and Fitzpatrick JM (1999). Regulation of Fas antibody induced neutrophil apoptosis is both caspase and mitochondrial dependent. FEBS Letters 453:67-71.

Weersink AJ, Van Kessel KP, Van Den Tol ME, Van Strijp JA, Torensma R, Verhoef J, Elsbach P, and Weiss J (1993). Human granulocytes express a 55-kDa lipopolysaccharidebinding protein on the cell surface that is identical to the bactericidal/permeability-increasing protein. J Immunol 150: 253-263.

Weinrauch Y, Elsbach P, Madsen LM, Foreman A, and Weiss $\mathrm{J}$ (1996). The potent anti-Staphylococcus aureus activity of a sterile rabbit inflammatory fluid is due to a $14-\mathrm{kD}$ phospholipase A2. J Clin Invest 97:250-257.

Weiss SJ (1989). Tissue destruction by neutrophils. N Engl J Med 320:365-376.

Weiss SJ, and Peppin GJ (1986). Collagenolytic metalloenzymes of the human neutrophil. Characteristics, regulation and potential function in vivo. Biochem Pharmacol 35:31893197.

Welch H, and Maridonneau-Parini I (1997). Lyn and Fgr are activated in distinct membrane fractions of human granulocytic cells. Oncogene 15:2021-2029.

Welsh MJ, and Fick RB (1987). Cystic fibrosis. J Clin Invest 80:1523-1526.

Wheeler MA, Smith SD, Garcia-Cardena G, Nathan CF, Weiss RM, and Sessa WC (1997). Bacterial infection induces nitric oxide synthase in human neutrophils. J Clin Invest 99:110-116.

Wieslander J (1991). How are antineutrophil cytoplasmic autoantibodies detected? Am J Kidney Dis 18:154-158.

Wilhelm SM, Collier IE, Marmer BL, Eisen AZ, Grant GA, and Goldberg Gl (1989). SV40-transformed human lung fibroblasts secrete a 92-kDa type IV collagenase which is identical to that secreted by normal human macrophages $\mathrm{J}$ Biol Chem 264:17213-17221. 
Winterbourn CC (1990). Neutrophil oxidants: Production and reactions. In: Das DK and Essman WB editors. Oxygen radicals: Systemic events and disease process. Basel: Karger, 31

Witko-Sarsat V, and Descamps-Latscha B (1994). Neutrophil-derived oxidants and proteinases as immunomodulatory mediators in inflammation. Mediat Inflamm 3:257-273.

Witko-Sarsat V, Delacourt C, Rabier D, Bardet J, Nguyen AT, and Descamps-Latscha B (1995). Neutrophil-derived longlived oxidants cystic fibrosis sputum. Amer J Respir Crit Care Med 152:1910-1916.

Witko-Sarsat V, Allen RC, Paulais M, Nguyen AT, Bessou G, Lenoir G, and Descamps-Latscha B (1996). Disturbed myeloperoxidase-dependent activity of neutrophils in cystic fibrosis homozygotes and heterozygotes, and its correction by amiloride. J Immunol 157:2728-2735.

Witko-Sarsat V, Friedlander M, Nguyen Khoa T, CapeillereBlandin C, Nguyen AT, Canteloup S, Dayer JM, Jungers P, Drueke T, and Descamps-Latscha B (1998). Advanced oxidation protein products as novel mediators of inflammation and monocyte activation in chronic renal failure. $\mathrm{J}$ Immunol 161:2524-2532.

Witko-Sarsat V, Cramer EM, Hieblot C, Guichard J, Nusbaum P, Lopez S, Lesavre P, and Halbwachs-Mecarelli L (1999a). Presence of proteinase 3 in secretory vesicles: Evidence of a novel, highly mobilizable intracellular pool distinct from azurophil granules. Blood 94:2487-2496.

Witko-Sarsat V, Halbwachs-Mecarelli L, Schuster A, Nusbaum P, Ueki I, Canteloup S, Lenoir G, Descamps-Latscha B, and Nadel JA. (1999b). Proteinase 3, a potent secretagogue in airways, is present in cystic fibrosis sputum. Am J Resp Cell Mol Biol 20:729-736.

Witko-Sarsat V, Lesavre P, Lopez S, Bessou G, Hieblot C, Prum B, Noel LH, Guillevin L, Ravaud P, Sermet-Gaudelus I, Timsit J, Grunfeld JP, and Halbwachs-Mecarelli L. (1999c). A large subset of neutrophils expressing membrane proteinase 3 is a risk factor for vasculitis and rheumatoid arthritis. J Am Soc Nephrol 10:1224-1233.

Wolff B, Burns AR, Middleton J, and Rot A (1998). Endothelial cell "memory" of inflammatory stimulation: Human venular endothelial cells store interleukin 8 in Weibel-Palade bodies. J Exp Med 188:1757-1762.

Worthen GS, Avdi N, Buhl AM, Suzuki N, and Johnson GL (1994). FMLP activates Rac and Raf in human neutrophils: Potential role in activation of MAP kinase. J Clin Invest 94:815-823.
Wright SD, and Silverstein SC (1983). Receptors for C3b and C3bi promote phagocytosis but not the release of toxic oxygen from human phagocytes. J Exp Med 158:2016-2023.

Wright SD, and Meyer BC (1986). Phorbol esters cause sequential activation and deactivation of complement receptors on polymorphonuclear leukocytes. J Immunol 136: 1759-1764.

Yago T, Tsukuda M, and Minami M (1999). P-selectin promotes the adhesion of monocytes to VCAM-1 under flow conditions. J Immunol 163:367-373.

Yamaguchi K, Nishio K, Sato N, Tsumura H, Ichihara A, Kudo H, Aoki T, Naoki K, Suzuki K, Miyata A, Suzuki Y, and Morooka S (1997). Leukocyte kinetics in the pulmonary microcirculation: Observations using real-time confocal luminescence microscopy coupled with high-speed video analysis. Lab Invest 76:809-822.

Yamamoto K, and Johnston RB Jr (1984). Dissociation of phagocytosis from stimulation of the oxidative metabolic burst in macrophages. J Exp Med 159:405-416.

Yoder MC, Checkley LL, Giger U, Hanson WL, Kirk KR, Capen RL, and Wagner WWJR (1990). Pulmonary microcirculatory kinetics of neutrophils deficient in leukocyte adhesion-promoting glycoproteins. J Appl Physio 69:207213.

Yokomizo T, Izumi T, Chang K, Takuwa $\mathrm{Y}$, and Shimizu T (1997). A G-protein-coupled receptor for leukotriene B4 that mediates chemotaxis. Nature 387:620-624.

Zanetti M, Gennaro R, and Romeo D (1997). The cathelicidin family of antimicrobial peptide precursors: A component of the oxygen-independent defense mechanisms of neutrophils. Ann of the New York Academy of Sciences 832:147162.

Zarewych DM, Kindzelskii AL, Todd RF, and Petty HR (1996). LPS induces CD14 association with complement receptor type 3 , which is reversed by neutrophil adhesion. $\mathrm{J} \mathrm{Immunol}$ 156:430-433.

Zemer D, Pras M, Sohar E, Modan M, Cabili S, and Gafni J (1986). Colchicine in the prevention and treatment of the amyloidosis of familial Mediterranean fever. $\mathrm{N}$ Engl $\mathrm{J}$ Med 314:1001-1005.

Zimmer M, Medcalf RL, Fink TM, Mattmann C, Lichter P, and Jenne DE (1992). Three human elastase-like genes coordinately expressed in the myelomonocyte lineage are organized as a single genetic locus on 19pter. Proc Natl Acad Sci U S A 89:8215-8219. 